\title{
Performance of Integrated Hydronic Heating Systems
}

\author{
Project Report \\ December 2007
}

Thomas A. Butcher

\author{
Prepared for the \\ New York State Energy Research and Development Authority \\ and \\ National Oilheat Research Alliance \\ Energy Resources Division \\ Department of Energy Sciences and Technology \\ Brookhaven National Laboratory \\ Brookhaven Science Associates \\ Upton, NY 11973-5000
}

\section{Under Contract No. DE-ACO2-98CH10886 with the United States Department of Energy}

Notice: This manuscript has been authored by employees of Brookhaven Science Associates, LLC under Contract No. DE-AC02-98CH10886 with the U.S. Department of Energy. The publisher by accepting the manuscript for publication acknowledges that the United States Government retains a non-exclusive, paid-up, irrevocable, world-wide license to publish or reproduce the published form of this manuscript, or allow others to do so, for United States Government purposes. 


\section{DISCLAIMER}

This report was prepared as an account of work sponsored by an agency of the United States Government. Neither the United States Government nor any agency thereof, nor any of their employees, nor any of their contractors, subcontractors, or their employees makes any warranty, express or implied, or assumes any legal liability or responsibility for the accuracy, completeness, or usefulness of any information, apparatus, product, or process disclosed, or represents that its use would not infringe privately owned rights. Reference herein to any specific commercial product, process, or service by trade name, trademark, manufacturer, or otherwise, does not necessarily constitute or imply its endorsement, recommendation, or favoring by the United States Government or any agency, contractor or subcontractor thereof. The views and opinions of authors expressed herein do not necessarily state or reflect those of the United States Government or any agency, contractor, or subcontractor thereof.

\section{Acknowledgements:}

The author would like to acknowledge the project sponsors: New York State Energy Research and Development Authority and the National Oilheat Research Alliance. In addition many manufacturers donated equipment for this work and participated in project reviews. Yusuf Celebi and George Wei provided a great deal of support in lab setup and operations. Roger McDonald provided many helpful comments and suggestions based on a great deal of prior, related work. I would also like to acknowledge Mr. John D. Marran of the Energy Kinetics company who will long be remembered as a strong supporter of advancing system energy efficiency. 


\begin{abstract}
A variety of system configurations are used in North America to meet the heating and domestic hot water needs of single-family homes. This includes, for example: warm air furnaces with electric water heaters; boilers with integrated hot water coils; and boilers with “indirect" hot water storage tanks. Integrated hydronic systems which provide both heat and hot water are more popular only in the Northeast and mid-Atlantic regions. For those making decisions about configurations of these integrated hydronic systems, including control options, little information is available concerning the annual energy cost implications of these decisions. This report presents results of a project to use a direct load emulation approach to measure the performance of hydronic systems, develop performance curves, and to provide decision tools to consumers. This is a laboratory measurement system involving direct energy input and output measurements under different load patterns. These results are then used to develop performance correlations for specific systems that can be used to predict energy use in specific applications. A wide range of system types have been tested under this project including conventional boilers with "tankless" internal coils for domestic hot water production, boilers with indirect external storage tanks, tank type water heaters which may also be used for space heating, condensing oil- and gas-fired systems, and systems with custom control features. It is shown that low load and idle energy losses can have a very large impact on the total annual energy use and that the potential energy savings associated with replacing old equipment with newer, high efficiency equipment with low losses at idle or low load can be in the $25 \%$ range. These savings are larger than simple combustion efficiency measurements would indicate.
\end{abstract}




\section{Table of Contents}

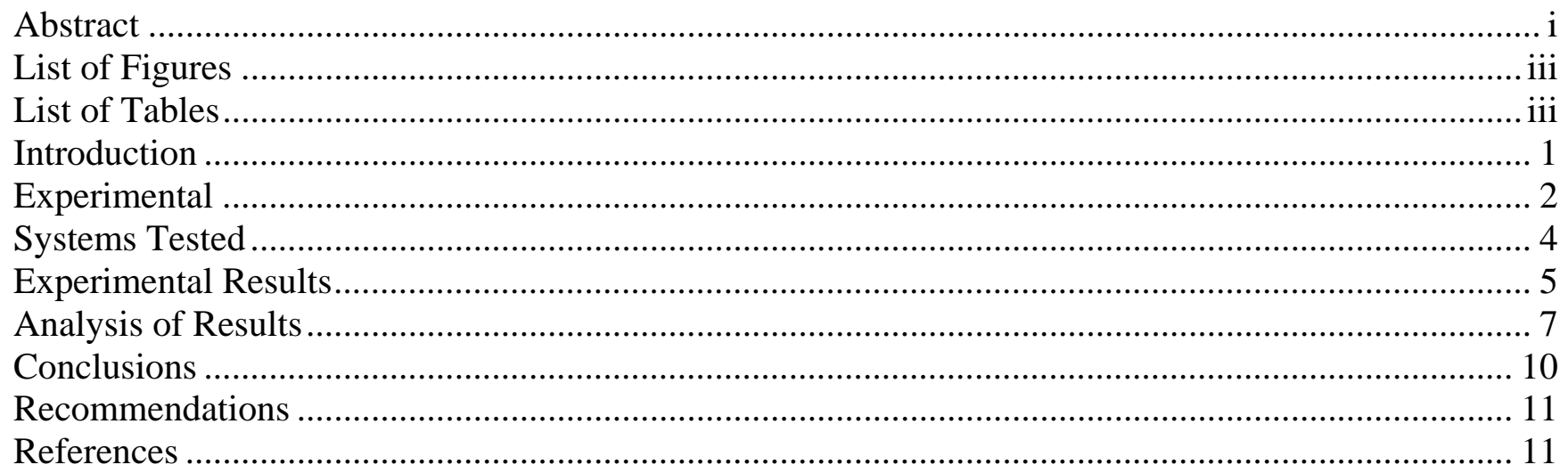

Appendices 1-12 - Test Results for all Units 


\section{List of Figures}

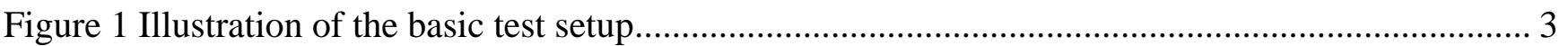

Figure 2. Example of a typical hourly distribution of domestic hot water load which can be used during

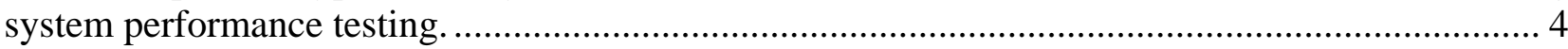

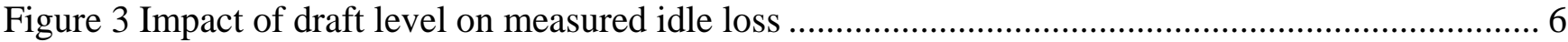

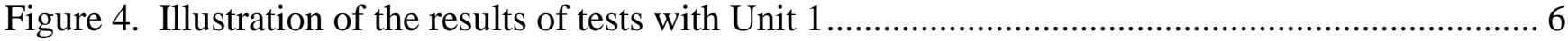
Figure 5 Illustration of interface screen on program developed to apply test results to simple bin

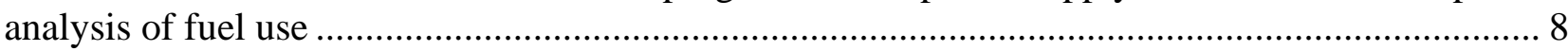

\section{List of Tables}

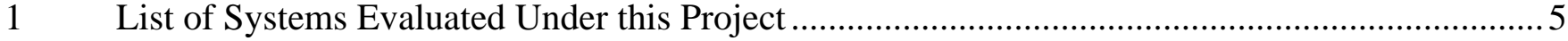

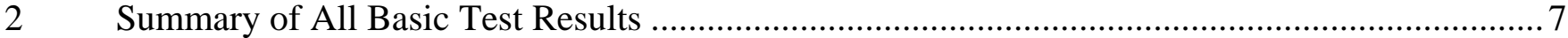

3 Results of Analysis of Annual Performance with Each Unit ...............................................9

4 Comp. of Annual Energy Savings Associated with Replacing System 10 with Other Systems... 10 


\section{Introduction}

Across the U.S. the dominant heating system in single family homes is a warm air furnace which integrates easily with central air conditioning. In the Northeast and some other colder regions, hydronic heating systems are more popular. For these systems there are a wide range of configurations used for producing domestic hot water including, for example, use of a domestic water coil inserted in the heating boiler (low cost, traditional system); use of an indirect domestic hot water tank heated from the heating boiler; and use of a separate, fuel or electric fired hot water heater. There are also an increasing range of control configuration options available including outdoor reset, cold start, thermal purge, and variable setpoint differential.

The main measure that is used for identifying the efficiency of heating systems in the U.S. is termed the Annual Fuel Utilization Efficiency (AFUE). A standard for this measure for boilers is maintained by the American Society of Heating Refrigeration and Air Conditioning Engineers (Standard 103 ASHRAE) [1] and this is adapted for a federal labeling procedure by the U.S. Department of Energy. The AFUE measure is based upon a heat loss method and involves measurement of excess air and flue gas temperature over operating cycles considered typical of national average conditions. This method considers heating load only, not domestic hot water. Annual efficiency is based on an assumption of a typical national oversize factor for the heating load of 1.7. In the case of a boiler the prescribed conditions are: supply temperature $140 \mathrm{~F}$, return temperature $120 \mathrm{~F}$, burner average on-time (9.68 minutes), burner average off-time (33.26 minutes). Energy loss during the off cycle is accounted for through the rate of cooling of flue gas following the burner shutdown and the mass flow of flue gas during the off cycle (estimated or measured). The ASHRAE procedure provides a method for measuring "jacket" energy losses for a boiler while firing in steady state and then calculating the annual cost of these losses based upon a location factor. The test involves measurement of the surface temperatures on the boiler jacket and then calculation of the convective and radiative heat loss. In lieu of a measurement a 1\% default value for steady state jacket loss can be assumed. In the formal labeling procedure it is assumed that all boilers are located within the conditioned space of the home and that jacket energy losses become useful heat, so in practice jacket loss is not commonly measured or used.

For appliances which have as their sole function heating domestic hot water there is a separate ASHRAE procedure (Standard 118 - ASHRAE) [2] which has also been adopted as part of a national labeling procedure. Termed the Energy Factor, the test method involves a direct input/output measure with the use of a standard domestic hot water draw pattern of 64.3 gallons in 6 draws over 6 hours, followed by 18 hours of idle period. Another ASHRAE test standard (Standard 124) [3] provides a method for combining the results of the AFUE and Energy Factor test into a combined measure for integrated systems. This standard is currently undergoing a regular revision and has not been adopted as part of a national labeling procedure.

Some field data which is available for integrated space and water heating appliances indicates much lower efficiency levels than heating only ratings indicate [4,5].

Presently there is under development an ASHRAE test standard for commercial boilers which provides an interesting alternative methodology (ASHRAE SPC155). Termed the Application Seasonal Efficiency (ASE) this standard would apply to steam or hot water boilers with capacity ranging from 88 to $3600 \mathrm{~kW}$ for space heating applications only. For the test boiler a heat input / 
output curve is developed from test data. This curve, for many boilers is linear providing the need to measure only steady state, full load efficiency and energy input at an idle condition. The procedure provides for optional tests at part load and steady state, full load at different supply water temperatures. Where the boiler control changes water temperature and series of different performance curves are produced, each for one temperature. These curves are then applied to specific buildings with an analysis procedure considering building type, location, design heat load, boiler size, number of boilers installed, and control strategy. The result is the ASE for this specific installation. The procedure to use the results for selecting among equipment options and/or evaluating existing equipment performance in specific buildings is implemented in a user-friendly computer tool.

The approach of a linear input/output relation to modeling the performance of a boiler has been explored by others [6,7]. Based on all results to date a linear model may not be expected to be fully accurate, even for a fixed temperature (supply, boiler average, or return flow) for all systems. The approach being taken here does not rely on a fully linear relationship but may allow for a curve also. Several standards for evaluating the performance of boilers take a related approach in which the efficiency is measured at several defined points along the partial load curve.

This project is focused on hydronic heating systems which also provide domestic hot water, and these are common in regions of the U.S. that use hydronic heating. It has been created to provide a method to estimate the actual energy savings that may be realized when replacing old equipment and the effects that different configuration decisions have on annual energy use. The basis approach taken relates to the ASE method discussed above. For integrated systems performance curves are developed based on direct energy input / output measurements over a range of load conditions. These performance curves can then be used in either a simple "bin" type analysis or in hourly simulation programs such as DOE-2 to estimate annual seasonal efficiency (performance).

\section{Experimental}

The basic test arrangement is shown in Figure 1. The "system" in this figure may include a boiler and water storage tank, a boiler with an internal coil for hot water production, a tank type water heater used also for domestic hot water, or any other integrated system. Fuel input is measured using a correolis flow meter calibrated against a precision balance. The fuel heating value and density are measured using the ASTM procedures.

For the heating load boiler water is circulated through a plate heat exchanger. The mass flow rate of cooling water through the heat exchanger is directly measured with a platform weigh scale which communicates with the lab computer. Average flow rate during a heat load period is determined using a linear regression of the scale readings. The mass flow rate is combined with inlet and outlet temperature readings on the cooling water to determine heating energy output.

For the domestic hot water load the approach is similar. Mass flow of hot water is measured with a platform weigh scale in the same way and temperature rise of the water is used to determine domestic hot water output.

Steady state efficiency is determined for hydronic heating only and the effect of supply water temperature on efficiency is determined by adjusting the cooling water flow rate. The boiler supply / 
return differential temperature is essentially set by the internal flow rate. Each steady state test is about 2 hours in duration.

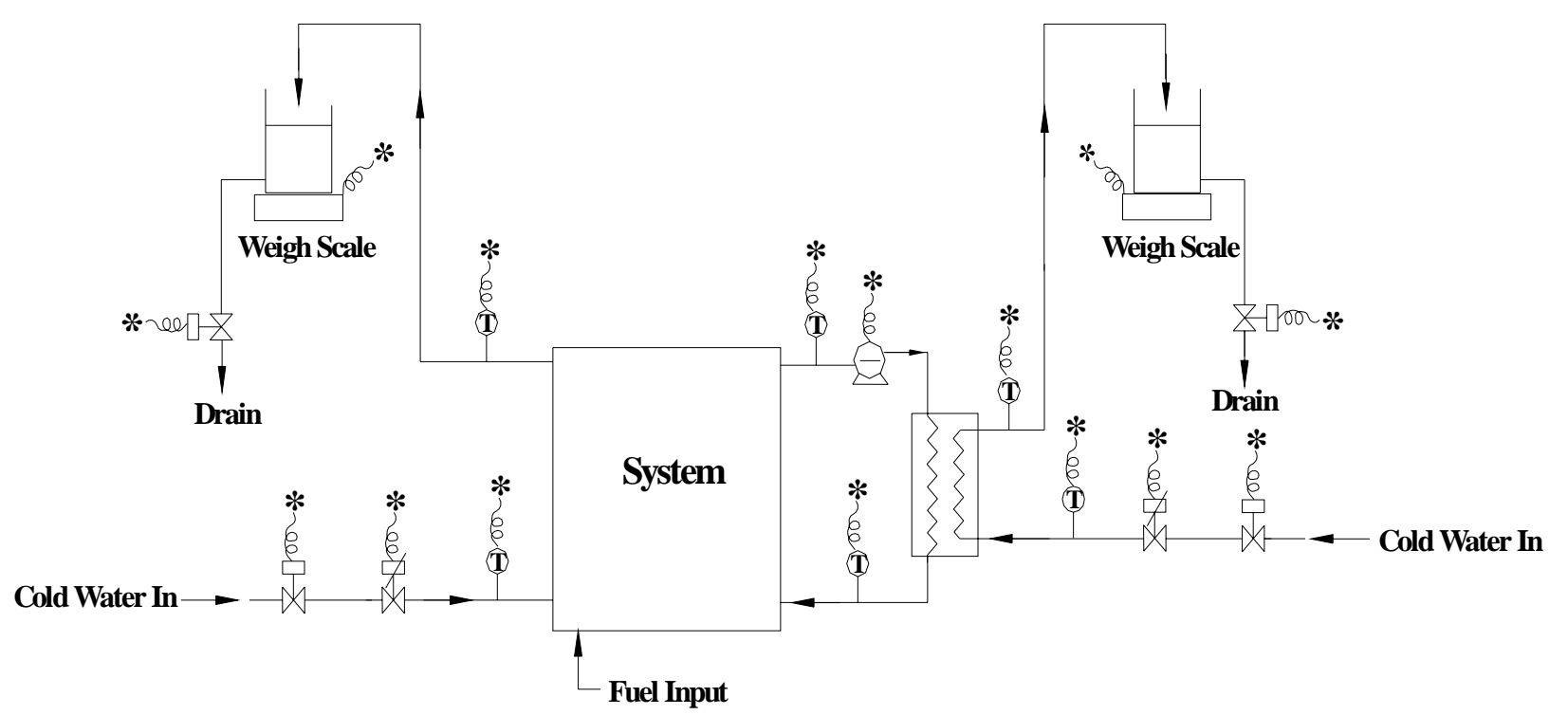

Domestic Hot Water Load

Hydronic Heating Load

\section{* To Data Acquisition/ Control System}

\section{Figure 1 Illustration of the basic test setup}

In the idle state the average fuel consumption required to maintain the system under a no-load condition is measured. This can vary widely among systems and is very dependent upon control decisions such as cold-start or "maintain-temperature" and the degree of system insulation. These tests normally take several days. Where systems have indirect storage tanks the temperature profile in the tanks is measured and a correction is made for differences in the amount of stored energy between the start and end of a test.

For part load tests periodic loads are imposed on the system and these may include heating only, domestic hot water only, or a load pattern that combines both load types. Test periods typically last from 12 to 72 hours. The load patterns can be very complex if desired. Figure 2, for example illustrates one domestic hot water load pattern tested which has been adopted from the literature [8] as a typical daily hot water draw pattern. All load patterns are defined in an input file to the computer, which controls the flow on/off valves, controls the weigh tank fill and draining, adjusts the modulating flow control valves, and records system temperatures.

Another parameter of interest in this project is the boiler "jacket" loss or energy lost to the surroundings through the boiler outer insulation. In a steady state test this could be evaluated through the difference between the combustion efficiency (based on flue gas measurements) and the thermal efficiency (based on input / output measurements) but the nominal accuracy of the fuel heating value 
measurement leads to the potential for large errors in this determination, particularly at low jacket loss values. As an alternative, a jacket loss estimation procedure, based on surface temperature measurements and defined in the ASHRAE Standard for heating boilers [1] has been adapted and applied to some of the units included in this project. This is useful in evaluating the impact of location of the system on heating costs and the sources of inefficiency which could be addressed.

For evaluation of the heating value of oil, samples were periodically analyzed for heating value and density at a commercial lab. For natural gas a gas chromatograph designed for online analysis of this fuel was installed. This provide an analysis of composition and, from this, heating value, density and Wobbe index are calculated.

\section{Daily distribution of hot water use (gal/hour)}

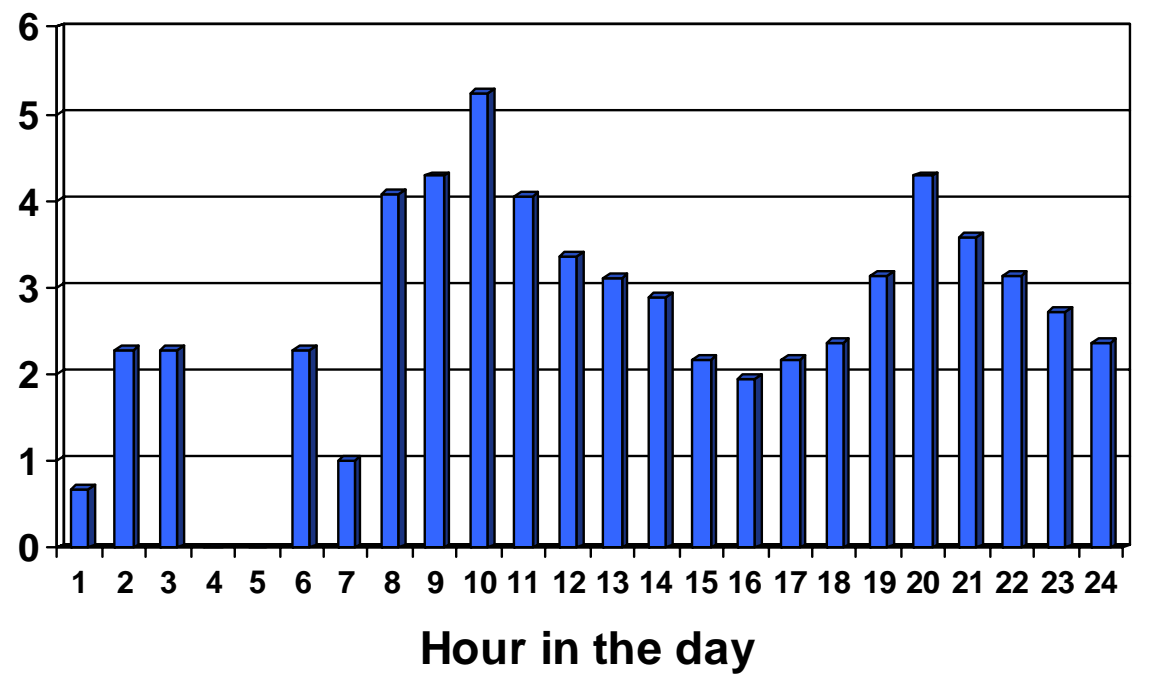

Figure 2. Example of a typical hourly distribution of domestic hot water load which can be used during system performance testing.

\section{Systems Tested}

This project was originally conceived to include a very specific set of systems, selected as representative, which would be tested in both a heating and domestic hot water mode. As the project evolved, however, and results were available for analysis, additional units were added, some of which were only tested on a limited basis to address specific questions. A total of 12 different units were tested and a very brief description of these is provided in Table 1, below.

More detailed descriptions and details of the results of all of the tests done on each of these units are provided in Appendixes 1 through 12. 
Table 1. List of Systems Evaluated Under this Project

\begin{tabular}{|c|c|c|}
\hline Number & Fuel & Description \\
\hline 1 & oil & $\begin{array}{l}\text { five section, non-condensing, cast iron boiler with an internal tankless coil for } \\
\text { domestic hot water production }\end{array}$ \\
\hline 2 & oil & $\begin{array}{l}\text { three section, non-condensing, cast iron boiler and } 40 \text { gallon domestic hot water } \\
\text { tank ("indirect"). The indirect tank has an internal heat exchanger and is heated as a } \\
\text { separate zone from the boiler }\end{array}$ \\
\hline 3 & oil & $\begin{array}{l}\text { steel, non-condensing boiler with a } 40 \text { gallon indirect tank. This boiler has a custom } \\
\text { control system that thermally purges the heat from the boiler into either the last } \\
\text { heating zone that called or the domestic hot water tank. }\end{array}$ \\
\hline 4 & oil & $\begin{array}{l}\text { steel, condensing boiler with a } 40 \text { gallon indirect tank. This boiler has separate } \\
\text { primary (non condensing) and secondary (condensing) heat exchangers and a } \\
\text { thermal mixing valve on the supply to the heating zones. }\end{array}$ \\
\hline 5 & oil & $\begin{array}{l}\text { cast iron, well insulated, non-condensing boiler with matched } 40 \text { gallon domestic } \\
\text { hot water tank. }\end{array}$ \\
\hline 6 & oil & $\begin{array}{l}\text { center-flue water heater which is often used (and was tested) for space heating and } \\
\text { integrated loads }\end{array}$ \\
\hline 7 & oil & $\begin{array}{l}\text { "combi” unit. integrates oil-fired heat exchanger and storage of water for space heat } \\
\text { and domestic hot water (separately) }\end{array}$ \\
\hline 8 & $\begin{array}{l}\text { nat. } \\
\text { gas }\end{array}$ & $\begin{array}{l}\text { cast iron boiler with an atmospheric burner and internal tankless coil for domestic } \\
\text { hot water production. }\end{array}$ \\
\hline 9 & $\begin{array}{l}\text { nat. } \\
\text { gas }\end{array}$ & center flue water heater with an atmospheric burner and vent damper \\
\hline 10 & oil & $\begin{array}{l}\text { cast iron boiler removed from the field after } 22 \text { years of service. representative of an } \\
\text { old boiler that would be replaced by a higher efficiency upgrade }\end{array}$ \\
\hline 11 & $\begin{array}{l}\text { nat. } \\
\text { gas }\end{array}$ & cast aluminum, condensing, boiler with a modulating radiant burner \\
\hline 12 & oil & $\begin{array}{l}\text { two section, cast iron, non-condensing boiler with a tankless coil. Used for targeted } \\
\text { comparisons of the tankless vs. indirect case. }\end{array}$ \\
\hline
\end{tabular}

\section{Experimental Results}

As a matter of course in this project a number of small, side studies were undertaken to evaluate the impact of specific technical questions. One of these involved a study of the impact of draft level on the idle loss with an oil-fired boiler. To evaluate draft impacts a chimney was arranged with a variable eductor arrangement to allow fixed control of this parameter. Figure 3 shows the impact of variable draft on the idle loss rate for System 1 from Table 1. The magnitude of draft, over the range explored is modest. For all subsequent tests a draft level on the order of .01-.02 inches of water, when the burner is firing, measured in the flue has been used. 


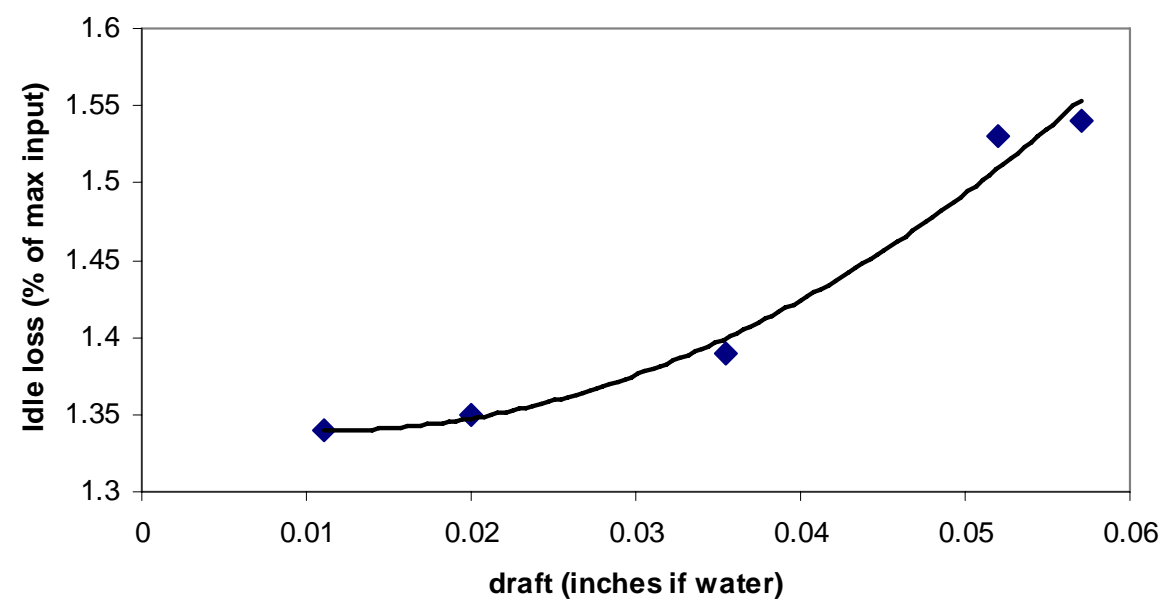

Figure 3 Impact of draft level on measured idle loss

Figure 4, provides an example of the input / output results of the testing procedure. This data is from Unit 1 and has been color coded to indicate the type of test: red indicated heating only, blue is a domestic hot water load, and green represents tests during which there was a combination of space and domestic hot water loads. For this case an output of 0 corresponds to an input of approximately $1.2 \%$.

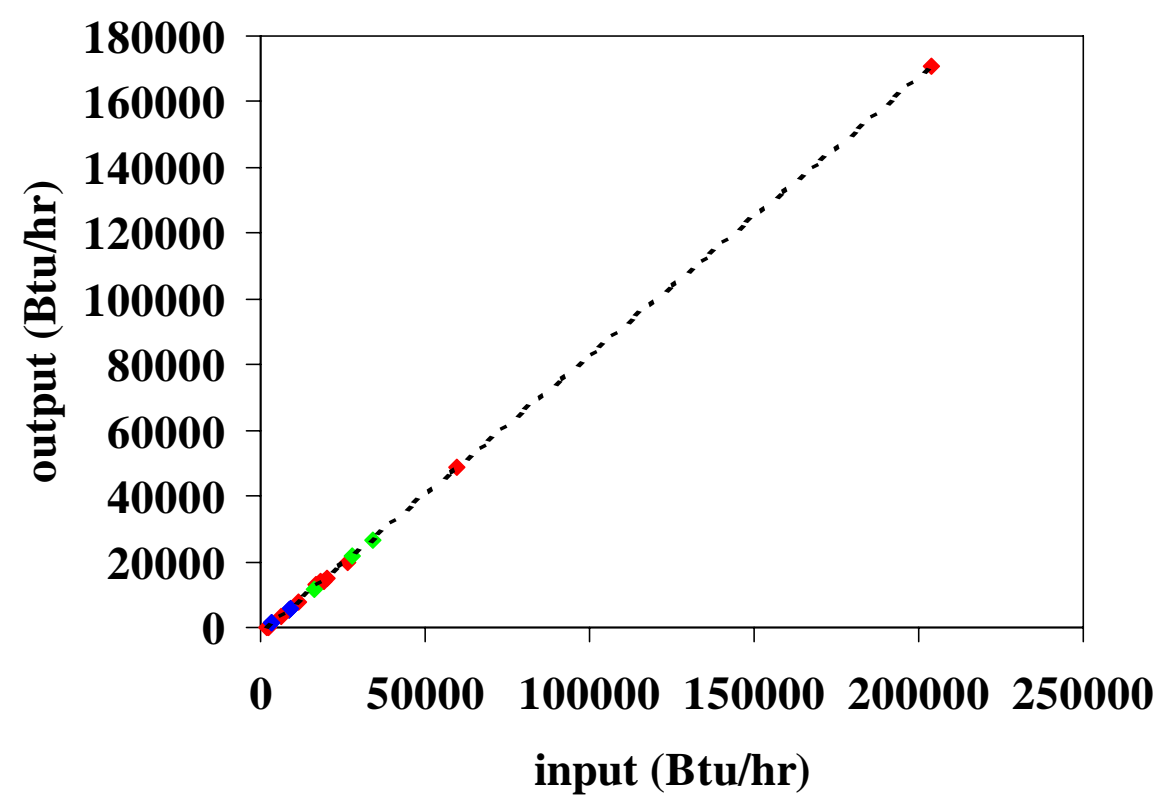

Figure 4. Illustration of the results of tests with Unit 1 
This figure shows a strong linear relationship for this unit even under different load patterns.

For all of the units tested, test results, presented in the appendices, lead to steady state thermal efficiency at full load, idle loss, and combustion efficiency. In addition, as developed in the appendices, for each unit, as tested the efficiency with which it would meet a summer average load of $1720 \mathrm{Btu} / \mathrm{hr}$ for domestic hot water is determined. A summary of these results for all units is provided in Table 2. In this table unit 12 has been divided into two parts. This unit was tested for a very specific purpose - to directly compare the performance of the same boiler in a tankless water heating mode and an indirect mode. These two case 12a and 12b reflect these.

Table 2. Summary of All Basic Test Results.

\begin{tabular}{|l|l|l|l|l|l|}
\hline Unit & Description & $\begin{array}{l}\text { Steady State } \\
\text { Thermal } \\
\text { Efficiency } \\
(\%)\end{array}$ & $\begin{array}{l}\text { Combustion } \\
\text { Efficiency } \\
(\%)\end{array}$ & $\begin{array}{l}\text { Idle Loss } \\
(\%)\end{array}$ & $\begin{array}{l}\text { Summer } \\
\text { domestic hot } \\
\text { water } \\
\text { efficiency (\%) }\end{array}$ \\
\hline 1 & $\begin{array}{l}\text { Oil, cast iron boiler } \\
\text { with tankless }\end{array}$ & 83.7 & 85.5 & 1.2 & 40.6 \\
\hline 2 & $\begin{array}{l}\text { Oil, cast iron boiler } \\
\text { with indirect }\end{array}$ & 78.4 & 84.6 & 2.1 & 38.3 \\
\hline 3 & $\begin{array}{l}\text { Oil, steel boiler with } \\
\text { purge control }\end{array}$ & 86.5 & 88.1 & .15 & 74.9 \\
\hline 4 & Oil condensing boiler & 92.0 & 95 & 1.5 & 55.4 \\
\hline 5 & $\begin{array}{l}\text { Oil, well insulated cast } \\
\text { iron }\end{array}$ & 87.5 & 88.3 & 0.60 & 68.3 \\
\hline 6 & $\begin{array}{l}\text { Oil, water heater used } \\
\text { also for heating }\end{array}$ & 81.5 & 83.9 & 1.2 & 57.1 \\
\hline 7 & Oil, combi System & 79.5 & 82.6 & 0.8 & 47.9 \\
\hline 8 & $\begin{array}{l}\text { Gas atmospheric } \\
\text { with tankless }\end{array}$ & 72.5 & 77.6 & 1.7 & 37.2 \\
\hline 9 & $\begin{array}{l}\text { Gas atmospheric water } \\
\text { heater }\end{array}$ & 74.5 & 77.0 & 0.65 & 57.5 \\
\hline $8+9$ & $\begin{array}{l}\text { Gas boiler + separate } \\
\text { gas water heater }\end{array}$ & & & & 57.5 \\
\hline 10 & Old cast iron boiler & 72.8 & 79.7 & 2.1 & 31.0 \\
\hline 11 & Gas cond. modulating & 88.5 & 93.6 & 0.60 & 58.7 \\
\hline $12 \mathrm{a}$ & tankless mode & 78.0 & 82.5 & 4.87 & 24.7 \\
\hline $12 \mathrm{~b}$ & indirect mode & 78.0 & 82.5 & 1.16 & 51.4 \\
\hline
\end{tabular}

\section{Analysis of Results}

As discussed above, the input/output performance curves for each system tested can be used to estimate annual fuel consumption in specific applications. To illustrate this, a relatively simple analysis procedure has been developed based on a bin method. The heating season is divided into 10 
degree (F) bins and the number of hours in each of these bins is determined from statistical weather data for specific regions. The heating load in each bin is assumed to be proportional to the temperature difference from the balance point for the building, taken as $65 \mathrm{~F}$.

In the heating season, the domestic hot water load is added to the heating load and the nonheating season (domestic hot water load only) is created as a separate bin. In each bin, based on the average load the heating system fuel input required and efficiency can be determined from the performance curves. In the example procedure for this the amount of fuel energy which is not useful ("wasted fuel") is explicitly calculated. To illustrate the use of this procedure the following assumptions are taken:

Building location: Harrisburg, Pennsylvania

Design day temperature: $+7^{\circ} \mathrm{F}$

Design day heat load: 40,000 Btu/hr

Average daily domestic hot water consumption -64.2 gallons/day

For this simple analysis a linear approximation for the input/output performance curves has been made based on steady state thermal efficiency and system idle loss (see appendices). This analysis have been implemented with a Visual Basis (VB6) program and an image of the interface and results display is provided in Figure 5

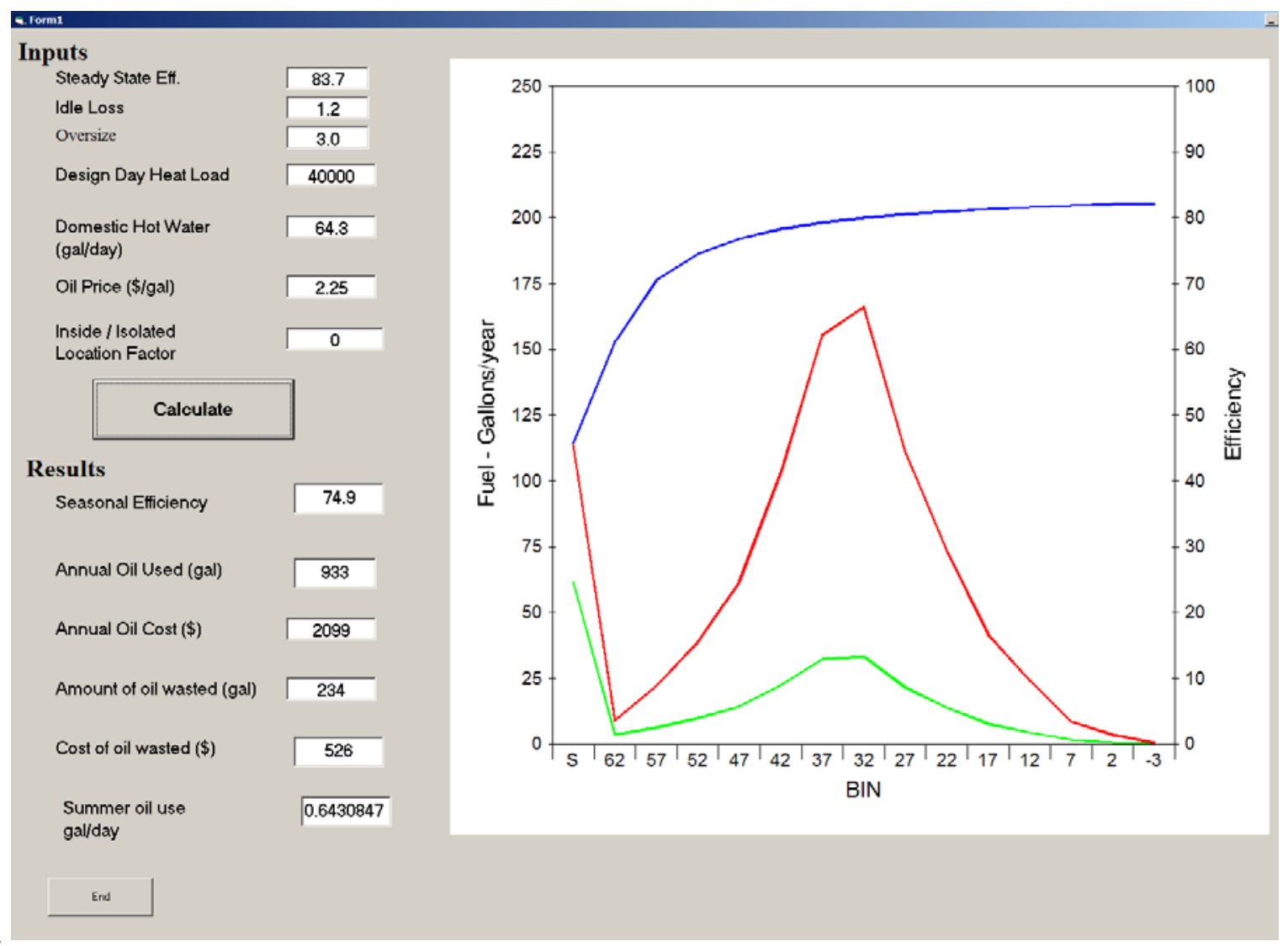

Figure 5 Illustration of interface screen on program developed to apply test results to simple bin analysis of fuel use 
In the chart in Figure 5 the blue (top) line represents efficiency at the load level in the specific temperature bin, the red (middle) line represents the annual oil use in the specific bin, and the green (bottom) line represents oil wasted in the specific bin. The amount of oil wasted is the sum of jacket loss, idle losses, and flue latent and sensible losses.

Table 3, below, provides results of this simple bin analysis for all of the units tested under specific selected conditions. Clearly there is a wide range of assumptions for oversize factors, buildings design day heat loads, and daily average domestic hot water use that could be explored. The conditions chosen to include in this table represent conditions seen as typical of existing homes in the region of the country where hydronic heating is most common. This bin analysis leads to an annual efficiency for the integrated load and annual fuel use, and provides an opportunity to understand the sources of inefficiency.

Table 3. Results of Analysis of Annual Performance with Each Unit

\begin{tabular}{|c|c|c|c|c|c|c|c|}
\hline Unit & Description & $\begin{array}{l}\text { Steady } \\
\text { State } \\
\text { Thermal } \\
\text { Efficiency } \\
\text { (\%) }\end{array}$ & $\begin{array}{l}\text { Idle Loss } \\
\text { (\%) }\end{array}$ & 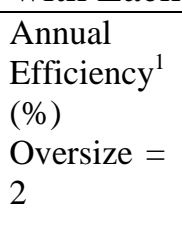 & 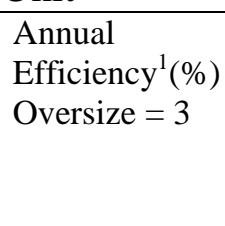 & $\begin{array}{l}\text { Summer } \\
\text { DHW oil } \\
\text { use (gal) } \\
\text { Oversize = } 2\end{array}$ & 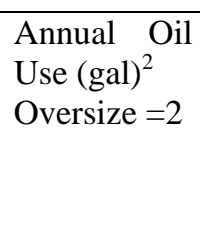 \\
\hline 1 & $\begin{array}{l}\text { Oil, cast iron boiler } \\
\text { with tankless }\end{array}$ & 83.7 & 1.2 & 77.9 & 74.9 & .54 & 897 \\
\hline 2 & $\begin{array}{l}\text { Oil, cast iron boiler } \\
\text { with indirect }\end{array}$ & 78.4 & 2.1 & 72.9 & 65.1 & .74 & 1007 \\
\hline 3 & $\begin{array}{l}\text { Oil, steel boiler } \\
\text { with purge control }\end{array}$ & 86.5 & .15 & 85.7 & 85.3 & .36 & 816 \\
\hline 4 & $\begin{array}{l}\text { Oil condensing } \\
\text { boiler }\end{array}$ & 92.0 & 1.5 & 84.2 & 80.3 & .54 & 830 \\
\hline 5 & $\begin{array}{l}\text { Oil, well insulated } \\
\text { cast iron }\end{array}$ & 87.5 & .69 & 84.4 & 82.7 & .42 & 828 \\
\hline 6 & $\begin{array}{l}\text { Oil, water heater } \\
\text { used also for } \\
\text { heating }\end{array}$ & 81.5 & 1.2 & 75.9 & 73.0 & .56 & 921 \\
\hline 7 & Oil, combi System & 79.5 & .8 & 75.8 & 73.8 & .51 & 923 \\
\hline 8 & $\begin{array}{l}\text { Gas atmospheric } \\
\text { with tankless }\end{array}$ & 72.5 & 1.7 & 65.6 & 62.2 & .72 & 1065 \\
\hline 9 & $\begin{array}{l}\text { Gas atmospheric } \\
\text { water heater }\end{array}$ & 74.5 & .65 & & & .51 & 976 \\
\hline $8+9$ & $\begin{array}{l}\text { Gas boiler }+ \\
\text { separate gas } \\
\text { heater }\end{array}$ & & & 66.6 & 64.7 & .51 & 1081 \\
\hline 10 & Old cast iron boiler & 72.8 & 2.1 & 64.5 & 60.4 & .79 & 1085 \\
\hline 11 & $\begin{array}{ll}\begin{array}{l}\text { Gas } \\
\text { modulating }\end{array} & \text { cond. } \\
\end{array}$ & 88.5 & .60 & 85.3 & 83.6 & .42 & 819 \\
\hline $12 \mathrm{a}$ & tankless mode & 78.0 & 4.87 & 60.0 & 52.9 & 1.22 & 1165 \\
\hline $12 \mathrm{~b}$ & indirect mode & 78.0 & 1.16 & 72.8 & 70.1 & .57 & 960 \\
\hline
\end{tabular}

1. Based on oversize factor stated, not actual firing rate tested. 


\section{For gas-fired appliances consumption is oil equivalent.}

From the results of Table 3, another result that directly follows is an estimate of the amount of oil, or oil-equivalent that could be saved on an annual basis by replacing an existing oil-fired heating system with one of these systems. For this system 10, the oil, oil-fired cast iron boiler that had been removed from the field was chosen as the baseline. This unit is actually better than system 12a and this, arguably, could have been used as the baseline as well. Results of this comparison are shown in Table 4. One of the key conclusions from this is that the energy savings potential is quite large.

Table 4. Comparison of Annual Energy Savings Associated with Replacing System 10 with Other Systems

\begin{tabular}{|c|c|c|}
\hline Unit & Description & $\begin{array}{l}\text { Annual } \\
\text { Reduction in } \\
\text { Fuel Use } \\
\text { Relative to } \\
\text { the Baseline }\end{array}$ \\
\hline 1 & $\begin{array}{l}\text { Oil, cast iron boiler } \\
\text { with tankless }\end{array}$ & 17.3 \\
\hline 2 & $\begin{array}{l}\text { Oil, cast iron boiler } \\
\text { with indirect }\end{array}$ & 0.7 \\
\hline 3 & $\begin{array}{l}\text { Oil, steel boiler with } \\
\text { purge control }\end{array}$ & 24.8 \\
\hline 4 & Oil condensing boiler & 23.5 \\
\hline 5 & $\begin{array}{l}\text { Oil, well insulated cast } \\
\text { iron }\end{array}$ & 23.7 \\
\hline 6 & $\begin{array}{l}\text { Oil, water heater used } \\
\text { also for heating }\end{array}$ & 15.1 \\
\hline 7 & Oil, combi System & 14.9 \\
\hline 8 & $\begin{array}{l}\text { Gas atmospheric } \\
\text { with tankless }\end{array}$ & 1.8 \\
\hline 9 & $\begin{array}{l}\text { Gas atmospheric water } \\
\text { heater }\end{array}$ & \\
\hline $8+9$ & $\begin{array}{l}\text { Gas boiler }+ \text { separate } \\
\text { gas water heater }\end{array}$ & 0.4 \\
\hline 10 & Old cast iron boiler & 0.0 \\
\hline 11 & Gas cond. modulating & 24.5 \\
\hline $12 \mathrm{a}$ & tankless mode & -7.4 \\
\hline $12 \mathrm{~b}$ & indirect mode & 11.5 \\
\hline
\end{tabular}

\section{Conclusions}

Results of this study have shown that the input/output method, as is being developed by ASHRAE Technical Committee 155, can be applied to residential integrated appliances and that these results can be used to draw conclusions about energy use under a wide range of load and oversize scenarios. The ideal case would be where the only testing required is idle loss and steady state thermal efficiency. For 
some systems, however, the results are not quite linear and at least one intermediate point would improve the characterization of the unit.

The units tested have a broad range of thermal efficiency levels and idle loss. The impact of thermal efficiency on annual performance is expected. The idle loss is shown to also have a very large impact on annual performance.

The energy savings that can be realized by upgrading old equipment is shown to be large - in the $25 \%$ range, based on specific units tested under this program.

\section{Recommendations}

This work has essentially served to demonstrate the basic method and to show the magnitude of potential savings associated with better systems. Further efforts are planned to: better map the performance impacts of variable water temperature; better estimate infiltration loss effects, better estimate jacket loss impacts; and to recommend better routine test procedures. It is also planned to extend the analysis results to other cities, leading to a software tool for comparison of systems.

\section{References}

[1] Method of Testing for Annual Fuel Utilization Efficiency of Residential Central Furnaces and Boilers, American Society of Heating, Refrigeration, and Air Conditioning Engineers (ASHRAE), Standard 103-1993, 1993.

[2] Methods of Testing for Rating Residential Water Heaters. American Society of Heating, Refrigeration, and Air Conditioning Engineers (ASHRAE), Standard 118.2-2006, 2006.

[3] Methods of Testing for Rating Combination Space-Heating and Water-Heating Appliances. American Society of Heating, Refrigeration, and Air Conditioning Engineers (ASHRAE), Standard 124-1991, 1991.

[4] Subherwal, B.R., Combination water-heating/space-heating appliance performance. ASHRAE Transactions, Vol. 92, pp 415-432, 1986.

[5] Caron, R. and Wilson, R. Water-Heating Efficiency of Integrated Systems Designed for Space and Water Heating, ASHRAE Transactions Vol. 89, pp18-29, 1983.

[6] DeCicco, J.M., Applying a linear model to diagnose boiler fuel consumption. ASHRAE Transactions, Vol. 96, pp 296-304, 1990.

[7] Rosa, L. and Tosato, R. Experimental Evaluation of Seasonal Efficiency of Condensing Boilers. Energy and Buildings, 14, pp 237-241, 1990.

[8] HVAC Applications. American Society of Heating, Refrigeration, and Air Conditioning Engineers (ASHRAE), 2003. 


\section{Appendix 1 \\ Results of Tests with Unit 1}

Unit Description: non-condensing, 5 section cast iron boiler

Fuel:

Capacity:

Net IBR:

oil

Aquastat: $\quad$ Triple Function (L8124A)

Domestic Hot Water: Tankless Coil integrated with boiler

Burner type: conventional retention head

Features:

Nominal AFUE: $\quad 83.9$

Table A1-1. Summary of Tests Done with Unit 1 and Results:

\begin{tabular}{|c|c|c|c|c|c|c|c|c|c|}
\hline & ID & Code & Ended & Duration & Pattern & Input & Output & Efficiency & \begin{tabular}{|l} 
Boiler \\
Temp
\end{tabular} \\
\hline Units: & & - & - & hrs & on/off ${ }^{1}$ & Btu/hr & Btu/hr & $(\%)$ & $\mathrm{F}$ \\
\hline & 1-1 & SS & & 3 & Steady On & 203998 & 170706 & 83.68 & \\
\hline & $1-2$ & SI & & 12 & Idle & 1805 & 0 & 0.00 & \\
\hline & $1-3$ & $\mathrm{HO}$ & $10 / 14 / 2005$ & 5 & $5 / 25$ & 20116 & 15000 & 74.57 & \\
\hline & 1-4 & $\mathrm{HO}$ & $10 / 17 / 2005$ & 6 & $15 / 15$ & 59504 & 48543 & 81.58 & \\
\hline & $1-5$ & $\mathrm{HO}$ & $10 / 21 / 2005$ & 20 & $10 / 120$ & 11503 & 7879.15 & 68.50 & \\
\hline & $1-6$ & SI & $10 / 24 / 2005$ & 48 & Idle & 2384 & 0 & 0.00 & \\
\hline & $1-7$ & DO & $10 / 28 / 2005$ & 6 & - & 8425 & 5305 & 62.97 & \\
\hline & $1-8$ & DO & & 20 & - & 3563 & 1511 & 42.41 & \\
\hline & $1-9$ & DO & $11 / 2 / 2005$ & 20 & - & 8500 & 5179 & 60.93 & \\
\hline & $1-10$ & $\mathrm{HO}$ & $12 / 8 / 2005$ & 12 & $21.6 / 38.4$ & 16940 & 13025 & 76.89 & \\
\hline & $1-11$ & $\mathrm{HO}$ & $12 / 8 / 2005$ & 6 & $9 / 51$ & 18189 & 13973 & 76.82 & \\
\hline & $1-12$ & $\mathrm{HO}$ & $12 / 9 / 2005$ & 6 & $9 / 111$ & 6205 & 3229.3 & 52.04 & \\
\hline & $1-13$ & $\mathrm{HO}$ & $12 / 7 / 2005$ & 12 & $18 / 42$ & 19302 & 14175 & 73.44 & \\
\hline & $1-14$ & $\mathrm{HD}$ & $12 / 23 / 2005$ & 24 & Mixed & 16573 & 11594 & 69.96 & \\
\hline & $1-15$ & DO & $12 / 27 / 2005$ & 12 & Mixed & 9210 & 5899.8 & 64.06 & \\
\hline & $1-16$ & DO & $12 / 27 / 2005$ & 12 & Mixed & 3525 & 1474.95 & 41.84 & \\
\hline & $1-17$ & $\mathrm{HO}$ & $12 / 30 / 2005$ & 12 & Mixed & 26413 & 19941 & 75.50 & \\
\hline & $1-18$ & HD & $12 / 30 / 2005$ & 12 & Mixed & 34131 & 26682.5 & 78.18 & \\
\hline
\end{tabular}

Notes relevant to the Results Summary Table Above:

Condition Codes:

$\mathrm{BI}=$ idle test, boiler only

SI = idle test, system (DHW indirect tank included)

$\mathrm{HO}=$ heating load only, part load test

$\mathrm{DO}=$ domestic hot water load only, part load test

$\mathrm{HD}=$ combined heating and hot water, part load test

SS = steady state test, heating only 
1. refers to on/off pattern of the draw, not the burner operation. The burner operated under control of the aquastat as normal.

This unit was the first tested and, as shown in Table A1-1, many included mixed patterns of draw. Based on these results it was concluded that there is not much value in complex draw patterns, at least for the purposes of this project, and much simpler patterns were used.

\section{Analysis of Input / Output Relationship}

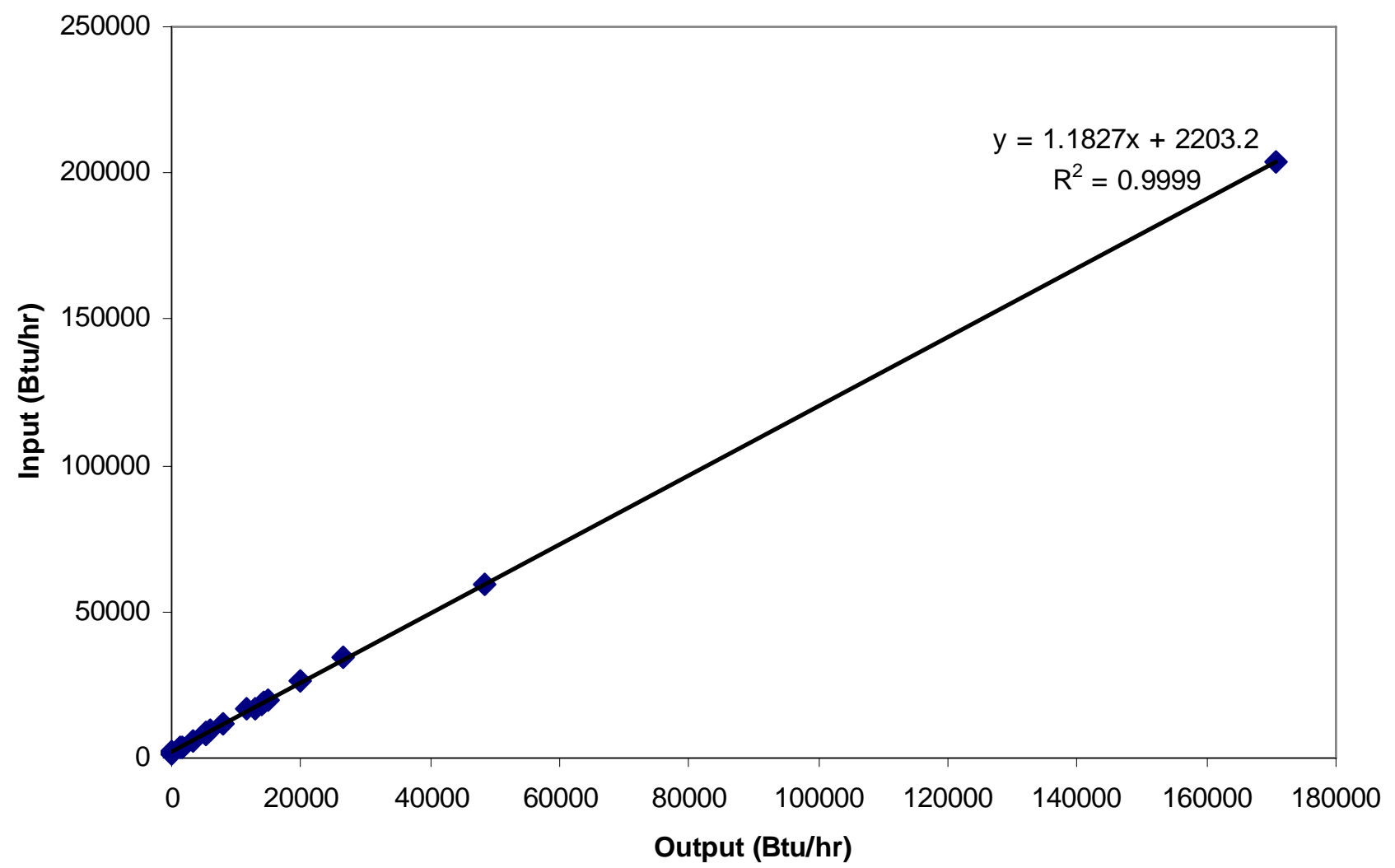

Figure A1-1. All measured input / output point.

The linear regression of this data has been used to produce the efficiency / output plot in Figure A1-2 


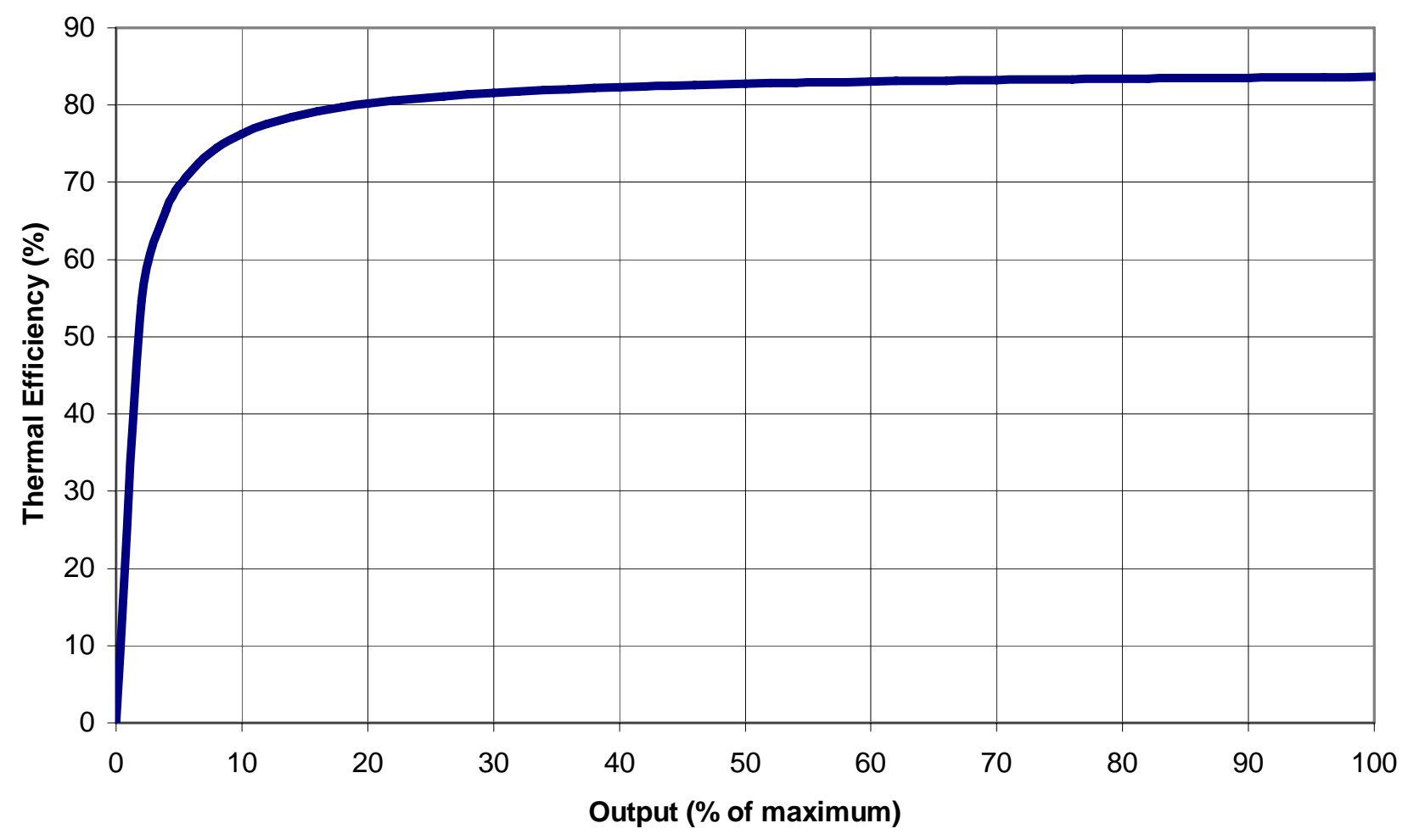

Figure A1-2. Thermal Efficiency vs. output expressed as a percentage of maximum output. Using regression from Figure A1-1.

From this curve, and the unit data, the steady state thermal efficiency of this unit is $83.6 \%$ and the idle loss is $1.08 \%$. The efficiency of this system for an average domestic hot water only load of 1720 $\mathrm{Btu} / \mathrm{hr}$ would be $40.6 \%$.

\section{Combustion Efficiency}

Flue gas oxygen was typically 3.8\%, corresponding to $12.9 \%$ CO2 and 21.8\% excess air. Combustion efficiency was typically $87.1 \%$. 


\section{Appendix 2 \\ Results of Tests with Unit 2}

Unit Description: non-condensing, 3 section cast iron boiler

Fuel:

oil

\section{Capacity:}

117,000 Btu/hr

Net IBR:

101,700 Btu/hr

Aquastat: Triple Function

Domestic Hot Water: Indirect Tank, 40 gallon

Burner type: conventional retention head

Features...

Nominal AFUE: $\quad 84.0$

Table A2-1. Summary of Tests Done with Unit 2 and Results:

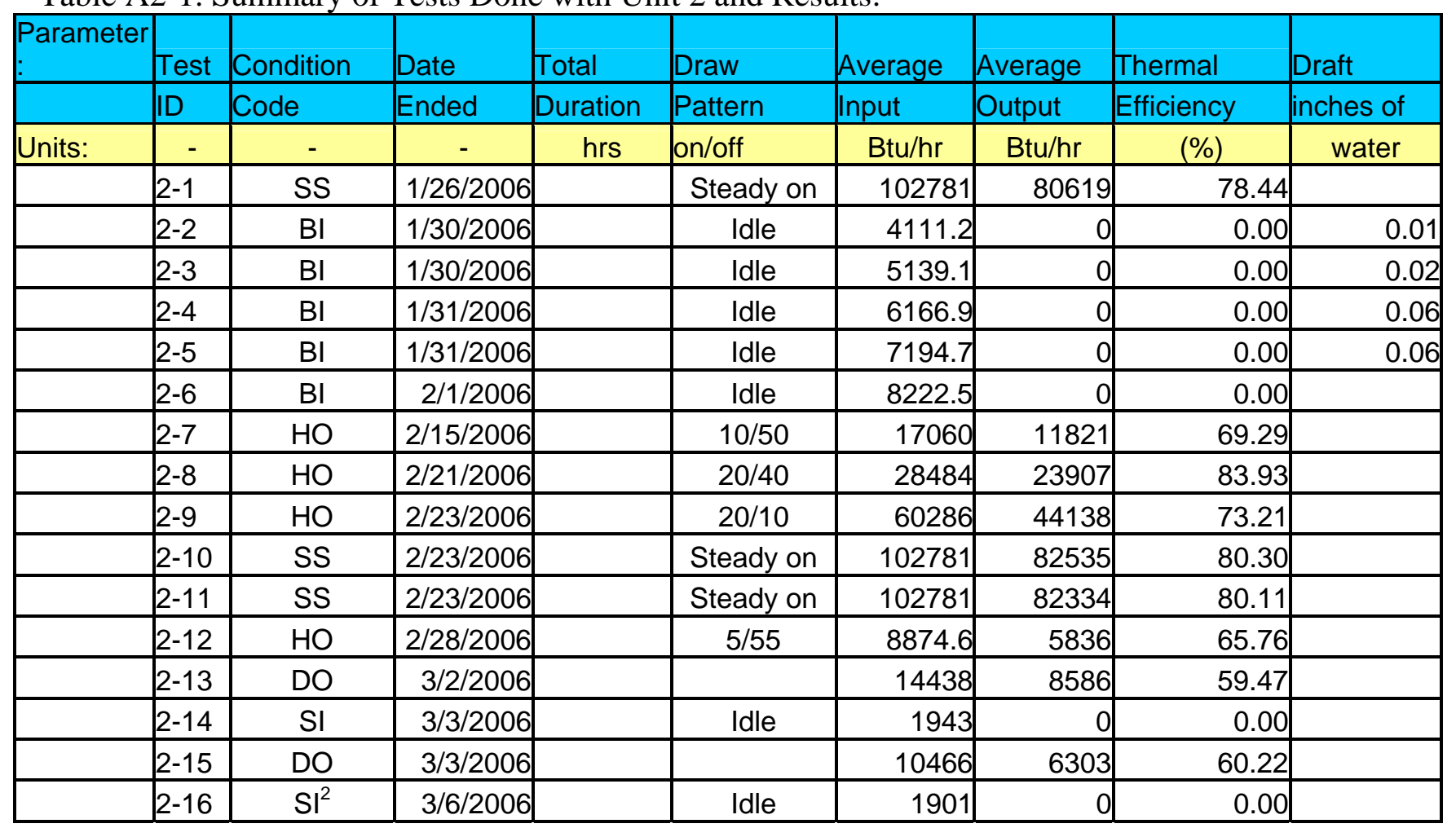

Notes relevant to the Results Summary Table Above:

Condition Codes:

$\mathrm{BI}=$ idle test, boiler only

SI = idle test, system (DHW indirect tank included)

$\mathrm{HO}=$ heating load only, part load test

DO $=$ domestic hot water load only, part load test 
$\mathrm{HD}=$ combined heating and hot water, part load test

SS = steady state test, heating only

1. Refers to on/off pattern of the draw, not the burner operation. The burner operated under control of the aquastat as normal.

2. Test 2-16 was run in a cold start mode - all other tests were done with the boiler operating with a low limit even when there was no call for heat from the domestic hot water tank.

The test work with this boiler included considerable exploration of the effects of draft level and aquastat setting. The boiler idle tests 2-2 through 2-6 were done specifically to explore draft level which was controlled by a variable speed mechanical eductor/fan arrangement. These tests were done with the boiler maintaining a high temperature - approaching $180 \mathrm{~F}$ and would not be representative of a normal idle situation. For most other tests the aquastat control was set for a 180 high limit, 150 low limit and $15 \mathrm{~F}$ differential. For some of the heating mode tests the low limit was set to off. However, because the heat loads were at roughly hourly intervals this had essentially no effect, the boiler never cooled below the low limit. Idle test 2-16 was done with the boiler in a cold start mode and this was somewhat more effective as the time between domestic hot water tanks calls was considerably longer.

\section{Analysis of Input/Output Relationship}

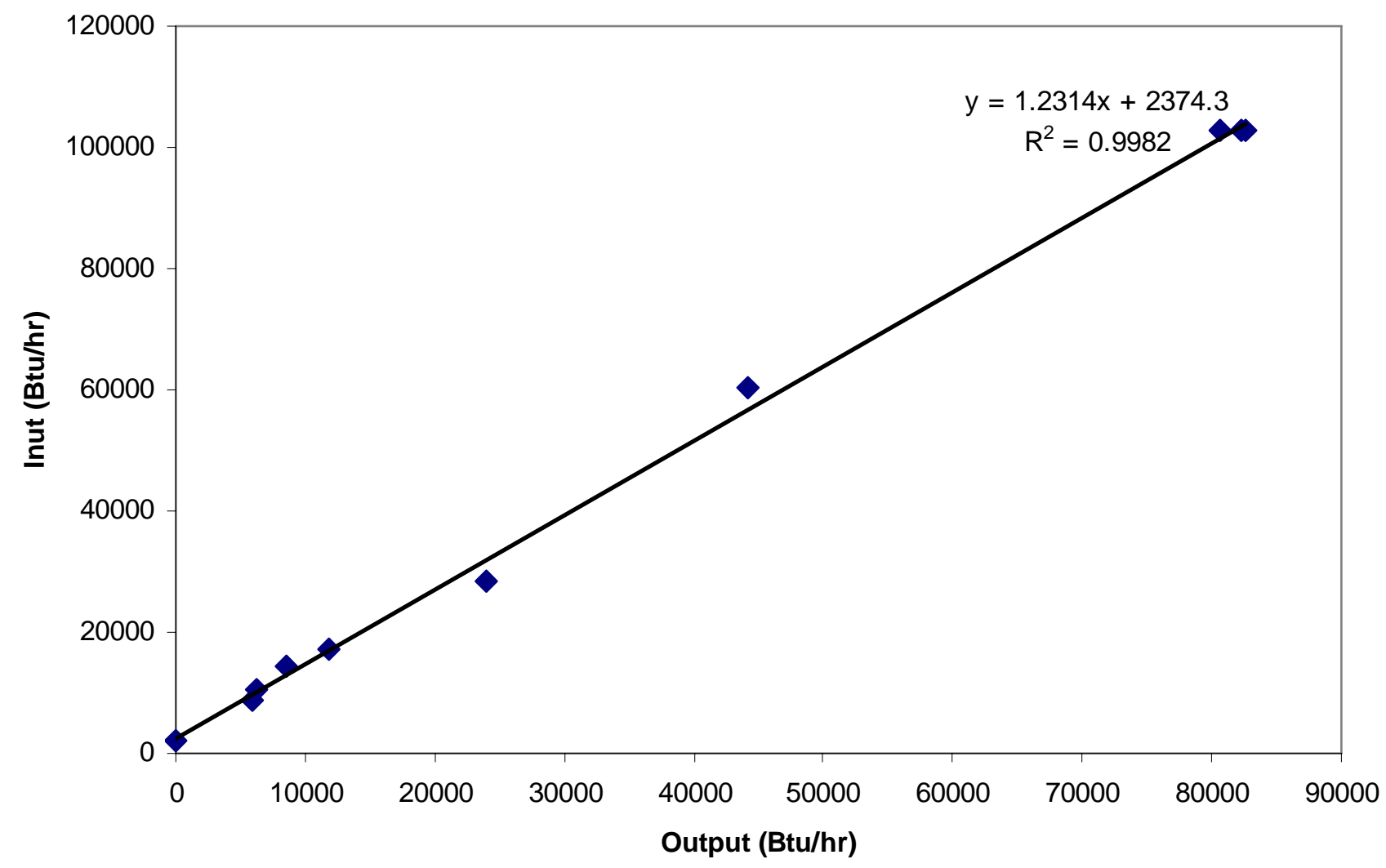

Figure A2-1. Measured input output points considered most representative of typical operation 
The linear regression of this data has been used to produce the efficiency / output plot in Figure A1-2

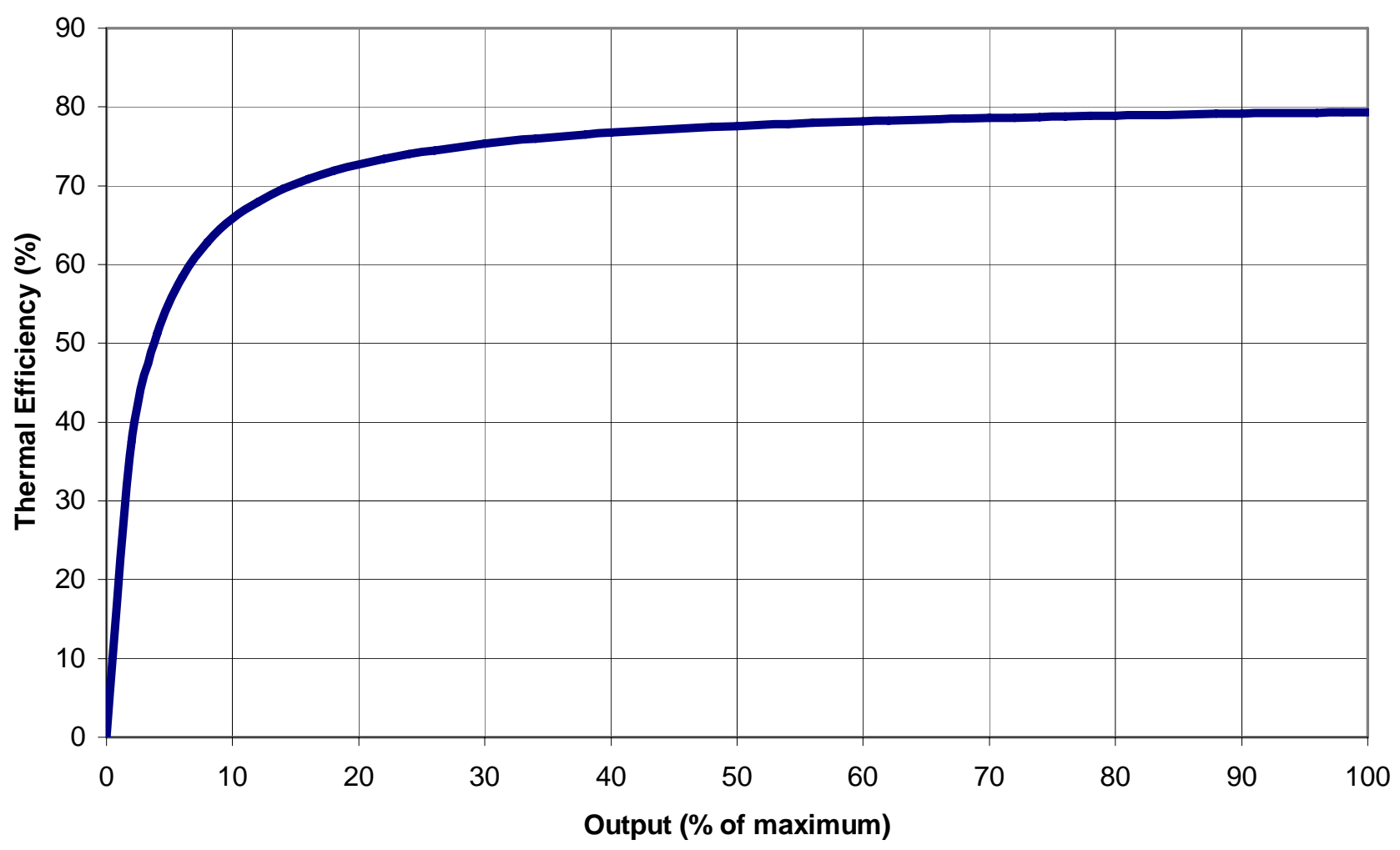

Figure A2-2. Thermal Efficiency vs. output expressed as a percentage of maximum output. Using regression from Figure A2-1.

From this curve, and the unit data, the steady state thermal efficiency of this unit is $79.4 \%$ and the idle loss is $2.28 \%$. The efficiency of this system for an average domestic hot water only load of $1720 \mathrm{Btu} / \mathrm{hr}$ would be $38.3 \%$.

\section{Combustion Efficiency}

Flue gas oxygen was typically $6.3 \%$, corresponding to $11.0 \% \mathrm{CO}_{2}$ and $44 \%$ excess air. Combustion efficiency was typically $84 \%$. 


\section{Appendix 3 \\ Results of Tests with Unit 3}

Unit Description: non-condensing, steel boiler

Fuel:

oil

Capacity: $\quad 90000$

Net IBR...

Aquastat: $\quad$ Custom, provided by manufacturer

Domestic Hot Water: Indirect, 40 gallons, provided by manufacturer as part of system

Burner type: $\quad$ forced draft, retention head

Features: $\quad$ Thermal purge control, see below

Nominal AFUE: $\quad 87.5$

This unit has a custom control system that functions to purge the heat out of the boiler either into the last heating zone which "called" or into the domestic hot water tank. This functions to reduce the boiler temperature to about $104 \mathrm{~F}$ following a heat or domestic hot water tank call. The boiler does not maintain a minimum temperature so that, during low periods of no load, the boiler will become "cold." These features have been developed specifically in an effort to reduce the idle losses.

Table A3-1. Summary of Tests Done with Unit 3 and Results:

\begin{tabular}{|c|c|c|c|c|c|c|c|c|c|c|}
\hline Parameter & Test & Condition & Date & Total & Draw & Average & Average & Thermal & Maximum & Maximum \\
\hline & ID & Code & Ended & Duration & Pattern & Input & Output & Efficiency & $\begin{array}{l}\text { Boiler } \\
\text { Temp }\end{array}$ & Draft \\
\hline Units: & - & - & - & hrs & on/off & Btu/hr & Btu/hr & $(\%)$ & $F$ & in $\mathrm{H} 2 \mathrm{O}$ \\
\hline & $3-1$ & SI & $3 / 27 / 2006$ & 48 & Idle & 166.5 & 0 & 0.00 & & \\
\hline & 3-2 & SS & $4 / 12 / 2006$ & 3 & Steady On & 109401 & 94398 & 86.29 & & \\
\hline & $3-3$ & $\mathrm{HO}$ & $3 / 31 / 2006$ & 20 & $10 / 45$ & 17931 & 14749 & 82.25 & & \\
\hline & $3-4$ & $\mathrm{HO}$ & $4 / 3 / 2006$ & 20 & $10 / 105$ & 8920 & 7035 & 78.87 & & \\
\hline & $3-5$ & $\mathrm{HO}$ & $4 / 3 / 2006$ & 20 & $10 / 15$ & 34923 & 28826 & 82.54 & & \\
\hline & $3-6$ & SI & $4 / 11 / 2006$ & 48 & Idle & 292 & 0 & 0.00 & & \\
\hline & $3-7$ & $\mathrm{HO}$ & $4 / 13 / 2006$ & 8 & $10 / 5$ & 72402 & 60783 & 83.95 & & \\
\hline & 3-8 & $\mathrm{HO}$ & $4 / 14 / 2006$ & 6 & $15 / 10$ & 54149 & 45728 & 84.45 & & \\
\hline & $3-9$ & $\mathrm{HO}$ & $4 / 19 / 2006$ & 20 & $7 / 48$ & 12312 & 10189 & 82.76 & & \\
\hline & $3-10$ & DO & $4 / 26 / 2006$ & 20 & $5 / 15$ & 5896 & 4701 & 79.73 & & \\
\hline & $3-11$ & DO & $4 / 28 / 2006$ & 24 & $5 / 115$ & 3193 & 2303 & 72.13 & & \\
\hline
\end{tabular}

Notes relevant to the Results Summary Table Above:

Condition Codes:

$\mathrm{BI}=$ idle test, boiler only

SI = idle test, system (DHW indirect tank included)

$\mathrm{HO}=$ heating load only, part load test

$\mathrm{DO}=$ domestic hot water load only, part load test

$\mathrm{HD}=$ combined heating and hot water, part load test 
SS = steady state test, heating only

1. refers to on/off pattern of the draw, not the burner operation. The burner operated under control of the aquastat as normal.

For this specific unit the test method had to be modified to accommodate the custom control system. Following each heating load draw period, the circulator, which is integrated with the system runs for additional time to accomplish the thermal purge. During this time the heat exchanger cooling water continued to run and energy extracted was determined and included in the accounting of the total system output. This does not affect the domestic hot water draws. However, when the tank calls for recovery, and that recovery is finished the system circulator runs for several minutes to accomplish the thermal purge. No explicit accommodation for this is needed in the test procedure. 


\section{Analysis of Input/Output Relationship}

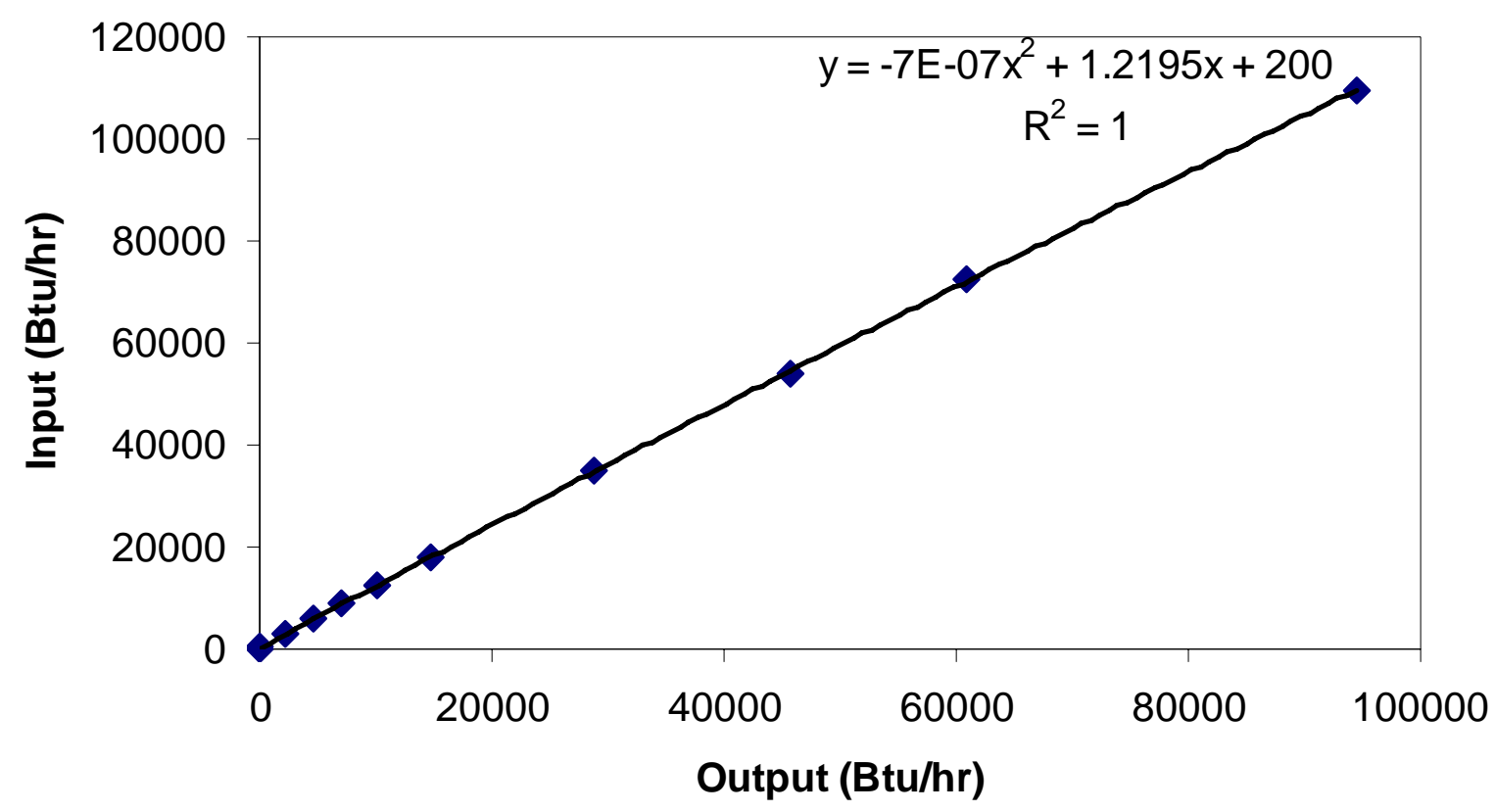

Figure A3-1. All measured input/output point.

Note: For this specific unit a polynomial fit of the input output data was selected although the relationship is nearly linear.

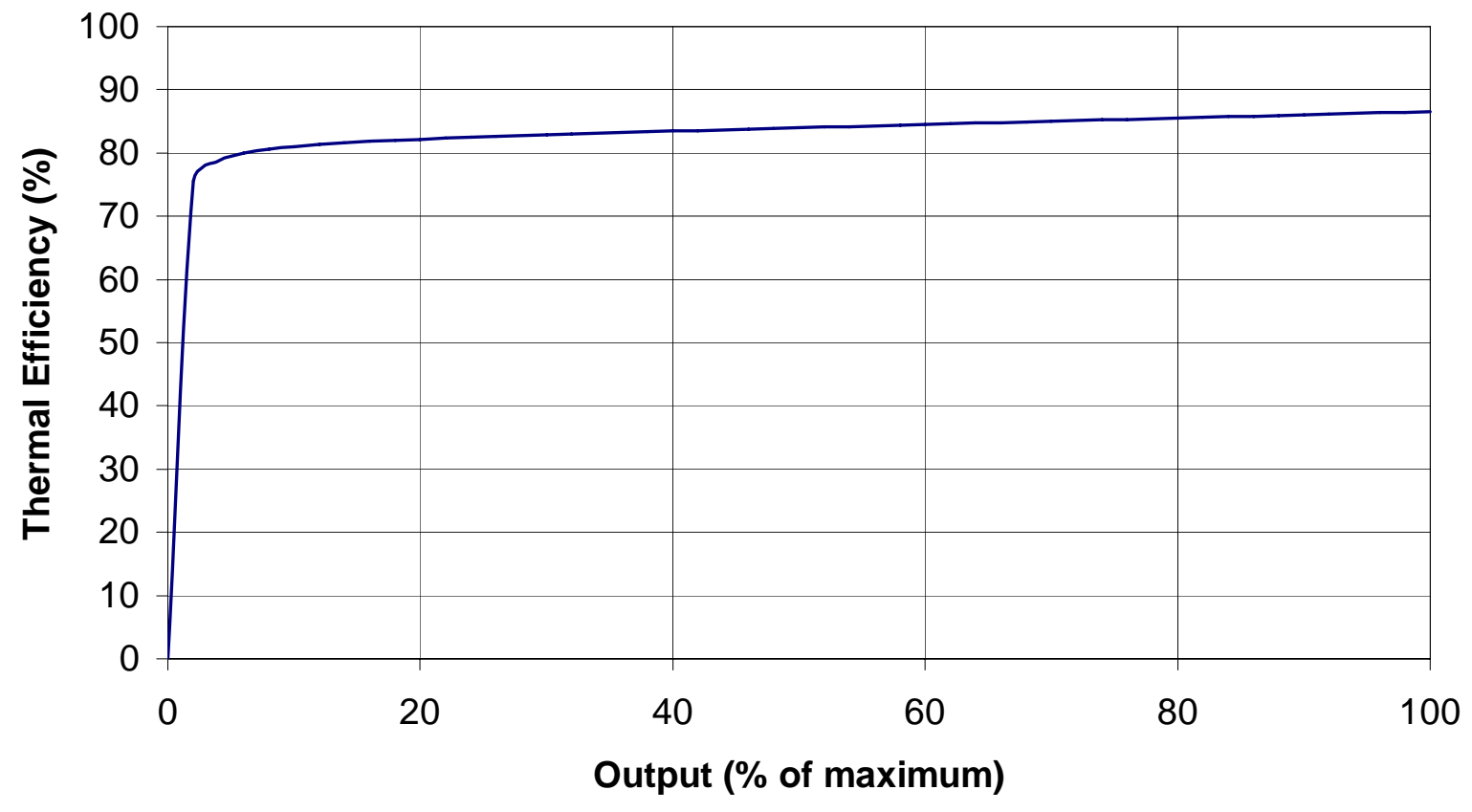

Figure A3-2. Thermal Efficiency vs. output expressed as a percentage of maximum output. Using regression from Figure A3-1. 
From this curve, and the unit data, the steady state thermal efficiency of this unit is $86.5 \%$ and the idle loss is $0.15 \%$. The efficiency of this system for an average domestic hot water only load of $1720 \mathrm{Btu} / \mathrm{hr}$ would be $74.9 \%$.

\section{Combustion Efficiency}

Combustion efficiency was measured during the steady state test, 3-2. Flue gas oxygen was measured at $4.3 \%$ corresponding to a CO2 of $12.4 \%$ and excess air level of $26.3 \%$. At this condition, the supply water was $171 \mathrm{~F}$, the return water from the heat exchanger was $141 \mathrm{~F}$ and the combustion efficiency was $88.1 \%$.

\section{Electric Power}

On this specific unit some measurements were made of the electric power consumption under different conditions results are as follows:

System in idle mode: 2.4 watts

Circulator and zone valve only: 100 watts

Circulator + burner + zone valve: 262 watts

Circulator + burner + ignitor: 287 watts. 


\section{Appendix 4 \\ Results of Tests with Unit 4}

Unit Description: condensing, steel, rated as a water heater to UL 732

Fuel:

No. 2 fuel oil

Nominal heat output $76109 \mathrm{Btu} / \mathrm{hr}$

Aquastat:

custom control - packaged by manufacturer.

Domestic Hot Water: 40 gallon indirect

Burner type: $\quad$ conventional, yellow flame, retention head

Features: adjustable supply temperature with mixing valve

Nominal AFUE: not rated

Table A4-1. Summary of Tests Done with Unit 4 and Results:

\begin{tabular}{|c|c|c|c|c|c|c|c|c|c|}
\hline Parameter & Test & Condition & Date & Total & Draw & Average & Average & Thermal & Maximum \\
\hline & ID & Code & Ended & Duration & Pattern & Input & Output & Efficiency & Boiler Temp \\
\hline Units: & - & - & - & hrs & on/off & Btu/hr & Btu/hr & (\%) & $\mathrm{F}$ \\
\hline & $4-1$ & SS & $5 / 5 / 2006$ & 2 & Steady On & 77658 & 70746 & 91.10 & 120 \\
\hline & $4-2$ & SS & $5 / 5 / 2006$ & 2 & Steady On & 77658 & 68727 & 88.50 & 164 \\
\hline & $4-3$ & SS & $5 / 5 / 2006$ & 2 & Steady On & 77658 & 68339 & 88.00 & 177 \\
\hline & $4-4$ & SS & $5 / 5 / 2006$ & 2 & Steady On & 77658 & 71445 & 92.00 & 136 \\
\hline & $4-5$ & SS & $5 / 5 / 2006$ & 2 & Steady On & 77658 & 72454 & 93.30 & 131 \\
\hline & $4-6$ & $\mathrm{BI}$ & $5 / 10 / 2006$ & 24 & Idle & 868 & 0 & 0.00 & 157 \\
\hline & 4-7 & SI & $5 / 15 / 2006$ & 24 & Idle & 1168.1 & 0 & 0.00 & 140 \\
\hline & $4-8$ & $\mathrm{HO}$ & $5 / 17 / 2006$ & 12 & $5 / 55$ & 7489 & 4600 & 61.42 & 157 \\
\hline & $4-9$ & $\mathrm{HO}$ & $5 / 19 / 2006$ & 14 & $10 / 50$ & 12619 & 10498 & 83.19 & 168 \\
\hline & $4-10$ & DO & $5 / 24 / 2006$ & 12 & $5 / 55$ & 7255 & 6208 & 85.57 & 183 \\
\hline & 4-11 & $\mathrm{DO}$ & $5 / 25 / 2006$ & 24 & $\mathrm{DHW}$ & 2833 & 1555 & 54.89 & 180 \\
\hline & 4-12 & $\mathrm{HO}$ & $6 / 2 / 2006$ & 5 & $15 / 15$ & 36899 & 31955 & 86.60 & 180 \\
\hline & 4-13 & DO & $6 / 6 / 2006$ & 14 & $2.5 / 57.5$ & 3641 & 2285 & 62.76 & 180 \\
\hline
\end{tabular}

Notes relevant to the Results Summary Table Above:

Condition Codes:

$\mathrm{BI}=$ idle test, boiler only

$\mathrm{SI}=$ idle test, system (DHW indirect tank included)

$\mathrm{HO}=$ heating load only, part load test

$\mathrm{DO}=$ domestic hot water load only, part load test

$\mathrm{HD}=$ combined heating and hot water, part load test

SS = steady state test, heating only

1. refers to on/off pattern of the draw, not the burner operation. The burner operated under control of the aquastat as normal.

The plastic vent system for this boiler is under positive pressure (from the burner fan). Vent pressure was not measured and so is not reported in Table A4-1 as it is for other systems tested. 
This boiler is configured with a primary (non-condensing) and secondary (condensing) heat exchanger configuration. It has two hot water "supply" connections. One is hot water directly from the primary heat exchanger and this is directed to the domestic hot water tank to provide rapid recovery. The second supply connection is a mix of water from the primary part of the heat exchanger and the return flow from the heat distribution system (e.g. baseboard convectors). A circulation pump and thermal mixing valve are integrated within the boiler jacket. The thermal mixing valve can be either fixed, manually adjusted or an automatic mixing valve with an outdoor temperature sensor can be used to implement an outdoor reset function. With the manual valve, the temperature of the supply water to the heating system would be adjusted based on the type of distribution system - a radiant floor heating system, for example, would have a lower mix supply temperature.

The boiler also has two return connections. One is at the end of the secondary heat exchanger such that this return water flow through the entire condensing heat exchanger. The second is also into the secondary heat exchanger but close to the transition between the primary and secondary heat exchangers so that this return flow would pass through only part of the secondary heat exchanger. For these tests both returns were connected to the first return port and so the flow was through the entire secondary exchanger at all times.

Figure A4-1 provides a simple illustration of how this boiler was setup for these tests.

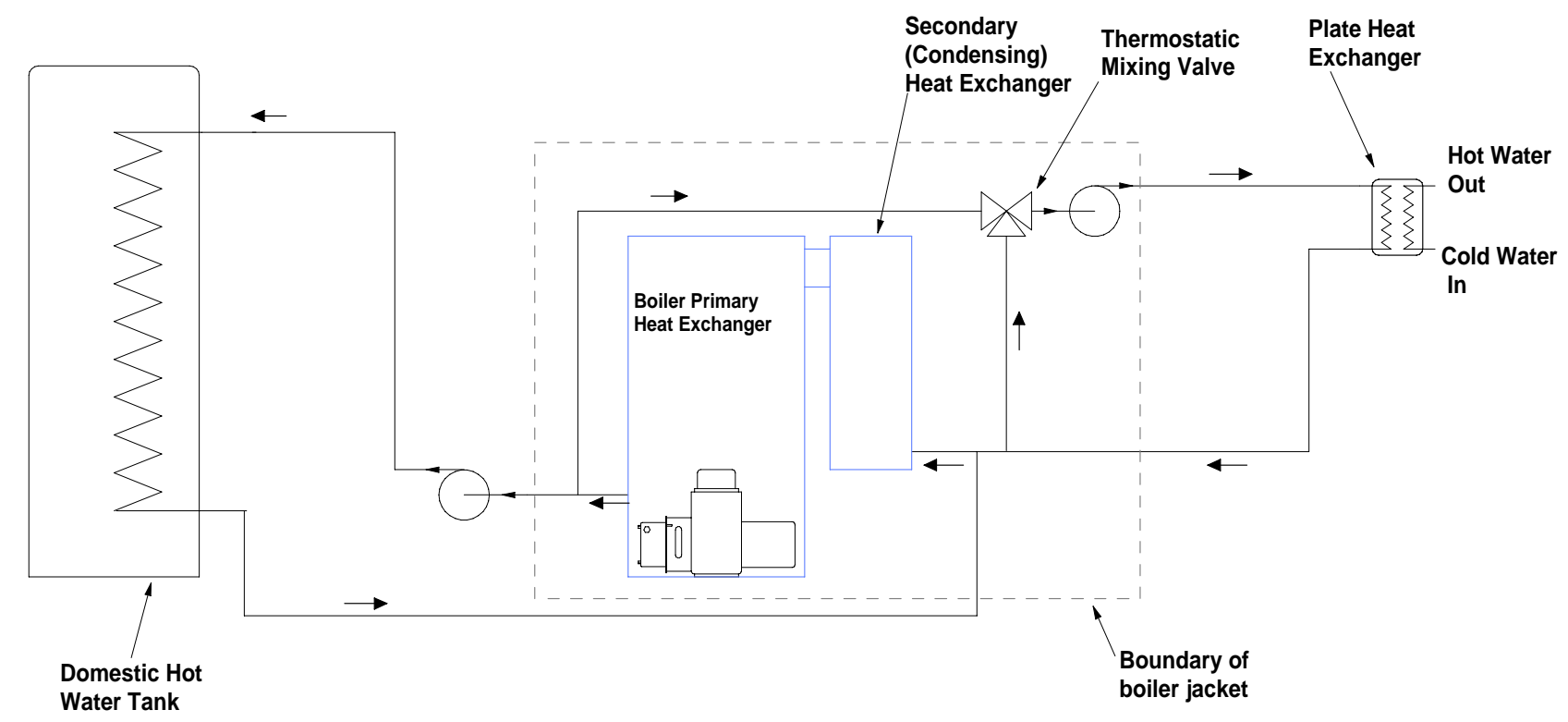

Figure A4-1. Basic test arrangement for Unit \#4.

In the test arrangement during steady state, heating mode tests, the temperature of the supply and return, can be varied in two ways: 1) With a fixed setting of the mixing valve the flow rate of cooling water to the heat exchanger can be varied and 2) With essentially constant boiler temperature, the setting of the mixing valve can 
be changed. For the tests presented in Table A4-1, the first approach was used with the mixing valve adjusted to a high setting. Following completion of all tests covered in Table A4-1 a separate study was done of the impact of each of these two methods and results are presented later in this section.

Two idle tests are included in Table 4-1, one with the boiler only and one with the boiler and domestic hot water tank. Clearly the idle losses with the boiler only are lower. This particular boiler is not intended for operation in a cold start mode, so that the burner will operate to keep the boiler at its setpoint temperature even when there is no heating or domestic hot water load.

\section{Analysis of Input / Output Relationship}

Figure A4-2 shows all input output points with the exception of the boiler-only idle point. At the highest load point there are a cluster of data points because these steady state tests were run at different water temperature conditions as shown in Table A4-1. This plot is repeated in Figure A4-3 with only one steady state data point shown, Test 4-2, during which the boiler average temperature was similar to that used during the part load tests. A comparison of Figures A4-2 and A4-3 shows that this step does not significantly affect the regression which is subsequently used to develop the efficiency / load curve.

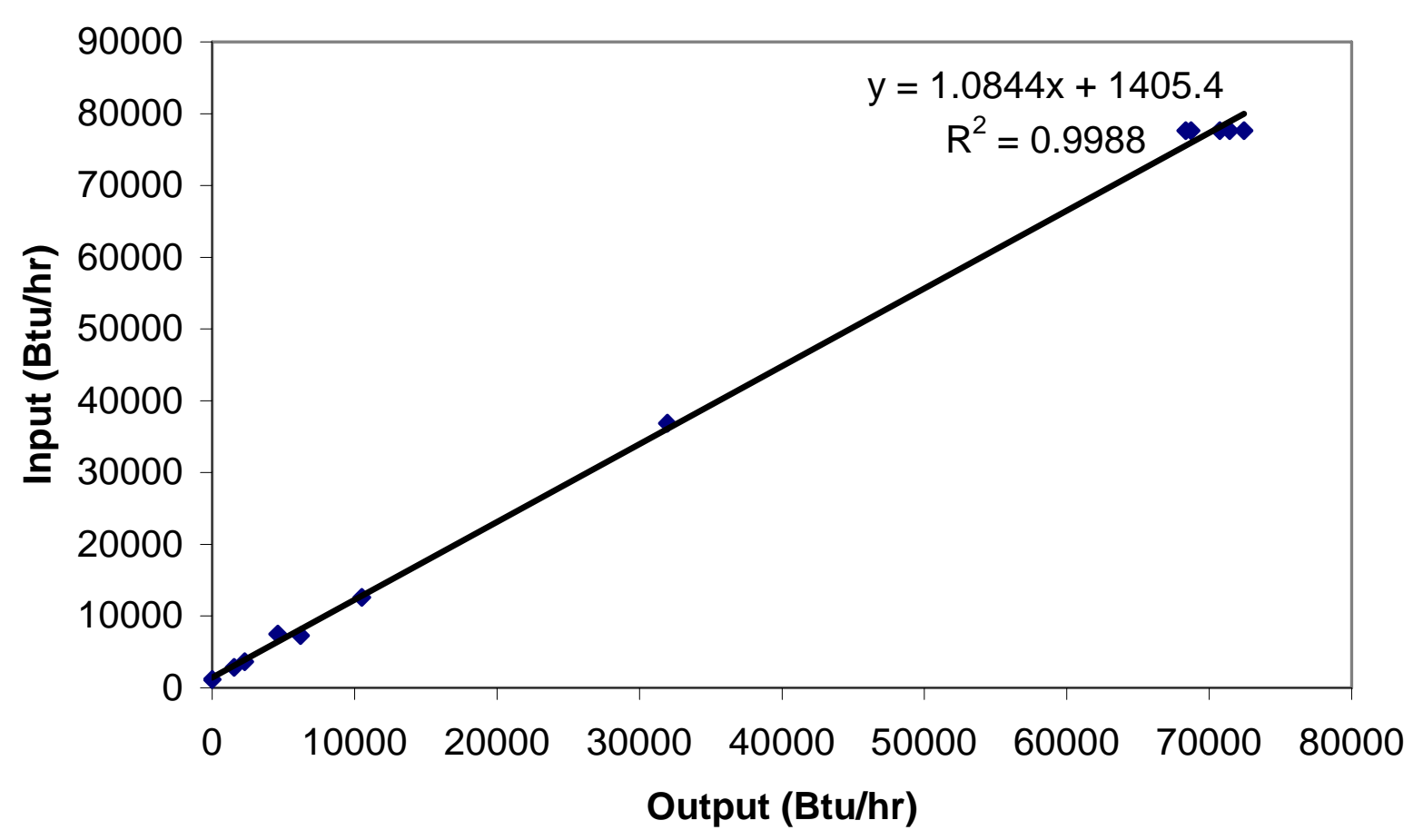

Figure A4-2. All measured input /output points with exception of boiler idle (only system idle shown) 


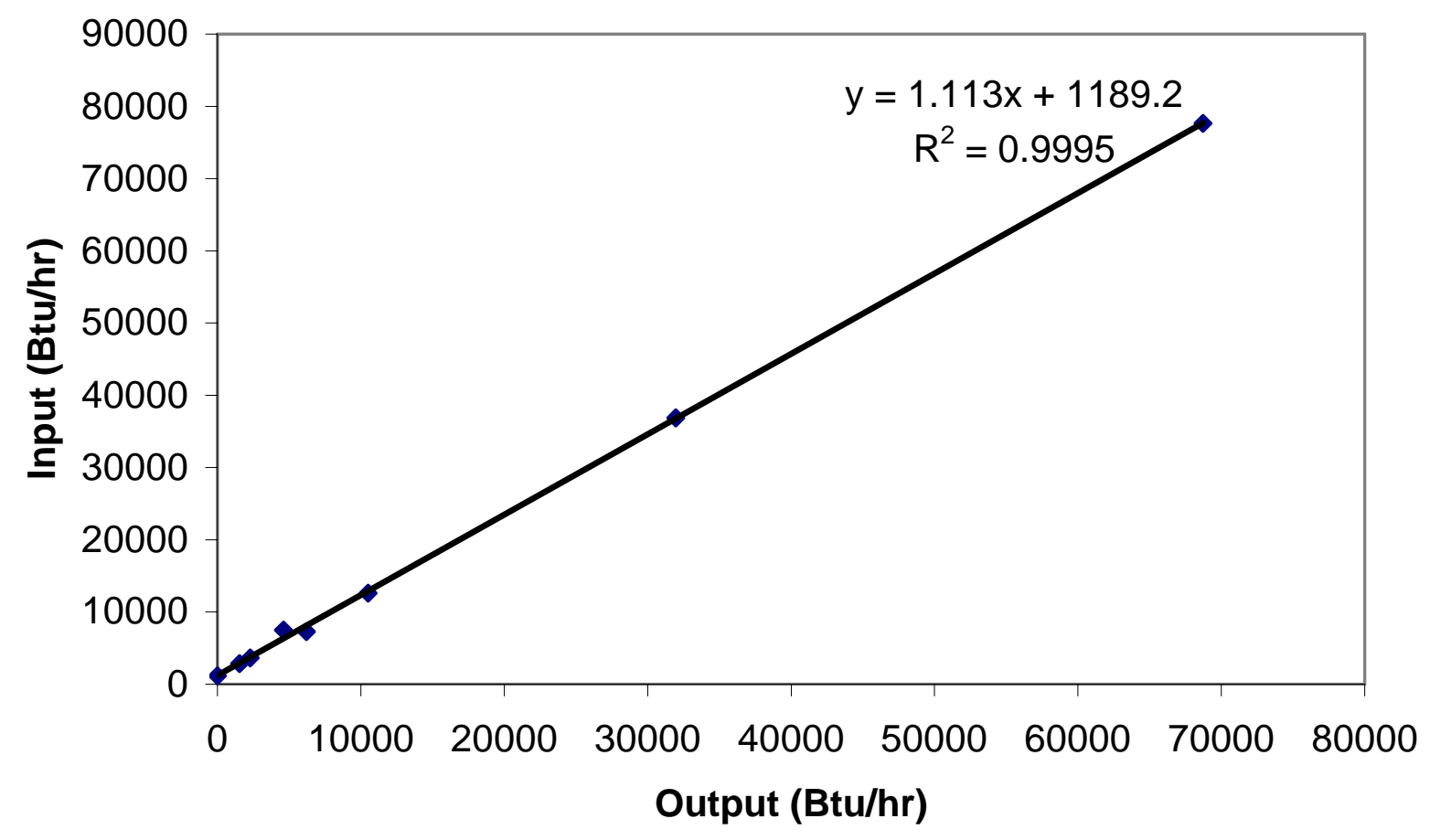

Figure A4-3. Input / output points with only 164 F supply steady state point included.

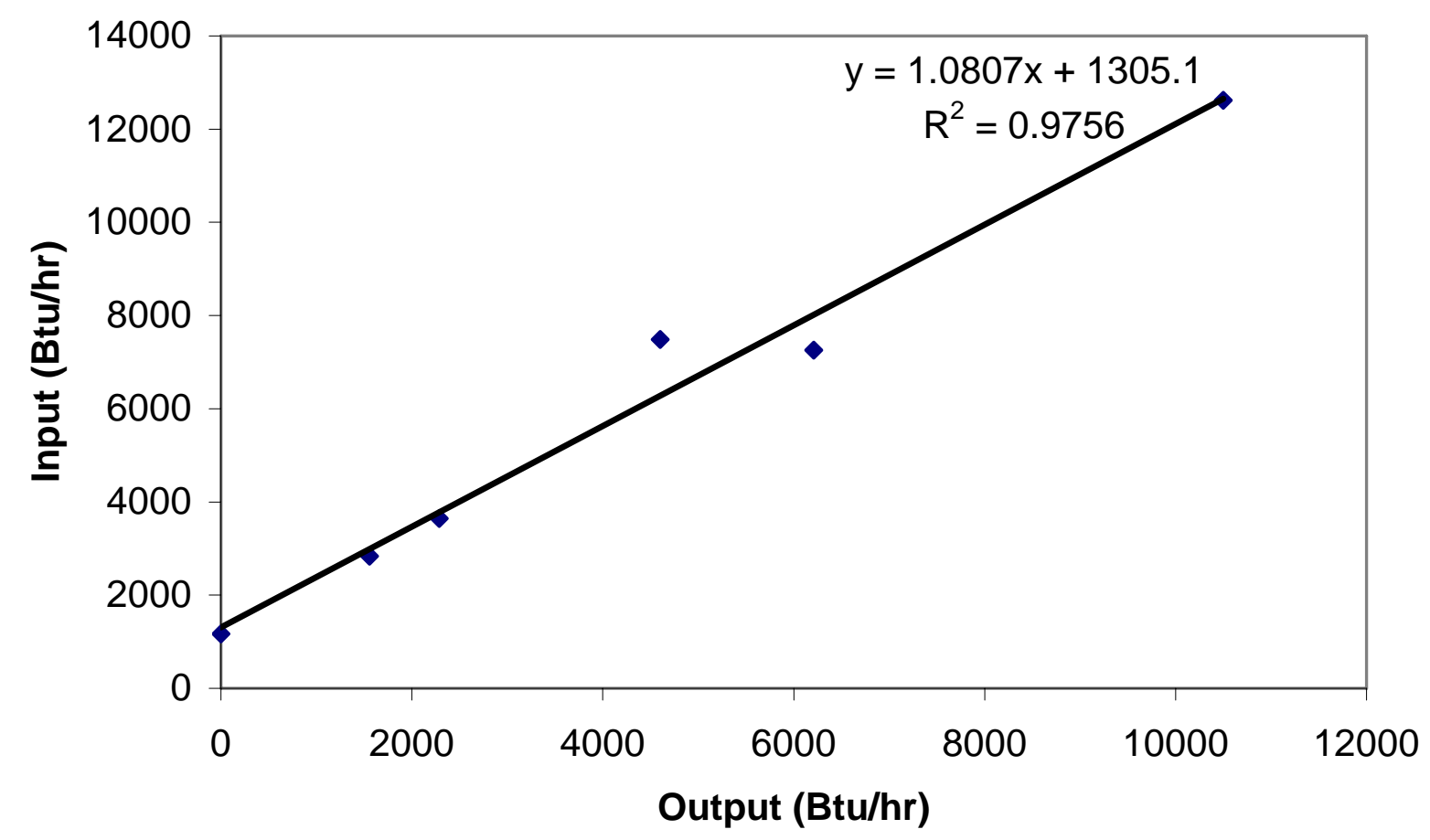

Figure A4-4. All data with input under 20,000 Btu/hr. 


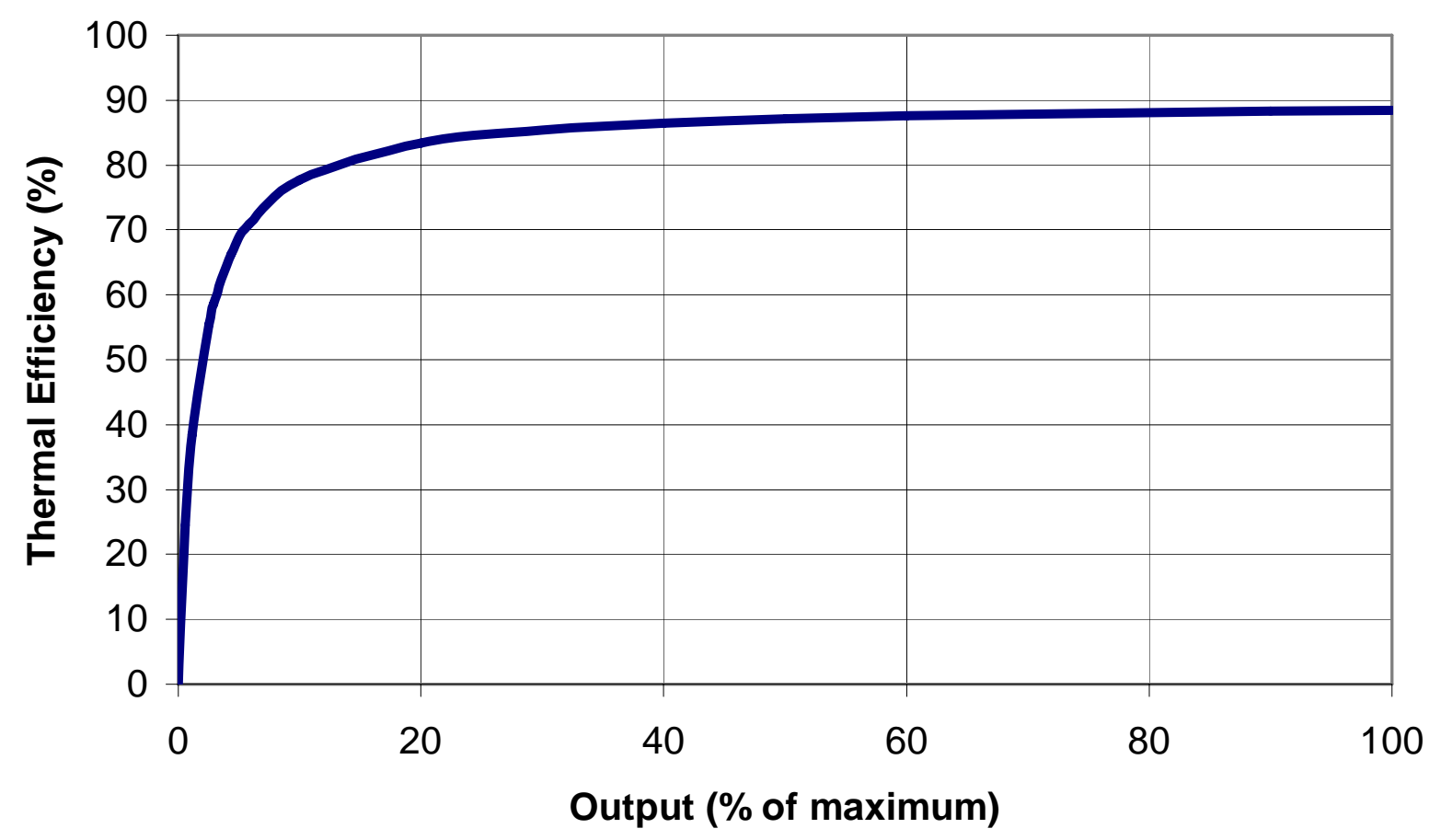

Figure A4-5. Thermal efficiency vs. output expressed as a percentage of maximum output. Using regression from Figure A4-3.

From this curve, and the unit data, the steady state thermal efficiency of this unit is $88.5 \%$ and the idle loss is $1.53 \%$. The efficiency of this system for an average domestic hot water only load of $1720 \mathrm{Btu} / \mathrm{hr}$ would be $55.4 \%$.

\section{Example Temperature Profiles}

Figure A4-6 shows a typical profile for the supply and return water from the domestic hot water tank during a system idle test. During this test the burner fired to maintain just the boiler temperature at a time interval of 3 hours. The burner typically fired for about $1 \frac{1 / 2}{2}$ minutes. Every 12 hours the domestic hot water tank called for heat under this no-load test. The return water temperature as shown is much too high for condensing to occur during this type of load. 


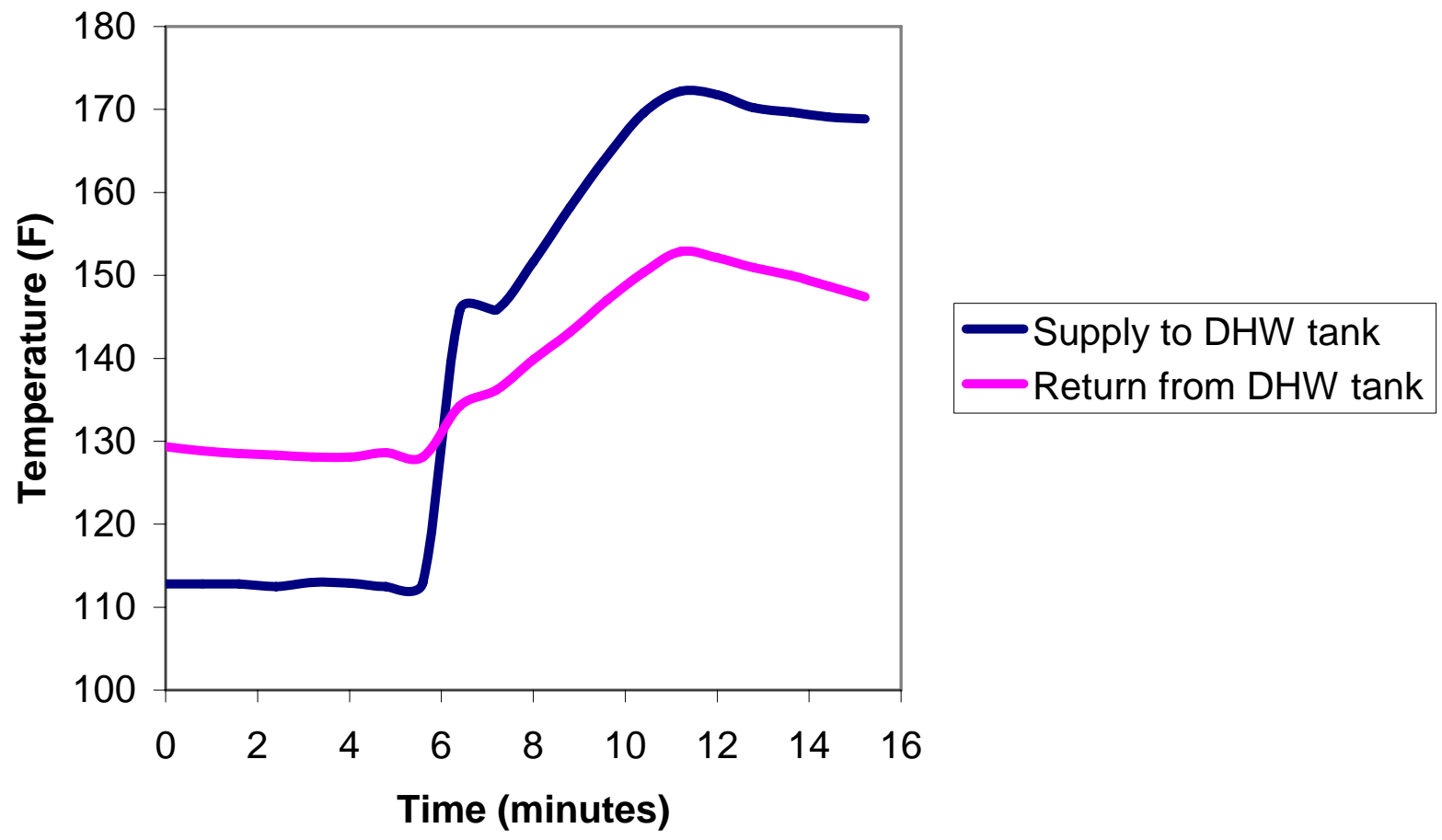

Figure A4-6. Example boiler supply and return water temperatures during a tank heat call in a system idle test. The tank aquastat “called” at about the 5.5 minute point in this plot.

Figure A4-7 shows how the tank average temperature varies during a DHW draw test. This specific data set was taken during Test 4-10. The time interval between "points" shown in this figure is 3 seconds. 


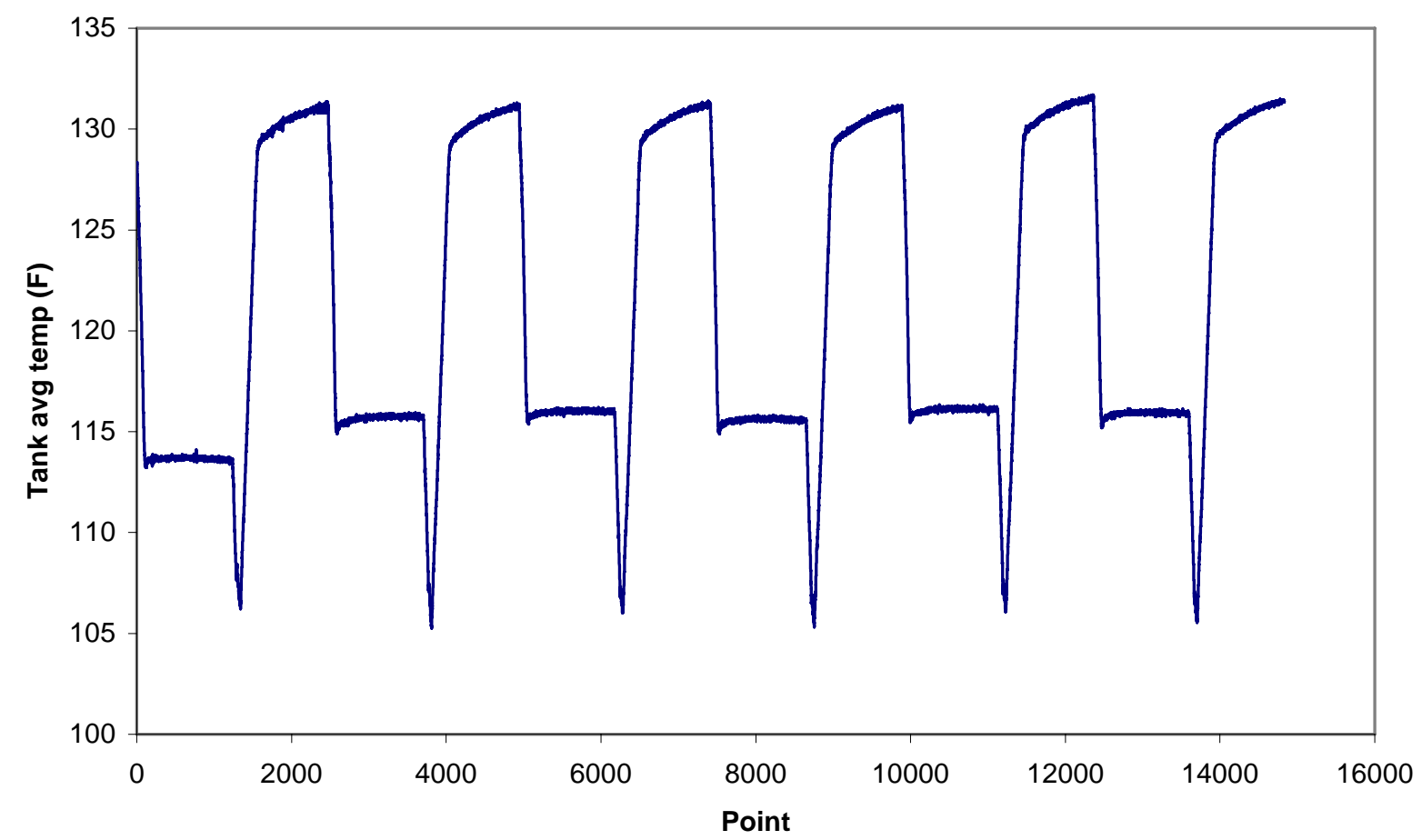

Figure A4-7 Example average DHW tank temperatures during DHW draw test, 4-10.

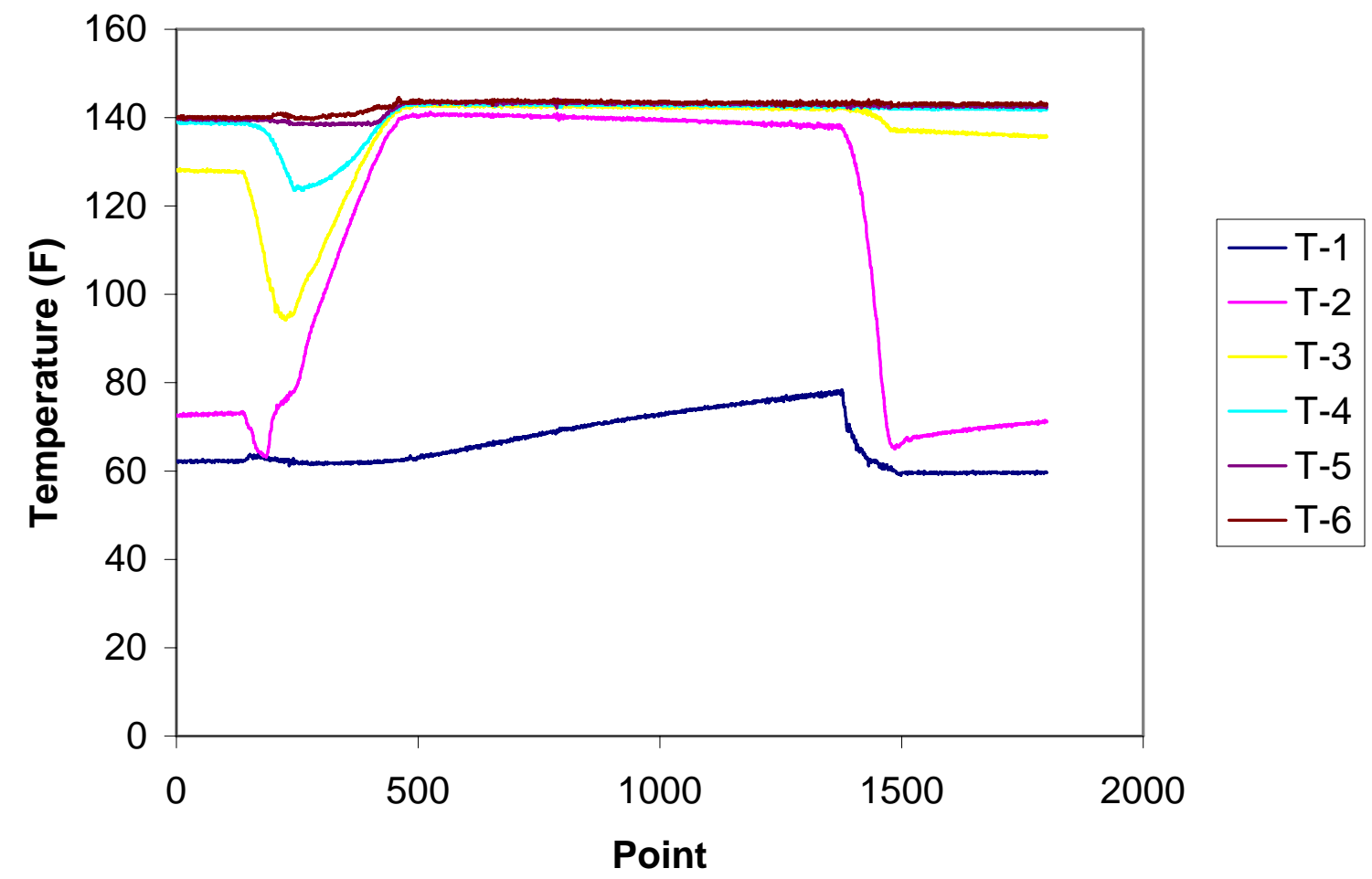

Figure A4-8. Typical internal water tank temperatures during a DHW draw test - Test 4-10. Temperatures are measured from bottom (T1) to top (T-6). 
Figure A4-9 provides example data during a typical heat call in a heat only test. In this figure boiler temperature is the temperature of the boiler water entering the mixing valve. Supply is the mix temperature. Gas temperature is measured between the primary and secondary heat exchangers. This measure is a useful indicator of burner operation. Heat call started at the 1 minute point and ended at the 6 minute point. The cooling water out temperature is the temperature of the cooling water leaving the heat exchanger.

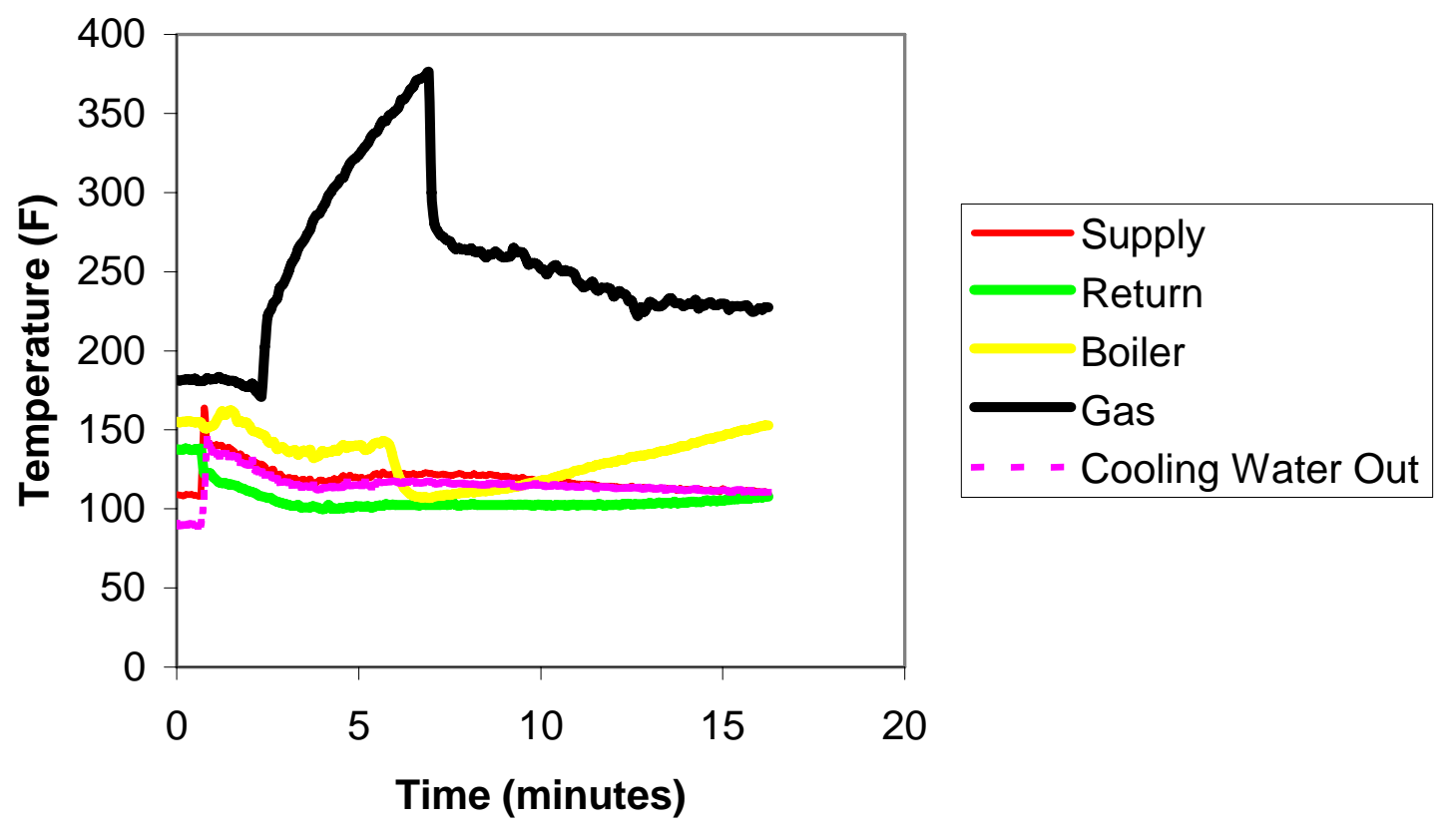

Figure A4-9. Example temperature data during a heating only test (Test 4-8 ).

\section{Supplemental Tests on Impact of Water Temperature}

As discussed above, the temperature of the boiler water can be controlled in two ways: 1) With a fixed setting of the mixing valve the flow rate of cooling water to the heat exchanger can be varied and 2) With essentially constant boiler temperature, the setting of the mixing valve can be changed. The actual temperatures in the field will depend very much upon the control settings, which in turn is based on the type of distribution system. Baseboard radiators will require higher temperature water than radiant floor heating. With an outdoor reset or other type of control the temperature of the supply water can vary considerably during the heating season. To evaluate the impact of water temperature on efficiency a series of steady state tests were done using both of the two above approaches. Figure A4-10 shows the measured steady state thermal efficiency and indicates that somewhat higher efficiency can be reached, particularly at lower return water temperatures if the entire boiler temperature is modulated. While this specific boiler is not designed for operation in this mode as it would lead to condensation and, likely, high corrosion rates in the primary heat exchanger, some other condensing boilers are designed in this way. It is not an unexpected result - if the boiler can condense anywhere it will achieve higher efficiency than if it condenses only in the secondary heat exchanger. All of these steady state tests were conducted with a relatively low excess air setting: flue gas $\mathrm{O}_{2}$ was $2.7 \%$ and the corresponding $\mathrm{CO}_{2}$ is $13.7 \%$ and excess air is $14.3 \%$. 


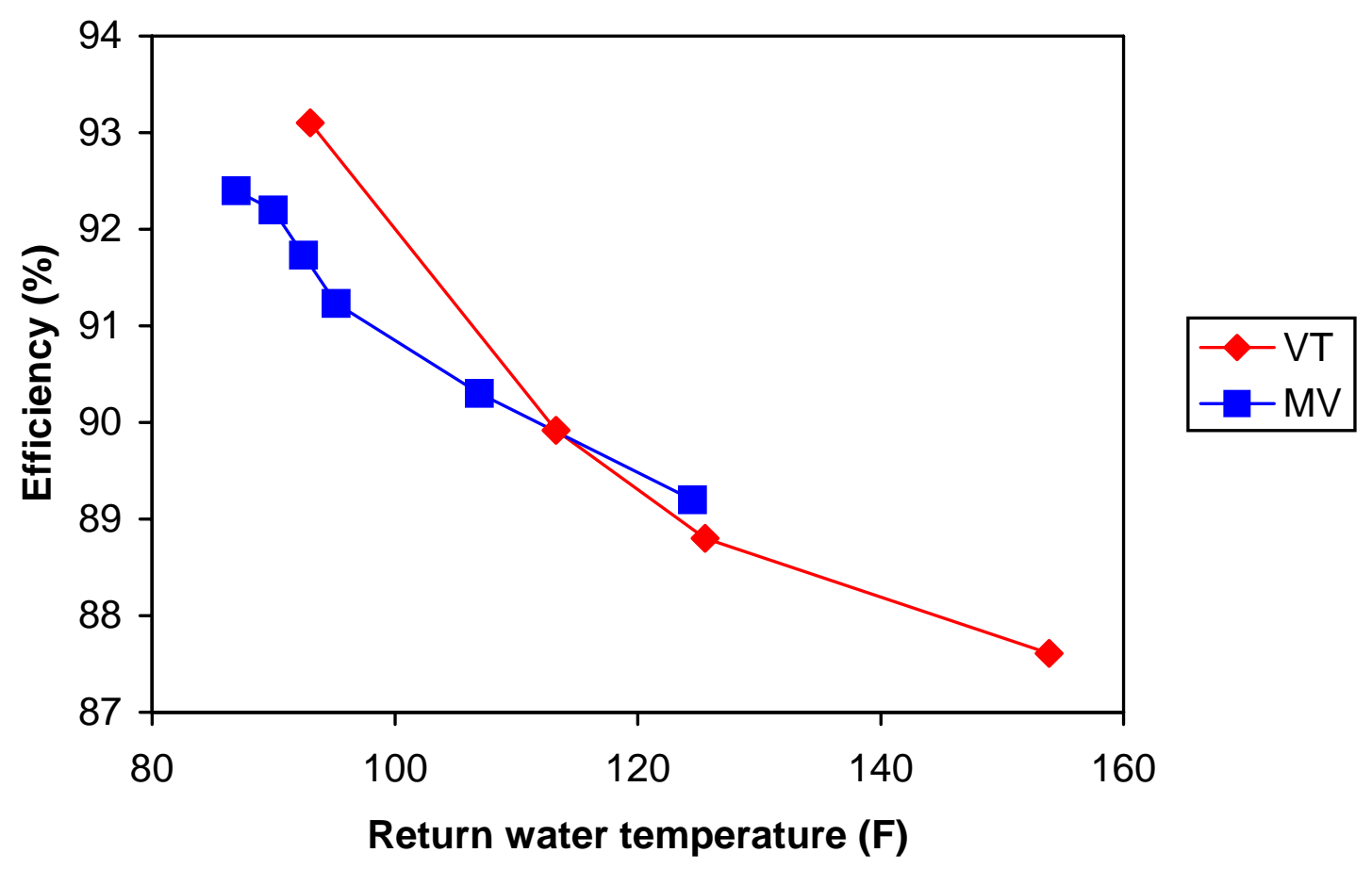

Figure A4-10. Steady state thermal efficiency as a function of water temperature (return water temperature selected as independent variable). MT - refers to case with constant boiler temperature and supply/return temperature changed by changing mix valve setting. VT - refers to case where temperature of entire boiler is modulated. In this case mix valve is set to provide boiler water directly (unmixed) to heating load.

For this same set of tests Figure A4-11 shows the rate of condensate collection from the boiler as a function of return water temperature and Figure A4-12 shows this in the form of latent heat recovery. This latent heat recovery is expressed as a percentage of the fuel energy input. In other terms, it is the improvement in the boilers thermal efficiency due only to the latent heat recovered by condensation. 


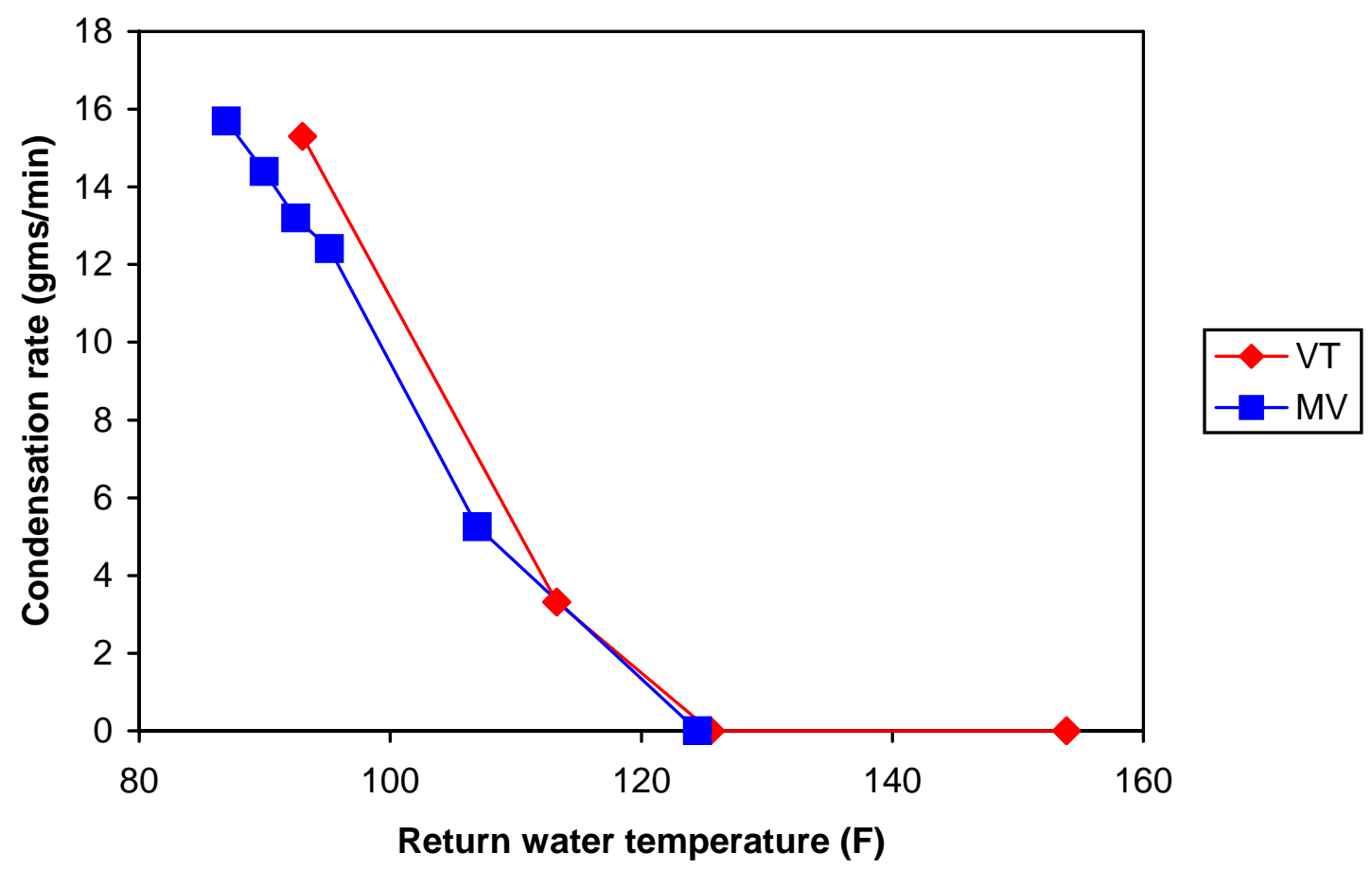

Figure A4-11. Steady state tests with variable water temperature. Condensation rate vs. return.

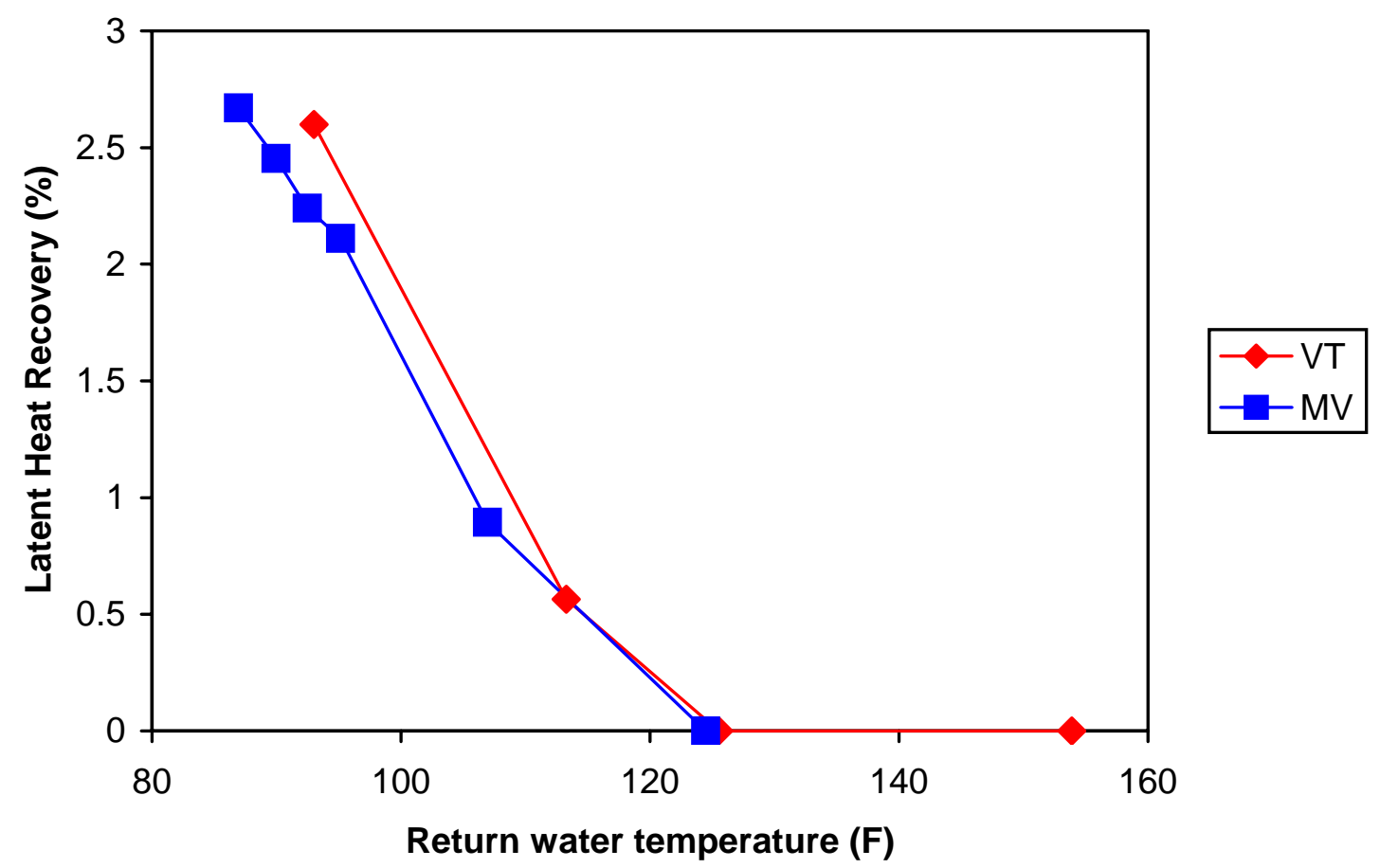

Figure A4-12. Steady state tests with variable water temperature. Latent heat recovery vs. return. 


\section{Electric Power Consumption}

Measurements of individual burner components were made as follows:

Boiler control system alone: 40 watts

Circulator: 84 watts

Burner with igniter on - 203 watts

Burner with igniter off - 273 watts.

The burner primary control has interrupted ignition feature so that, on startup the igniter is on but after ignition has been proven the igniter power is off. Total running power for the burner, circulator, and controls then is 327 watts. 


\section{Appendix 5 \\ Results of Tests with Unit 5}

Unit Description: non-condensing, cast iron boiler, imported from Germany

Fuel:

oil

Capacity: $\quad 98,000 \mathrm{Btu} / \mathrm{hr}$

Net IBR: $\quad$ 85,000 Btu/hr

Aquastat: $\quad$ Custom, provided by manufacturer

Domestic Hot Water: Indirect, 40 gallons, provided by manufacturer as part of a system

Burner type: $\quad$ custom, blue flame burner

Features...

Nominal AFUE: $\quad 86.5$

This unit comes with a custom control from the manufacturer that implements outdoor reset. For all test conducted as part of this project, the outdoor reset control was not used and boiler water temperature was manually controlled. The burner used was an advanced, low-NOx burner not currently available on the market. Some of the tests done with this unit were specifically planned to evaluate the impacts of boiler water temperature and, in turn, outdoor reset.

Table A5-1. Summary of Tests Done with Unit 5 and Results:

\begin{tabular}{|c|c|c|c|c|c|c|c|c|c|}
\hline Paramete & Test & Condition & Date & Total & Draw & Average & Average & Thermal & Maximum \\
\hline & ID & Code & Ended & Duration & Pattern & Input & Output & Efficiency & Boiler Temp \\
\hline Units: & - & - & - & \begin{tabular}{|l|}
$\mathrm{hrs}$ \\
\end{tabular} & on/off & Btu/hr & Btu/hr & $(\%)$ & $\mathrm{F}$ \\
\hline & $5-1$ & SS & $7 / 21 / 2006$ & 2 & Steady On & 122794 & 107407.6 & 87.47 & 138 \\
\hline & $5-2$ & SS & $7 / 21 / 2006$ & 2 & Steady On & 124066.8 & 107963 & 87.02 & 152 \\
\hline & $5-3$ & SS & $7 / 21 / 2006$ & 2 & Steady On & 124761 & 108138.7 & 86.68 & 160 \\
\hline & $5--4$ & SS & $7 / 21 / 2006$ & 2 & Steady On & 124877 & 108893 & 87.20 & 175 \\
\hline & $5-5$ & SS & $7 / 21 / 2006$ & 2 & Steady On & 124877 & 110525 & 88.51 & 143 \\
\hline & $5-6$ & DO & $8 / 1 / 2006$ & 17 & $2.5 / 57.5$ & 2593.6 & 1778.3 & 68.56 & \\
\hline & $5-7$ & $\mathrm{HO}$ & $8 / 2 / 2006$ & 4 & $10 / 50$ & 21106.8 & 11397.25 & 54.00 & 180 \\
\hline & $5-8$ & $\mathrm{HO}$ & $8 / 3 / 2006$ & 8 & $10 / 50$ & 14094 & 9679 & 68.67 & 150 \\
\hline & $5-9$ & $\mathrm{HO}$ & $8 / 4 / 2006$ & 8 & $18 / 42$ & 18093 & 17530 & 96.89 & 130 \\
\hline & $5-10$ & SS & $8 / 7 / 06$ & 2 & Steady On & 110341 & 95940 & 86.95 & 143 \\
\hline & $5-11$ & SS & $8 / 7 / 2006$ & 2 & & 110584 & 96184 & 86.98 & 160 \\
\hline & $5-12$ & SS & 8/7/2006 & 2 & Idle & 110574 & 95687 & 86.54 & 177 \\
\hline & $5-13$ & $\mathrm{HO}$ & $8 / 13 / 2006$ & 6 & $6 / 54$ & 6159 & 4930 & 80.05 & 130 \\
\hline & $5-14$ & $\mathrm{HO}$ & $8 / 13 / 2006$ & 6 & $10 / 20$ & 19126 & 16118.4 & 84.27 & 130 \\
\hline & $5-15$ & $\mathrm{HO}$ & $8 / 14 / 2006$ & 6 & $15 / 15$ & 27791 & 23717.2 & 85.34 & 130 \\
\hline & $5-16$ & $\mathrm{HO}$ & $8 / 15 / 2006$ & 6 & $6 / 24$ & 23128 & 18421.5 & 79.65 & 180 \\
\hline & $5-17$ & $\mathrm{HO}$ & $8 / 15 / 2006$ & 6 & $9 / 21$ & 32620 & 26974.9 & 82.69 & 180 \\
\hline & $5-18$ & $\mathrm{HO}$ & $8 / 15 / 2006$ & 6 & $4 / 56$ & 8775 & 6245.6 & 71.17 & 180 \\
\hline
\end{tabular}

Notes relevant to the Results Summary Table Above: 


\section{Condition Codes:}

$\mathrm{BI}=$ idle test, boiler only

SI = idle test, system (DHW indirect tank included)

$\mathrm{HO}=$ heating load only, part load test

$\mathrm{DO}=$ domestic hot water load only, part load test

HD = combined heating and hot water, part load test

SS = steady state test, heating only

1. refers to on/off pattern of the draw, not the burner operation. The burner operated under control of the aquastat as normal.

With this specific unit some expanded testing was done to carefully evaluate the effects of boiler water temperature on performance. The steady state tests 5-1 to 5-5 for example. Also the part load cyclic tests 5-13 to 5-15 were all done with a boiler maximum temperature of $130 \mathrm{~F}$ while the next 3 tests were done over a similar load range at a higher temperature for direct comparison.

\section{Analysis of Input / Output Relationship}

For the basic input/output relation only tests done within higher water temperatures are included. From Table A5-1 this includes tests 5-3, 5-4, 5-7, 5-11, 5-12, 5-16, 5-17, and 5-18. The input/output relation for these points is included in Figure A5-1.

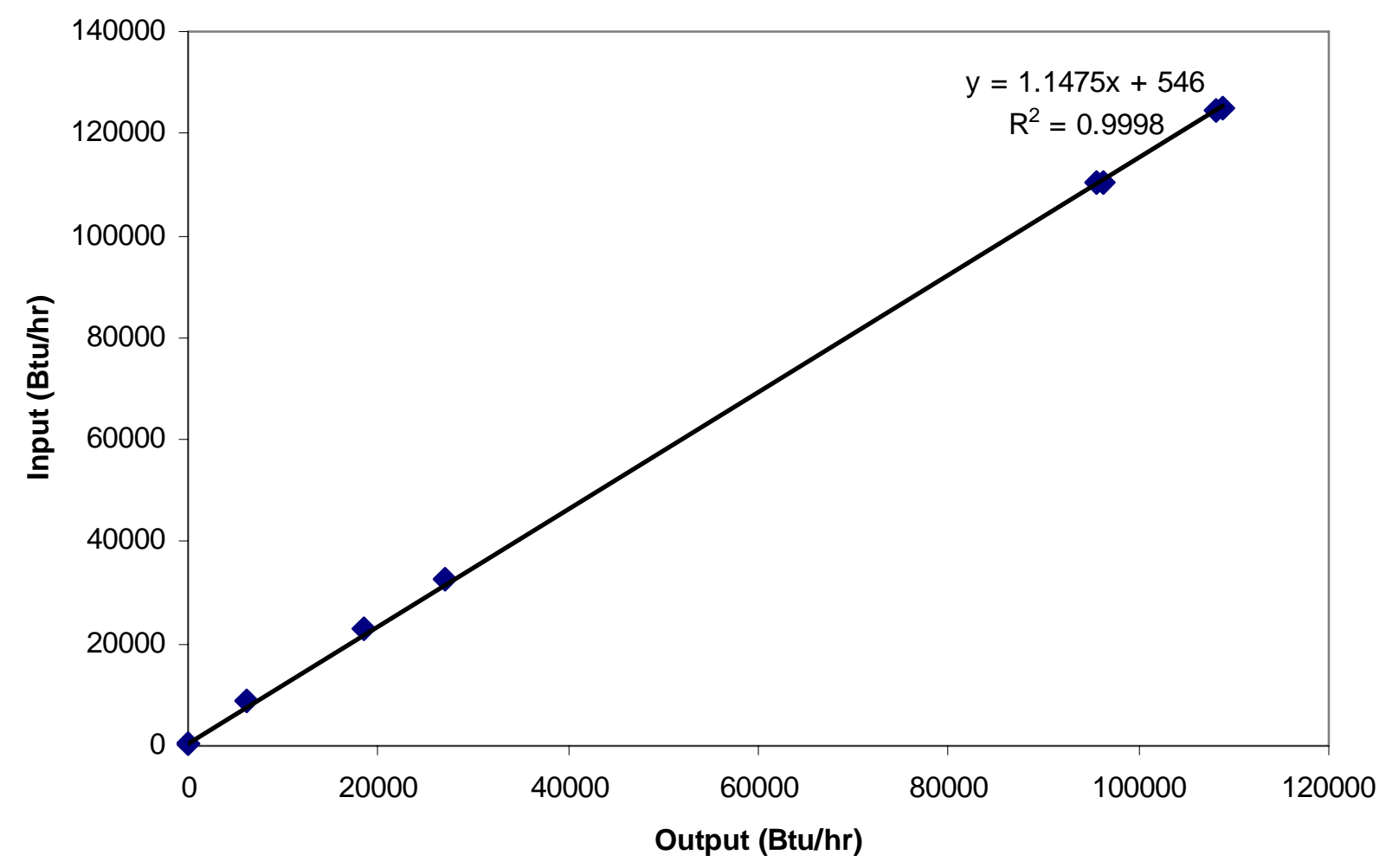

Figure A5-1. All measured input / output point. 
For this unit the measured system idle loss was very small, $546 \mathrm{Btu} / \mathrm{hr}$ or about $.44 \%$ of the steady state input. The domestic hot water tank is very well insulated and the boiler is configured for cold start - i.e. between tank calls the burner will not fire unless a heat load is present. In this case the measurement of a system idle loss involving only the domestic hot water tank may not provide an accurate representation of the system performance at loads close to but not zero. In the analysis of this data other curve fits were examined including second and third order polynomials and, of course they fit the data better. This point may be worth further examination. For the fit shown in Figure A5-1, a linear fit was used with a forced intercept at the measured idle loss rate. Using this fit a thermal efficiency, output curve for this unit has been presented in Figure A5-2.

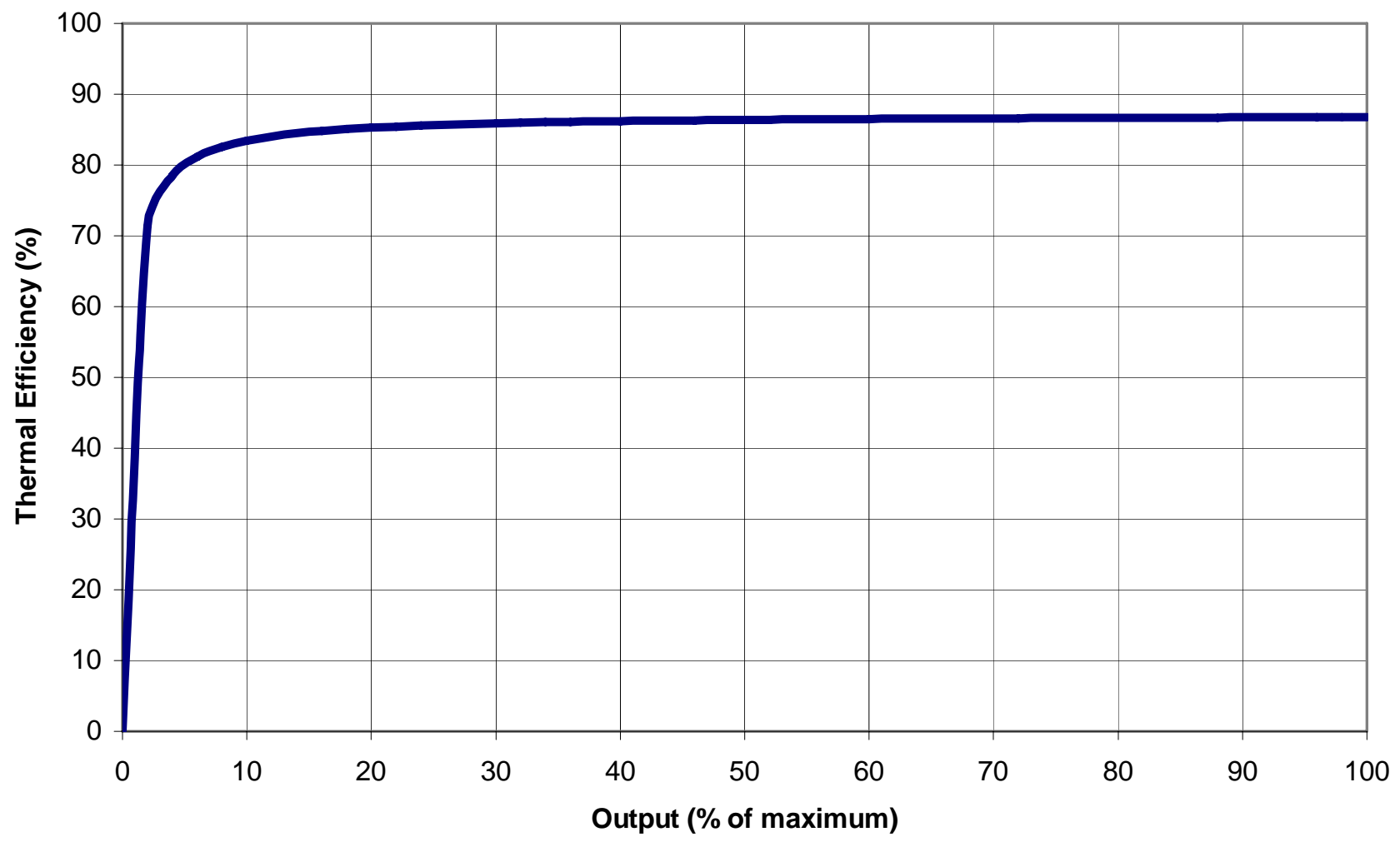

Figure A5-2. Thermal Efficiency vs. output expressed as a percentage of maximum output. Using regression from Figure A5-1.

From this curve, and the unit data, the steady state thermal efficiency of this unit is $86.8 \%$ and the idle loss is $0.45 \%$. The efficiency of this system for an average domestic hot water only load of $1720 \mathrm{Btu} / \mathrm{hr}$ would be $68.3 \%$.

\section{Combustion Efficiency}

Combustion efficiency was measured during all of the steady state tests. Because of the blue flame burner used in these tests the flue gas oxygen was very low - on the order of $2 \%$ which corresponds to $14.2 \%$ CO2 and $10.6 \%$ excess air. In this sense the test conditions were unrealistically optimistic. Combustion efficiency was typically $89.6 \%$. 


\section{Additional Data}

As discussed above part of the studies with this system focused on the effects of boiler water temperature. Figure A5-3 shows results in the form of efficiency vs. output for the $180 \mathrm{~F}$ case and the $130 \mathrm{~F}$ case. These results generally support the energy savings that might be produced with an outdoor reset control.

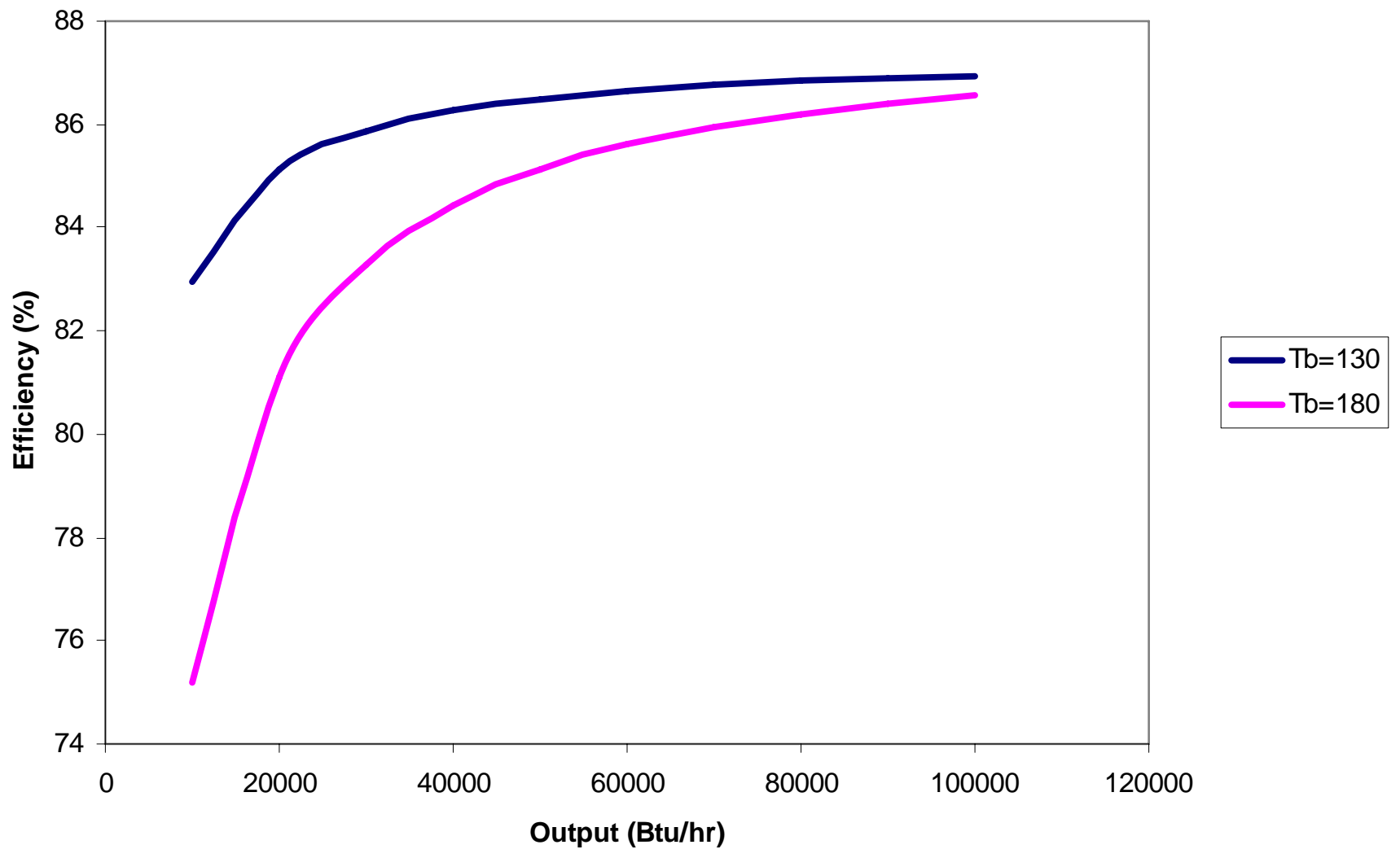

Figure 5-3. Efficiency vs. output at two different boiler water temperatures.

\section{Electric Power Consumption}

A limited set of power consumption data was taken with this unit. The burner draw was 244 watts with the ignitor on and 219 watts with the ignitor off. This is a blue flame burner and might have been expected to have higher power draw than conventional yellow flame burners but this is not the case, based on comparison to conventional burners in this study. Power draw on the domestic hot water circulator is 114 watts and the power draw of the controls alone is 2 watts. 


\section{Appendix 6 \\ Results of Tests with Unit 6}

Unit Description: Center flue, water heater

Fuel: oil

Capacity:

Net IBR:

Aquastat:

Domestic Hot Water: Directly from water heater

Burner type: conventional retention head

Features...

Nominal AFUE: $\quad$ Not rated for AFUE, Energy Factor $=0.68$

This water heater was tested a both a heating appliance and a water heater. In the space heating mode hot water from the tank was pumped through the test stand plate heat exchanger and back to the cold water inlet on the heater. In the domestic hot water mode, simply, cold water entered the tank as usual and hot water was directed to the lab weigh scale. A system of this type is often used, for example, for space heating in combination with a fan coil in an air duct.

Table A6-1. Summary of Tests Done with Unit 6 and Results:

\begin{tabular}{|c|c|c|c|c|c|c|c|c|c|}
\hline Parameter & Test & Condition & Date & Total & Draw & Average & Average & Thermal & Draft \\
\hline & ID & Code & Ended & Duration & Pattern & Input & Output & Efficiency & inches of \\
\hline Units: & - & - & - & hrs & on/off & Btu/hr & Btu/hr & (\%) & water \\
\hline & $6-1$ & SI & $9 / 28 / 2006$ & 12 & Idle & 636.612 & 0 & 0.00 & \\
\hline & $6-2$ & SS & $9 / 28 / 2006$ & 2 & Steady On & 110565 & 88937 & 80.44 & \\
\hline & $6-3$ & SS & $9 / 28 / 2006$ & 2 & Steady On & 110565 & 90058 & 81.45 & \\
\hline & $6-4$ & $\mathrm{HO}$ & $9 / 29 / 2006$ & 6 & $10 / 20$ & 20088 & 15209 & 75.72 & \\
\hline & $6-5$ & $\mathrm{HO}$ & $9 / 29 / 2006$ & 6 & $15 / 15$ & 28233 & 21771 & 77.11 & \\
\hline & $6-6$ & $\mathrm{HO}$ & $9 / 29 / 2006$ & 6 & $6 / 54$ & 6594 & 3184 & 48.29 & \\
\hline & $6-7$ & SI & $10 / 2 / 2006$ & 20 & Idle & 895 & 0 & 0.00 & \\
\hline & $6-8$ & DO & $10 / 3 / 2006$ & 15 & $2.5 / 57.5$ & 3560 & 1568 & 44.04 & \\
\hline & 6-9 & $\mathrm{HO}$ & $10 / 4 / 2006$ & 10 & $5 / 115$ & 3768 & 2898 & 76.90 & \\
\hline & $6-10$ & $\mathrm{HO}$ & $10 / 4 / 2006$ & 10 & $2 / 58$ & 1587 & 1070.5 & 67.45 & \\
\hline & $6-11$ & $\mathrm{DO}^{2}$ & $10 / 6 / 2006$ & 10 & $5 / 55$ & 6496 & 4051 & 62.36 & \\
\hline & $6-12$ & $\mathrm{DO}^{2}$ & $10 / 6 / 2006$ & 10 & $10 / 50$ & 13931 & 8997 & 64.58 & \\
\hline & $6-13$ & $\mathrm{HO}$ & $10 / 7 / 2006$ & 6 & $10 / 20$ & 31992 & 24851 & 77.68 & \\
\hline & $6-14$ & $\mathrm{HO}$ & $10 / 7 / 2006$ & 6 & $15 / 15$ & 46075 & 35953 & 78.03 & \\
\hline & $6-15$ & $\mathrm{HO}$ & $10 / 7 / 2006$ & 6 & $6 / 54$ & 10058 & 7633.62 & 75.90 & \\
\hline & $6-16$ & DO & $10 / 12 / 2006$ & 10 & $5 / 55$ & 4871 & 3371 & 69.21 & \\
\hline & $6-17$ & DO & $10 / 12 / 2006$ & 10 & $10 / 50$ & 9458 & 6740 & 71.26 & \\
\hline
\end{tabular}

Notes relevant to the Results Summary Table Above:

Condition Codes:

$\mathrm{BI}=$ idle test, boiler only

SI = idle test, system (DHW indirect tank included) 
$\mathrm{HO}=$ heating load only, part load test

$\mathrm{DO}=$ domestic hot water load only, part load test

HD = combined heating and hot water, part load test

SS = steady state test, heating only

1. refers to on/off pattern of the draw, not the burner operation. The burner operated under control of the aquastat as normal.

2. done at very high tank temp - approaching 170 F. Not used in input / output analysis

For all of the tests shown in Table A6-1, with the exception of tests 6-11 and 6-12 as discussed in the footnote above, the water heater control was set to provide maximum supply temperature in the 145-150 F range. For this unit some additional special tests were done to evaluate the effects of higher and low water tank temperature. Results of these special tests have been broken out in Table A6-2.

Table A6-2. Results of Special Heating Only Tests Done at Very High and Low Tank Temperatures

\begin{tabular}{|l|l|l|l|l|l|l|l|l|l|}
\hline Parameter: & Test & Condition & Date & Total & Draw & Average & Average & Thermal & Tank \\
\hline & ID & Code & Ended & Duration & Pattern & Input & Output & Efficiency & Temp \\
\hline Units: & - & - & - & hrs & on/off & \multicolumn{1}{l|}{ Btu/hr } & \multicolumn{1}{l|}{ Btu/hr } & \multicolumn{1}{c|}{$(\%)$} & \\
\hline & $6-19$ & $\mathrm{HO}$ & $10 / 10 / 2006$ & 6 & $15 / 15$ & 18533 & 16924.3 & 91.3 & $\min$ \\
\hline & $6-20$ & $\mathrm{HO}$ & $10 / 10 / 2006$ & 6 & $6 / 54$ & 3919.2 & 3559.5 & 90.8 & $\min$ \\
\hline & $6-21$ & $\mathrm{HO}$ & $10 / 11 / 2006$ & 6 & $10 / 20$ & 42361.3 & 32213 & 76.0 & $\max$ \\
\hline & $6-22$ & $\mathrm{HO}$ & $10 / 11 / 2006$ & 6 & $15 / 15$ & 59770 & 45750 & 76.5 & $\max$ \\
\hline & $6-23$ & $\mathrm{HO}$ & $10 / 11 / 2006$ & 6 & $6 / 54$ & 12538.1 & 10178.8 & 81.2 & $\max$ \\
\hline
\end{tabular}

\section{Analysis of Input / Output Relationship}

The analysis of the input/output relationship was done using all data points in Table A6-1 with the exception of the high temperature points 6-11 and 6-12. Results are shown in Figure A6-1 


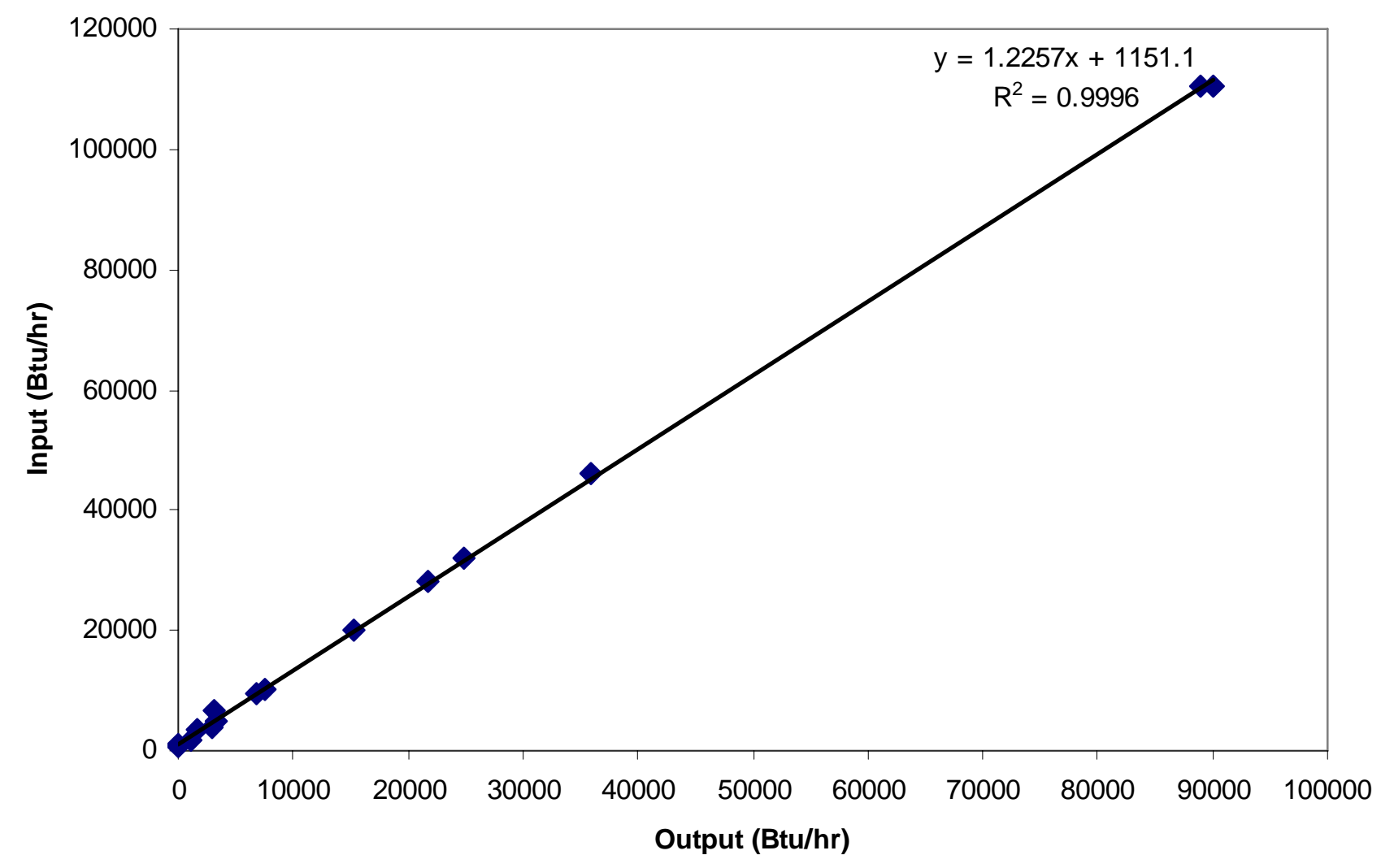

Figure A6-1. Measured input output points considered most representative of typical operation The linear regression of this data has been used to produce the efficiency/output plot in Figure A6-2 


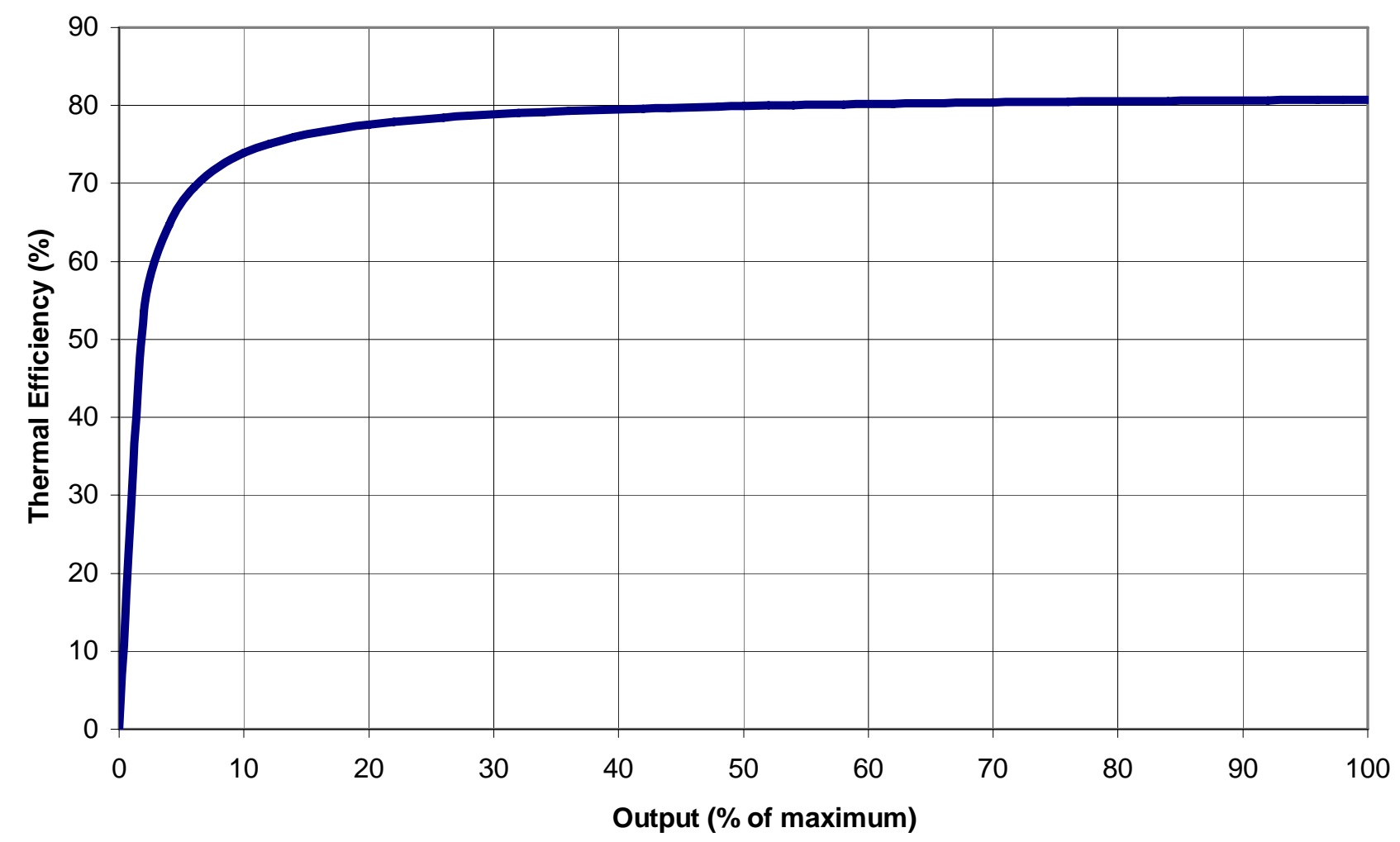

Figure A6-2. Thermal Efficiency vs. output expressed as a percentage of maximum output. Using regression from Figure A6-1.

From this curve, and the unit data, the steady state thermal efficiency of this unit is $80.7 \%$ and the idle loss is $0.8 \%$. The efficiency of this system for an average domestic hot water only load of $1720 \mathrm{Btu} / \mathrm{hr}$ would be $57.1 \%$.

Figure A6-3 illustrates the results of tests done at varied water temperature. Clearly going to very low water temperatures can lead to very high thermal efficiency levels.

\section{Combustion Efficiency}

Flue gas oxygen was typically $4.2 \%$, corresponding to $12.6 \% \mathrm{CO}_{2}$ and $25.2 \%$ excess air. Combustion efficiency was typically $85.5 \%$ 


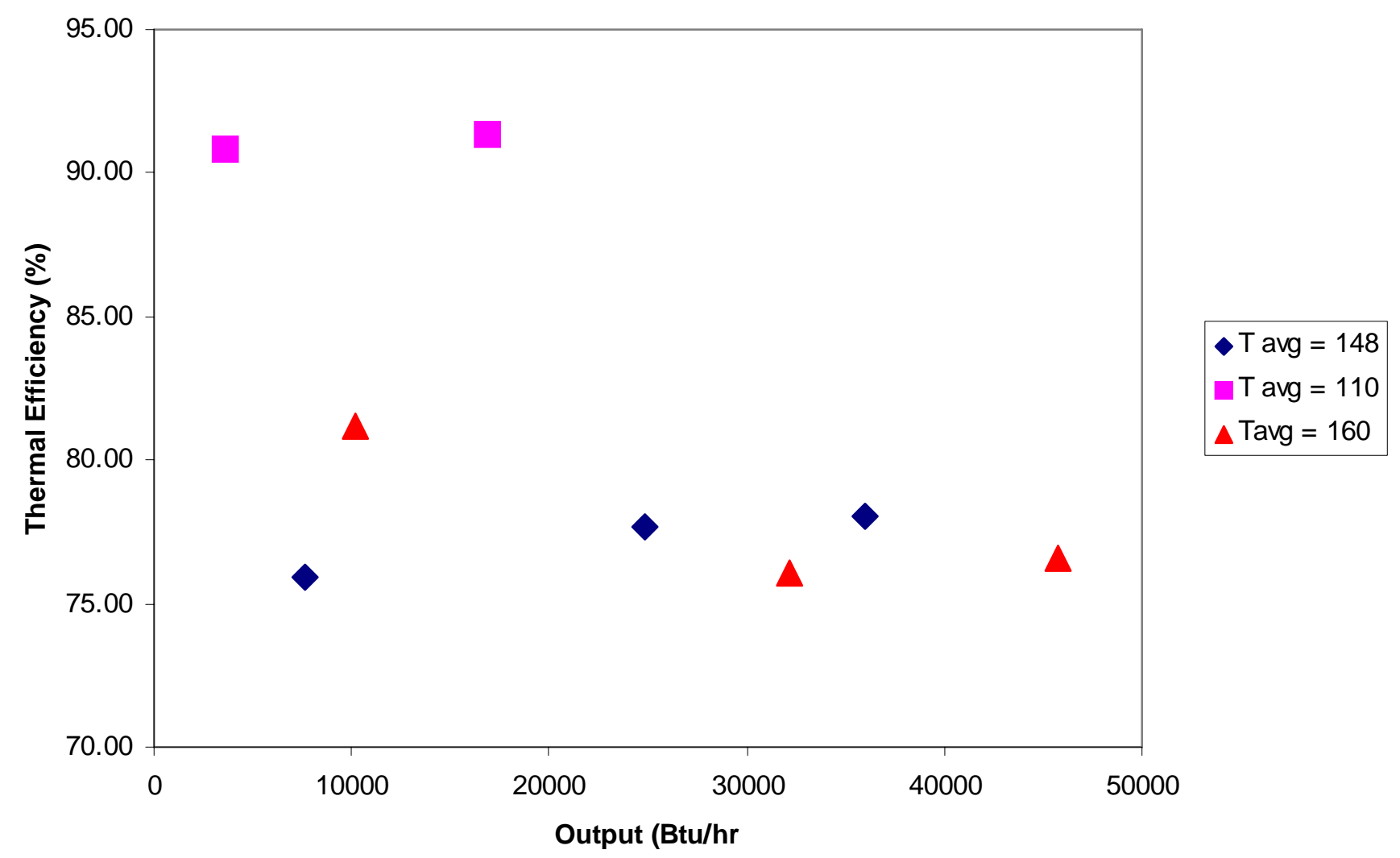

Figure A6-3. Results of thermal efficiency tests at different water temperatures. Heating only 


\section{Appendix 7 \\ Results of Tests with Unit 7}

Unit Description: non-condensing, "combination unit”

Fuel:

oil

DOE Capacity...

Net IBR...

Aquastat...

Domestic Hot Water: integrated tank, see discussion below

Burner type: $\quad$ forced draft, retention head

Features:

Nominal AFUE: $\quad 82.8$

This unit has two internal, separated water tanks. An inner tank which is for space heating with a nominal capacity of 20 gallons and an outer tank for domestic hot water with a nominal capacity of 22 gallons.

Table A7-1. Summary of Tests Done with Unit 7 and Results:

\begin{tabular}{|c|c|c|c|c|c|c|c|c|c|c|}
\hline Paramete & Test & Condition & Date & Total & Draw & Average & Average & Thermal & Maximum & Maximum \\
\hline & ID & Code & Ended & Duration & Pattern & Input & Output & Efficiency & Boiler Temp & Draft \\
\hline Units: & 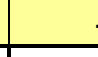 & - & - & hrs & on/off & Btu/hr & Btu/hr & $(\%)$ & $\mathrm{F}$ & in $\mathrm{H} 2 \mathrm{O}$ \\
\hline & $7-1$ & SI & $10 / 30 / 2006$ & 48 & Idle & 1123 & 0 & 0.00 & 160 & \\
\hline & $7-2$ & DO & $10 / 31 / 2006$ & 10 & $5 / 55$ & 5747 & 2544 & 44.27 & 177 & 0.04 \\
\hline & $7-3$ & SS & $10 / 31 / 2006$ & 2 & Steady on & 138226 & 111183.6 & 80.44 & 151 & 0.05 \\
\hline & $7-4$ & SS & $10 / 31 / 2006$ & 2 & Steady on & 138226 & 109815 & 79.45 & 177 & 0.05 \\
\hline & $7-5$ & $\mathrm{HO}$ & $11 / 1 / 2006$ & 8 & & 46185.3 & 36470.9 & 78.97 & 140 & 0.04 \\
\hline & $7-6$ & $\mathrm{HO}$ & $11 / 1 / 2006$ & 7 & $15 / 15$ & 68693.7 & 54620 & 79.51 & 153 & 0.04 \\
\hline & $7-7$ & $\mathrm{HO}$ & $11 / 2 / 2006$ & 14 & $6 / 54$ & 13212.3 & 9607.7 & 72.72 & 150 & 0.04 \\
\hline & 7-8 & DO & $11 / 3 / 2006$ & 10 & $5 / 55$ & 4273.5 & 2572.7 & 60.20 & 180 & 0.04 \\
\hline & $7-9$ & DO & $11 / 3 / 2006$ & 10 & $10 / 50$ & 8473 & 5580.8 & 65.87 & 180 & 0.04 \\
\hline
\end{tabular}

Notes relevant to the Results Summary Table Above:

Condition Codes:

$\mathrm{BI}=$ idle test, boiler only

SI = idle test, system (DHW indirect tank included)

$\mathrm{HO}=$ heating load only, part load test

$\mathrm{DO}=$ domestic hot water load only, part load test

$\mathrm{HD}=$ combined heating and hot water, part load test

SS = steady state test, heating only

1. refers to on/off pattern of the draw, not the burner operation. The burner operated under control of the aquastat as normal. 


\section{Analysis of Input/Output Relationship}

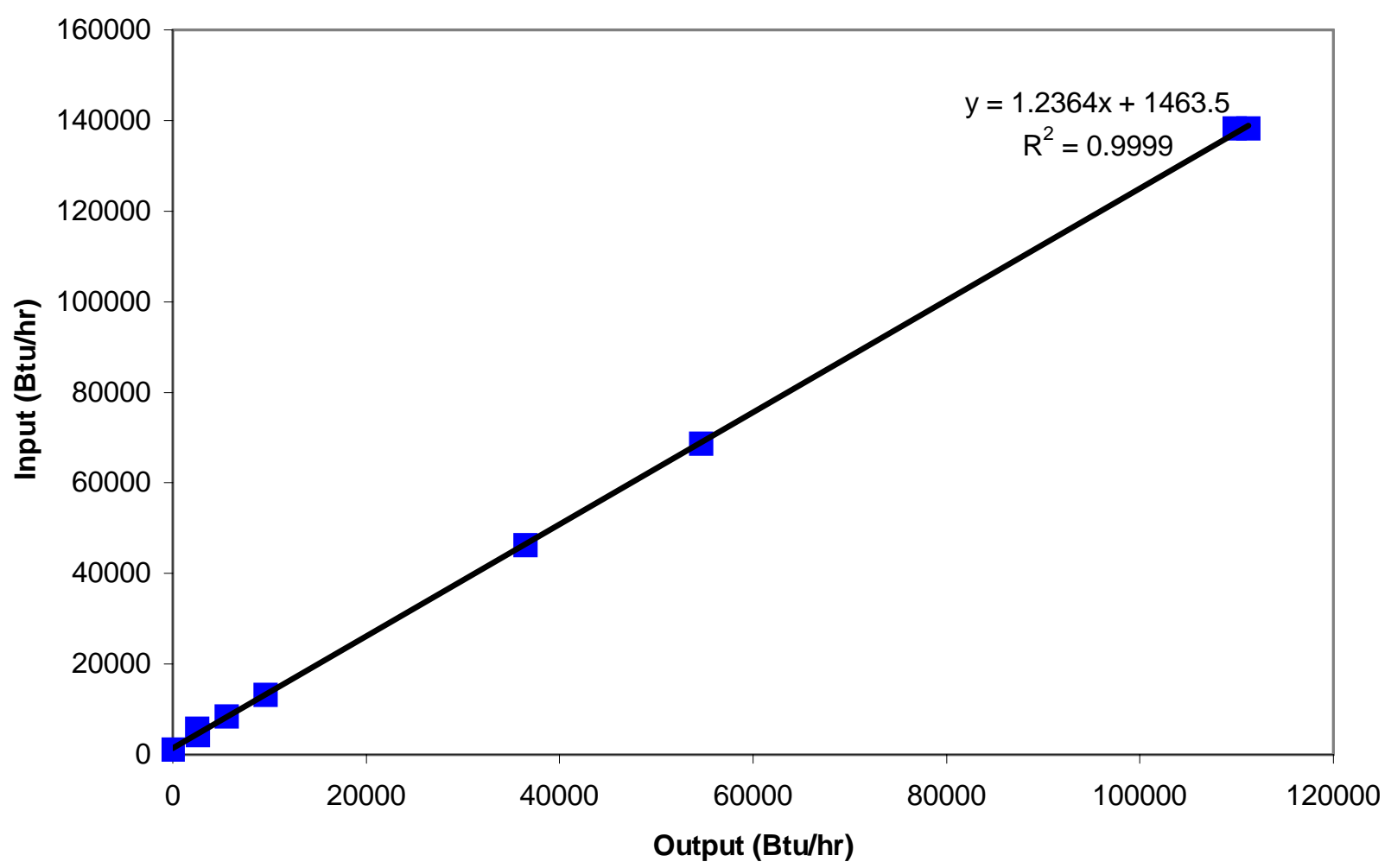

Figure A7-1. All measured input/output points.

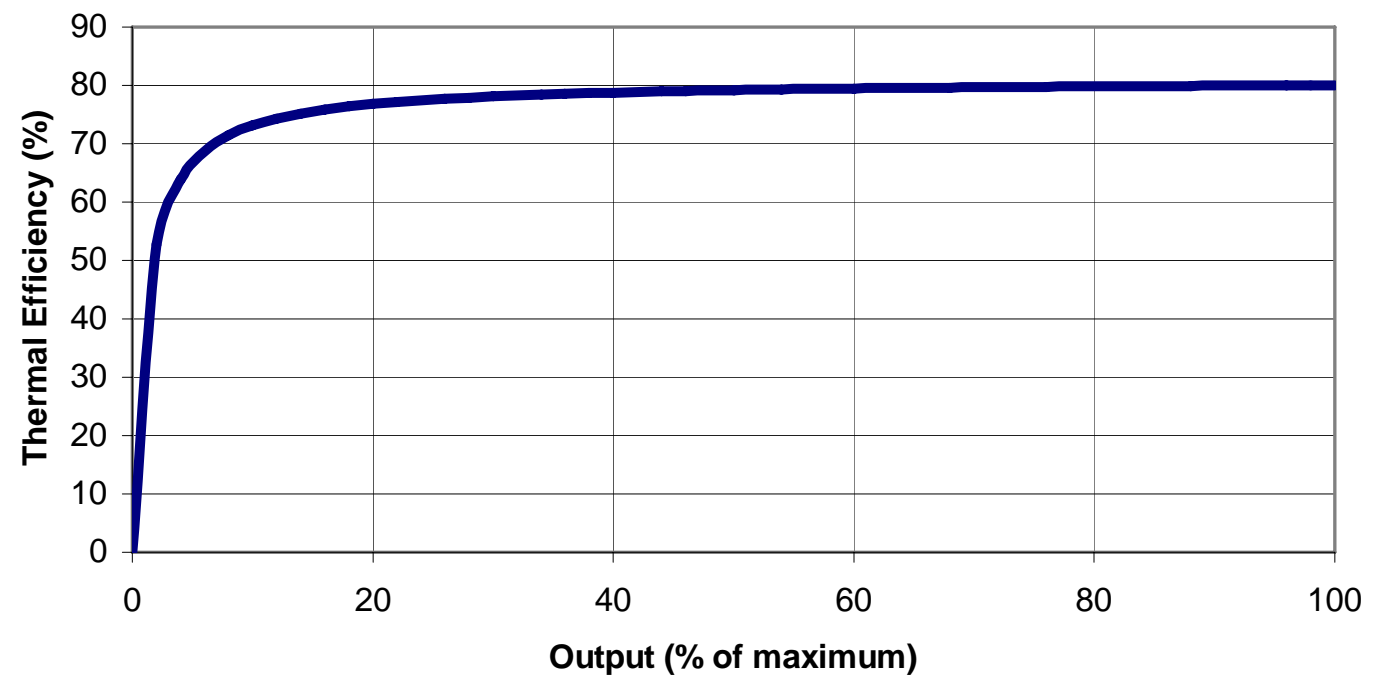

Figure A7-4. Thermal efficiency vs. output expressed as a percentage of maximum output. Using regression from Figure A7-1. 
From this curve, and the unit data, the steady state thermal efficiency of this unit is $80.0 \%$ and the idle loss is $1.0 \%$. The efficiency of this system for an average domestic hot water only load of $1720 \mathrm{Btu} / \mathrm{hr}$ would be $47.9 \%$.

\section{Combustion Efficiency}

Combustion efficiency was measured during the steady state tests. Flue gas oxygen content was typically found to be $5.5 \%$, corresponding to $11.6 \% \mathrm{CO} 2$ or $35 \%$ excess air. Flue gas temperature was typically around $480 \mathrm{~F}$, and combustion efficiency $84.2 \%$. 


\section{Appendix 8 \\ Results of Tests with Unit 8}

Unit Description: non-condensing, cast iron

Fuel:

Natural gas

DOE Capacity: $\quad 104,000 \mathrm{Btu} / \mathrm{hr}$

Net IBR: $\quad 90,000 \mathrm{Btu} / \mathrm{hr}$

Aquastat: $\quad$ Honeywell Type L8124E (Triple Function)

Domestic Hot Water: tankless coil

Burner type: atmospheric

Features: draft hood with damper

Nominal AFUE: $\quad 81.0$

Table A8-1. Summary of Tests Done with Unit 8 and Results:

\begin{tabular}{|c|c|c|c|c|c|c|c|c|c|c|}
\hline Parameter: & $\begin{array}{l}\text { Test } \\
\text { ID }\end{array}$ & $\begin{array}{l}\text { Condition } \\
\text { Code }\end{array}$ & $\begin{array}{l}\text { Date } \\
\text { Ended }\end{array}$ & $\begin{array}{l}\text { Total } \\
\text { Duration }\end{array}$ & $\begin{array}{l}\text { Draw } \\
\text { Pattern }^{1}\end{array}$ & \begin{tabular}{|l} 
Average \\
Input
\end{tabular} & $\begin{array}{l}\text { Average } \\
\text { Output }\end{array}$ & $\begin{array}{l}\text { Thermal } \\
\text { Efficiency }\end{array}$ & \begin{tabular}{|} 
Maximum \\
Boiler Temp
\end{tabular} & $\begin{array}{l}\text { Maximum } \\
\text { Draft }\end{array}$ \\
\hline Units: & - & - & - & hrs & on/off & Btu/hr & Btu/hr & (\%) & $\mathrm{F}$ & in $\mathrm{H} 2 \mathrm{O}$ \\
\hline & 8-1 & $\mathrm{HO}$ & $11 / 9 / 2006$ & 6 & $10 / 20$ & 37058 & 26682 & 72.00 & 170 & 0.0002 \\
\hline & $8-2$ & $\mathrm{HO}$ & $11 / 9 / 2006$ & 6 & $15 / 15$ & 58705 & 41300 & 70.35 & 171 & 0.0002 \\
\hline & $8-3$ & $\mathrm{HO}$ & $11 / 9 / 2006$ & 6 & $6 / 54$ & 11517 & 7054 & 61.25 & 157 & 0.0002 \\
\hline & $8-4$ & SI & $11 / 10 / 2006$ & 20 & Idle & 2023 & 0 & 0.00 & 168 & 0.0002 \\
\hline & $8-5$ & DO & $11 / 15 / 2006$ & 10 & $5 / 55$ & 7879 & 3635 & 46.14 & 163 & 0.0002 \\
\hline & $8-6$ & DO & $11 / 15 / 2006$ & 10 & $10 / 50$ & 13312 & 7935 & 59.61 & 160 & 0.0002 \\
\hline & 8-7 & SS & $11 / 20 / 2006$ & - & Steady On & 119028 & 86065 & 72.31 & 143 & 0.0002 \\
\hline & $8-8$ & SS & $11 / 20 / 2006$ & - & Steady On & 119028 & 85252 & 71.62 & 177 & 0.0002 \\
\hline & $8-9$ & SS & $11 / 20 / 2006$ & - & Steady On & 119028 & 86237 & 72.45 & 155 & 0.0002 \\
\hline & $8-10$ & DO & $11 / 21 / 2006$ & 20 & DHW & 4388 & 1282 & 29.23 & 163 & 0.0002 \\
\hline & 8-11 & SI & $11 / 30 / 2006$ & 20 & Idle & 1061 & 0 & 0.00 & 141 & 0.0002 \\
\hline
\end{tabular}

Notes relevant to the Results Summary Table Above:

Condition Codes:

$\mathrm{BI}=$ idle test, boiler only

$\mathrm{SI}=$ idle test, system (DHW indirect tank included)

$\mathrm{HO}=$ heating load only, part load test

$\mathrm{DO}=$ domestic hot water load only, part load test

$\mathrm{HD}=$ combined heating and hot water, part load test

SS = steady state test, heating only

1. refers to on/off pattern of the draw, not the burner operation. The burner operated under control of the aquastat as normal. 


\section{Analysis of Input/Output Relationship}

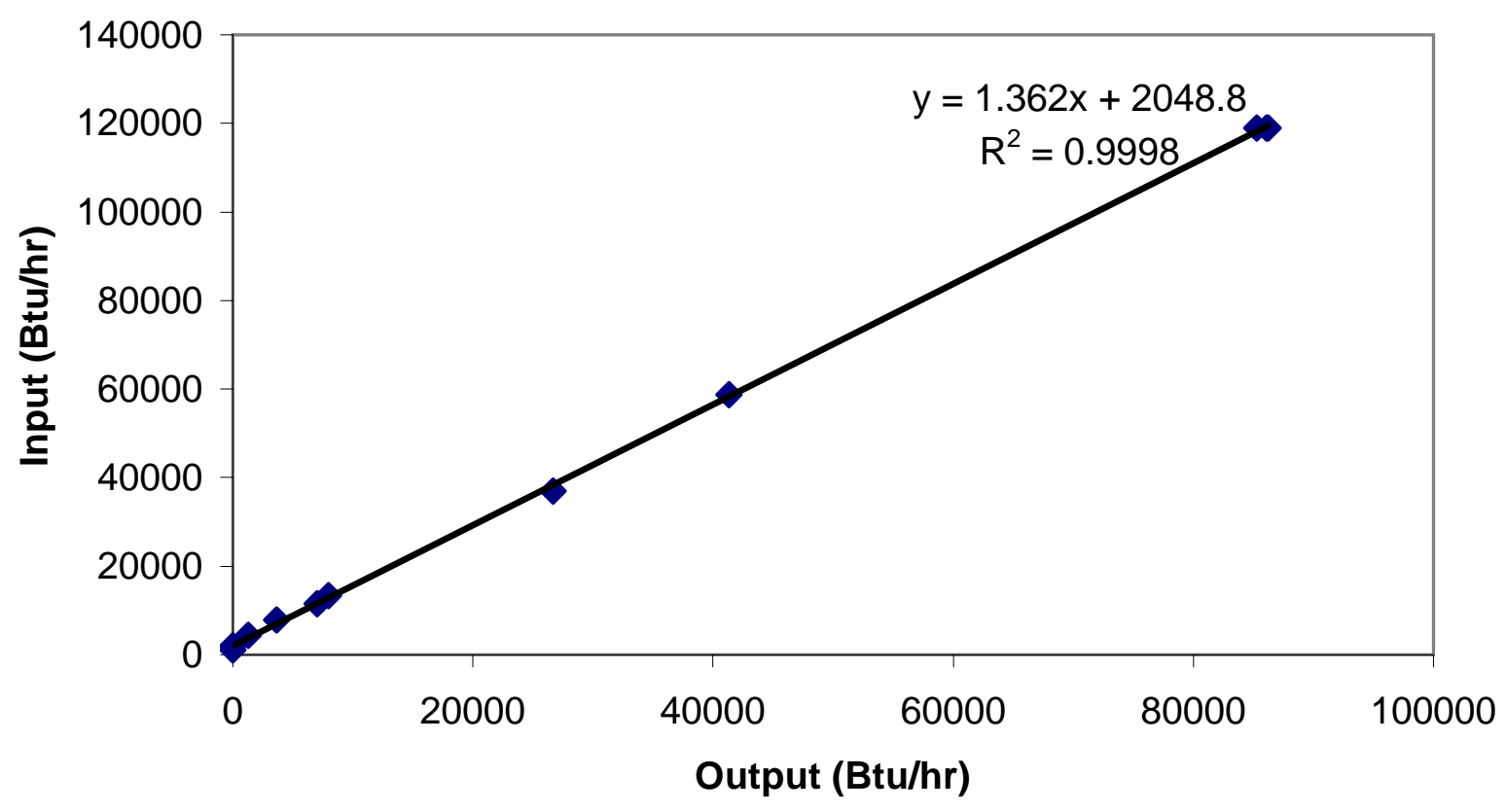

Figure A8-1. All measured input/output points.

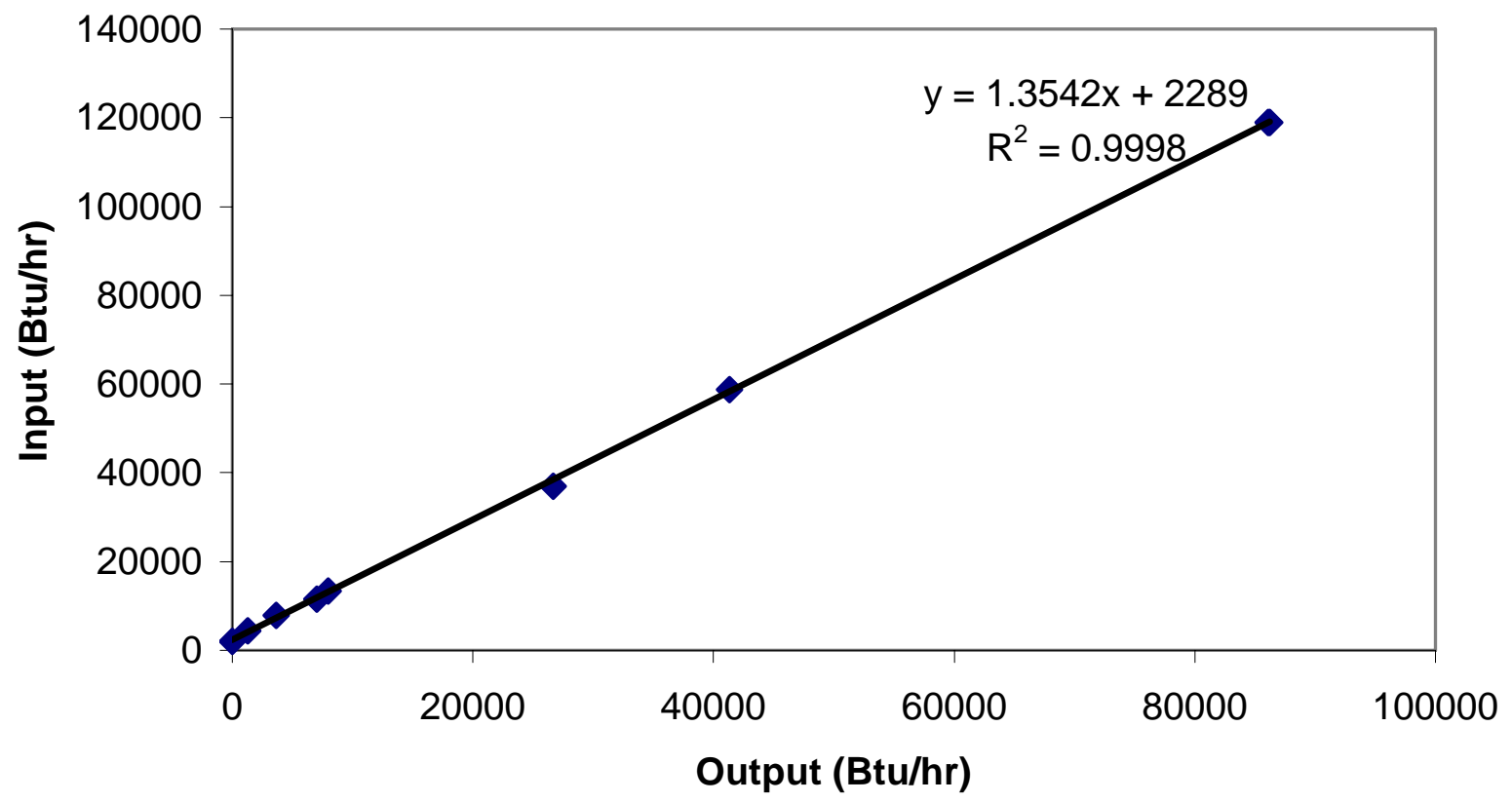

Figure A8-2. Points 8-8 and 8-11 from Table 8-1 removed (very high and very low boiler water temperatures) 


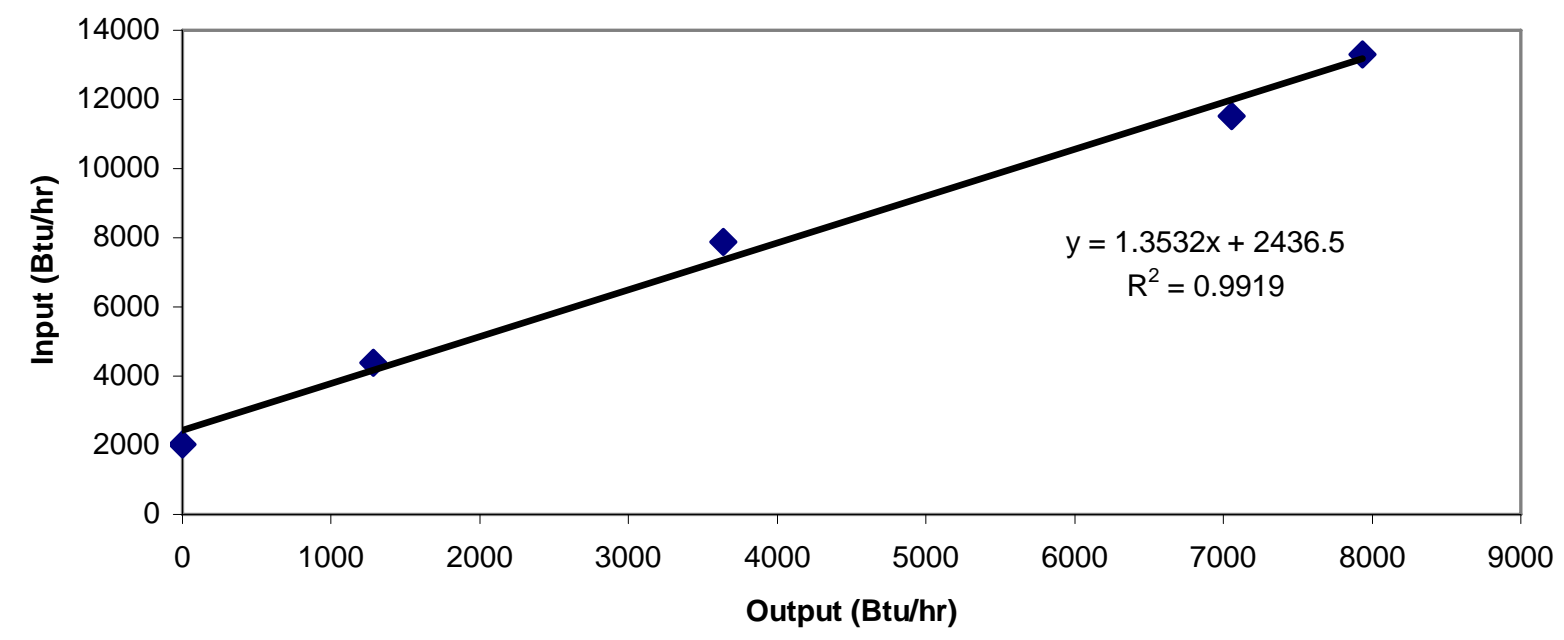

Figure A8-3. All data with input under 20,000 Btu/hr. Point 8-11 from Table A8-1 removed.

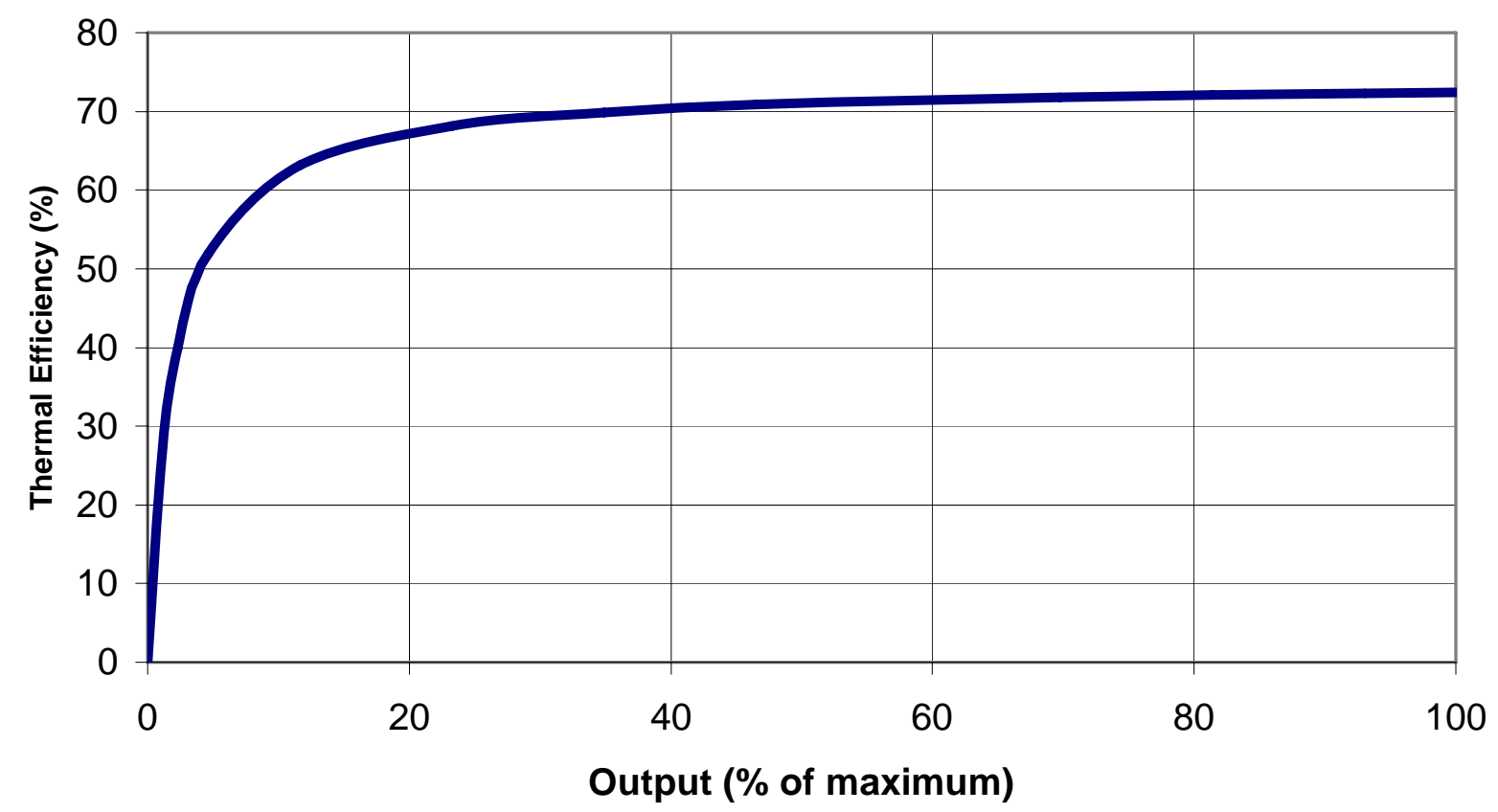

Figure A8-4. Thermal efficiency vs. output expressed as a percentage of maximum output. Using regression from Figure A8-2.

From this curve, and the unit data, the steady state thermal efficiency of this unit is $72.4 \%$ and the idle loss is $1.9 \%$. The efficiency of this system for an average domestic hot water only load of $1720 \mathrm{Btu} / \mathrm{hr}$ would be $37.2 \%$. 


\section{Combustion Efficiency}

Combustion efficiency was measured during the steady state tests. Flue gas oxygen content was typically found to be $8.5 \%$, or $69 \%$ excess air. Flue gas temperature ranged 530 to $550 \mathrm{~F}$. As shown in Table A8-1, above, steady state tests were done with three different water temperatures. Table A8-2, below, provides the measured combustion efficiency for each of these tests.

Table A8-2. Combustion efficiency measured during steady state tests

\begin{tabular}{|c|c|c|c|c|c|}
\hline Parameter & $\begin{array}{c}\text { Test } \\
\text { ID }\end{array}$ & $\begin{array}{c}\text { Exhaust } \\
\mathrm{O}_{2}\end{array}$ & $\begin{array}{c}\text { Exhaust } \\
\text { Temperature }\end{array}$ & CO & $\begin{array}{c}\text { Combustion } \\
\text { Efficiency }\end{array}$ \\
\hline Units & - & $\%$ dry & $\mathrm{F}$ & $\mathrm{ppm}$ & $\%$ \\
\hline & $8-7$ & 8.6 & 541 & 5 & 79.0 \\
\hline & $8-8$ & 8.5 & 530 & 3 & 79.5 \\
\hline & $8-9$ & 8.5 & 549 & 6 & 78.6 \\
\hline
\end{tabular}

1. Averaged over test period

\section{Example Temperature Profiles}

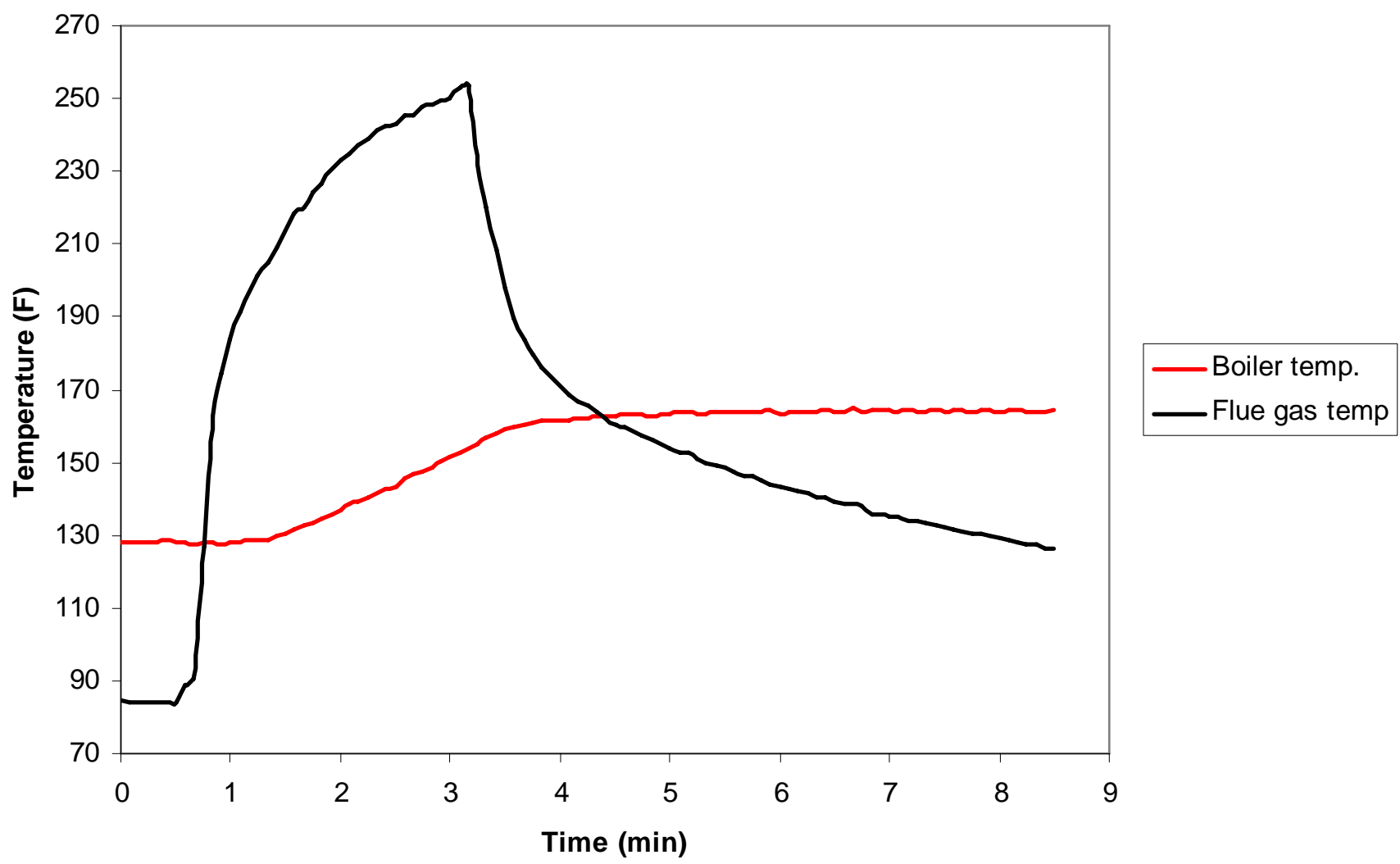

Figure A8-5. Example flue gas and boiler water temperature profile during part of system idle test 8-4. This part of the test data shows system response during a boiler temperature recovery. 


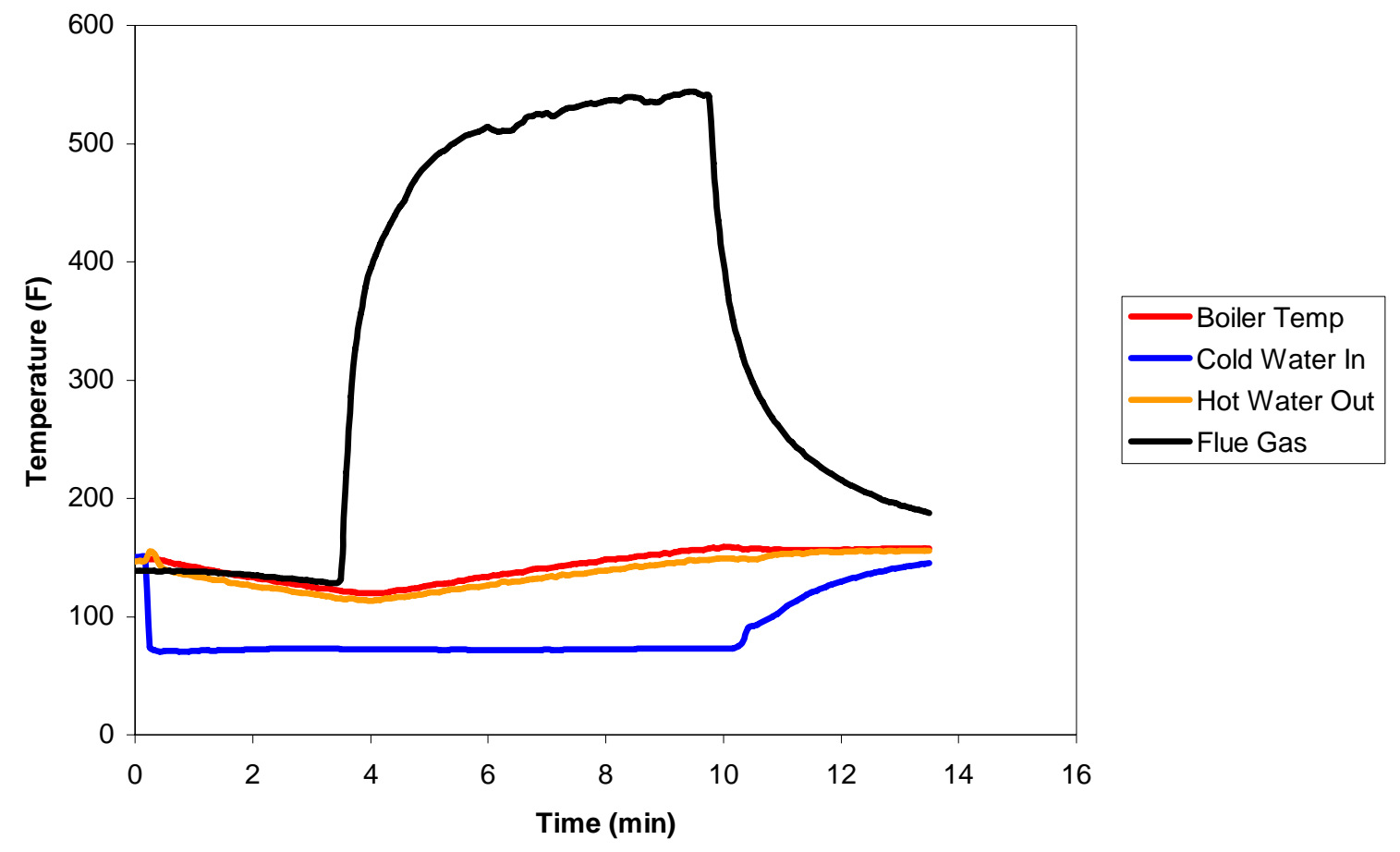

Figure A8-5. Example flue gas, boiler, cold water in and hot water out temperature profiles during a domestic hot water test - Test 8-6. Note that the Cold Water in thermocouple is located close to the tankless coil on this boiler and when there is no draw its temperature rises towards the boiler temperature.

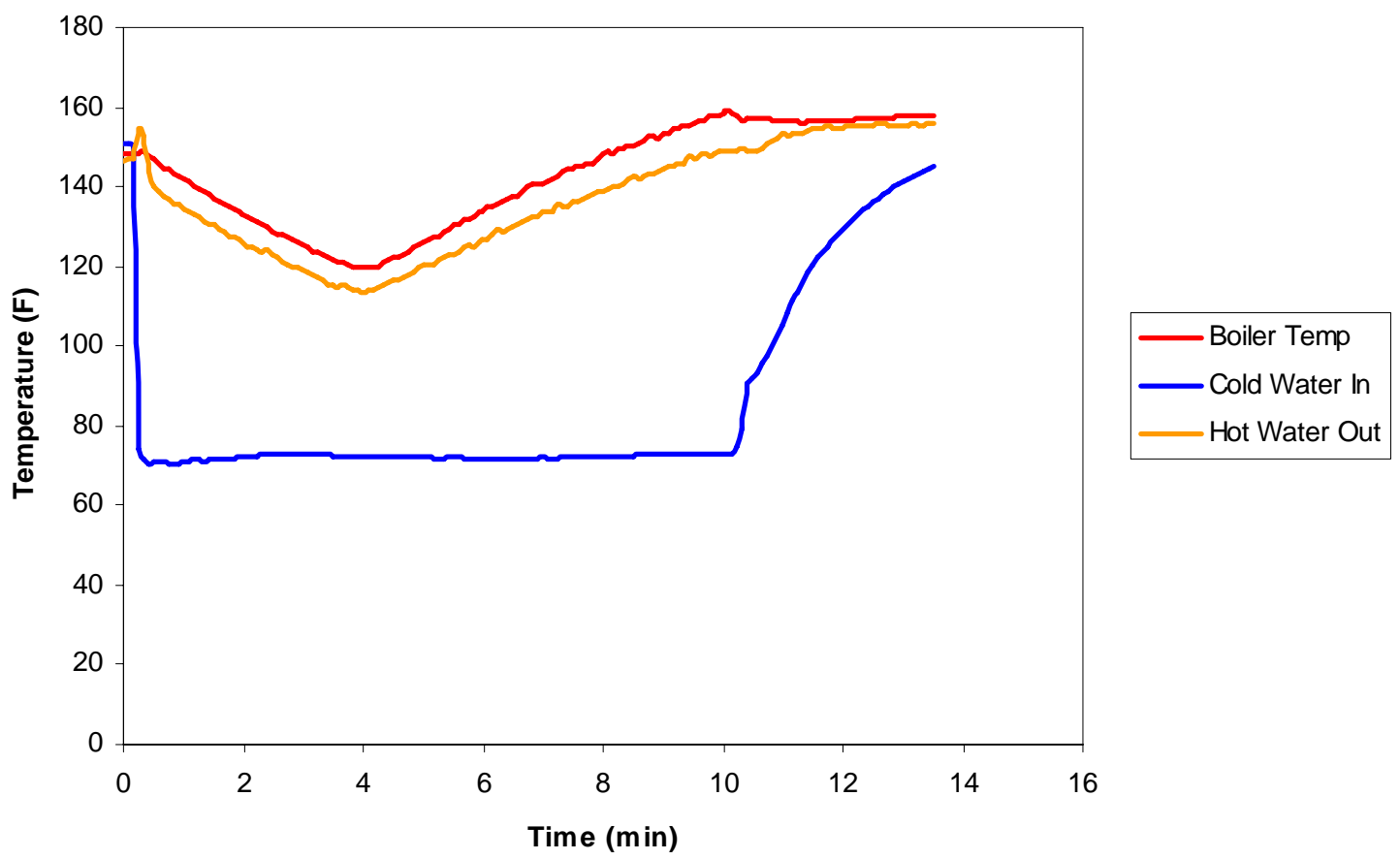

Figure A8-6. Same data set as for figure A8-5 but with the flue gas temperature removed to better illustrate the supply water temperature variation during a typical domestic hot water draw. 


\section{Jacket Loss}

Jacket surface temperature profiles were measured with the boiler operating in steady state with an average boiler temperature of $140 \mathrm{~F}$. Ambient room air temperature was $68 \mathrm{~F}$. The temperature profiles on the left, right and rear sides of the boiler were similar with surface temperatures near the top in the $95 \mathrm{~F}$ range and temperatures on the bottom in the $170 \mathrm{~F}$ range. On the top of the boiler the minimum and maximum temperatures measured were $101.3 \mathrm{~F}$ and $141 \mathrm{~F}$ respectively.

The bottom of this boiler sits off of the floor $31 / 4$ inches with support pieces. The temperature was measured on the raised bottom face and found to be very high - $300 \mathrm{~F}$ minimum and $540 \mathrm{~F}$ maximum. In the estimation of the boiler jacket loss this bottom section was treated separately as discussed below.

The total steady state jacket loss from the top of the boiler was calculated to be $257 \mathrm{Btu} / \mathrm{hr}$. The total jacket loss from the 4 sides was calculated to be $1522 \mathrm{Btu} / \mathrm{hr}$.

Estimating the jacket loss from the bottom of the boiler was difficult because the measured surface temperatures exceeded the values on the Charts in the ASHRAE 103 procedure and estimates of the heat transfer coefficients had to be made by extrapolation. Further, the radiation loss assumes that the boiler is radiating to surroundings near ambient temperature but when the boiler is close to the floor this surface will heat up and reduce the radiation loss. In effect the floor becomes an important part of the insulation system of the boiler.

When radiation from the bottom of the boiler is included in accordance with the ASHRAE 103 procedure the total bottom heat loss is $1824 \mathrm{Btu} / \mathrm{hr}$. When only convection is considered from the bottom the heat loss from this surface is $510 \mathrm{Btu} / \mathrm{hr}$.

In summary, when the bottom radiation loss is included the total jacket loss is $3603 \mathrm{Btu} / \mathrm{hr}$ or $3.0 \%$ of the steady

state input. When bottom radiation is neglected the total jacket loss is $2289 \mathrm{Btu} / \mathrm{hr}$ or $1.9 \%$ of the steady state input. 


\section{Appendix 9 \\ Results of Tests with Unit 9}

Unit Description: Center flue, water heater

Fuel:

gas

Capacity:

40 gallon, recovery - 33.9 gph

Domestic Hot Water: Directly from water heater, tested as water heater only

Burner type: atmospheric

Features...

Nominal AFUE: $\quad$ Not rated for AFUE, Energy Factor $=0.59$

This water heater was tested individually to obtain performance data in a water heating only mode. The purpose was to combine this with data from a gas-fired heating boiler to evaluate what is seen as a common arrangement - gas-fired heating only boiler plus gas-fired water heater.

Table A9-1. Summary of All Tests Done with Unit 9 and Results:

\begin{tabular}{|l|l|l|l|l|l|r|r|r|}
\hline Parameter: & Test & Condition & Date & Total & Draw & Average & Average & Thermal \\
\hline & ID & Code & Ended & Duration & Pattern & Input & Output & Efficiency \\
\hline Units: & - & - & - & hrs & - & \multicolumn{1}{c|}{ Btu/hr } & \multicolumn{1}{c|}{ Btu/hr } & \multicolumn{1}{c|}{$(\%)$} \\
\hline & $9-1$ & SI & $1 / 24 / 2007$ & 14 & Idle & 200 & 0 & 0.00 \\
\hline & $9-2$ & SS & $1 / 24 / 2007$ & 2 & Steady on & 30772 & 22726 & 73.85 \\
\hline & $9-3$ & DO & $1 / 26 / 2007$ & 10 & $5 / 55$ & 5233 & 3146 & 60.12 \\
\hline & $9-4$ & DO & $1 / 26 / 2007$ & 10 & $10 / 50$ & 10308 & 7002.4 & 67.93 \\
\hline & $9-5$ & DO & $2 / 6 / 2007$ & 10 & $5 / 55$ & 6295 & 3651 & 58.00 \\
\hline & $9-6$ & DO & $2 / 6 / 2007$ & 10 & $10 / 50$ & 12804 & 8566 & 66.90 \\
\hline & $9-7$ & SS & $2 / 7 / 2007$ & 2 & $6 / 54$ & 30512 & 23362 & 76.57 \\
\hline & $9-8$ & DO & $2 / 16 / 2007$ & 10 & $10 / 50$ & 1805 & 844 & 46.76 \\
\hline & $9-9$ & DO & $2 / 17 / 2007$ & 10 & $6 / 54$ & 1053 & 573 & 54.37 \\
\hline
\end{tabular}

Notes relevant to the Results Summary Table Above:

Condition Codes:

$\mathrm{BI}=$ idle test, boiler only

SI = idle test, system (DHW indirect tank included)

$\mathrm{HO}=$ heating load only, part load test

$\mathrm{DO}=$ domestic hot water load only, part load test

$\mathrm{HD}=$ combined heating and hot water, part load test

SS = steady state test, heating only

1. refers to on/off pattern of the draw, not the burner operation. The burner operated under control of the aquastat as normal.

For all tests with this water heater the maximum tank average temperature was $135 \mathrm{~F}$. 


\section{Analysis of Input / Output Relationship}

The analysis of the input/output relationship was done using all data points in Table A9-1 and results are shown in Figure 9-1.

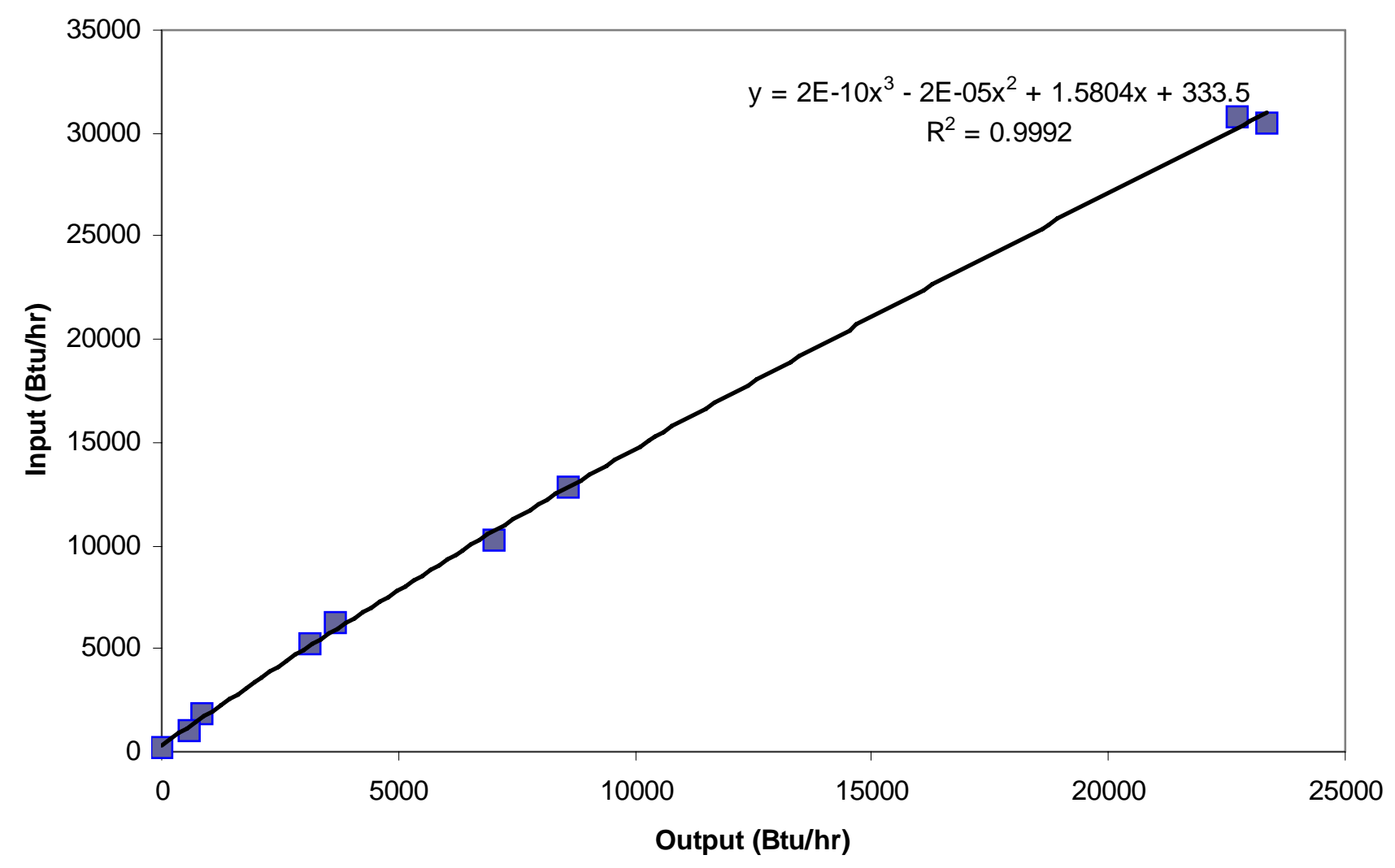

Figure A9-1. Input/Output relation

For this specific set of data a $3^{\text {rd }}$ order relation was used to fit the data as shown. This equation is used to generate the efficiency/output curve in Figure A9-2 


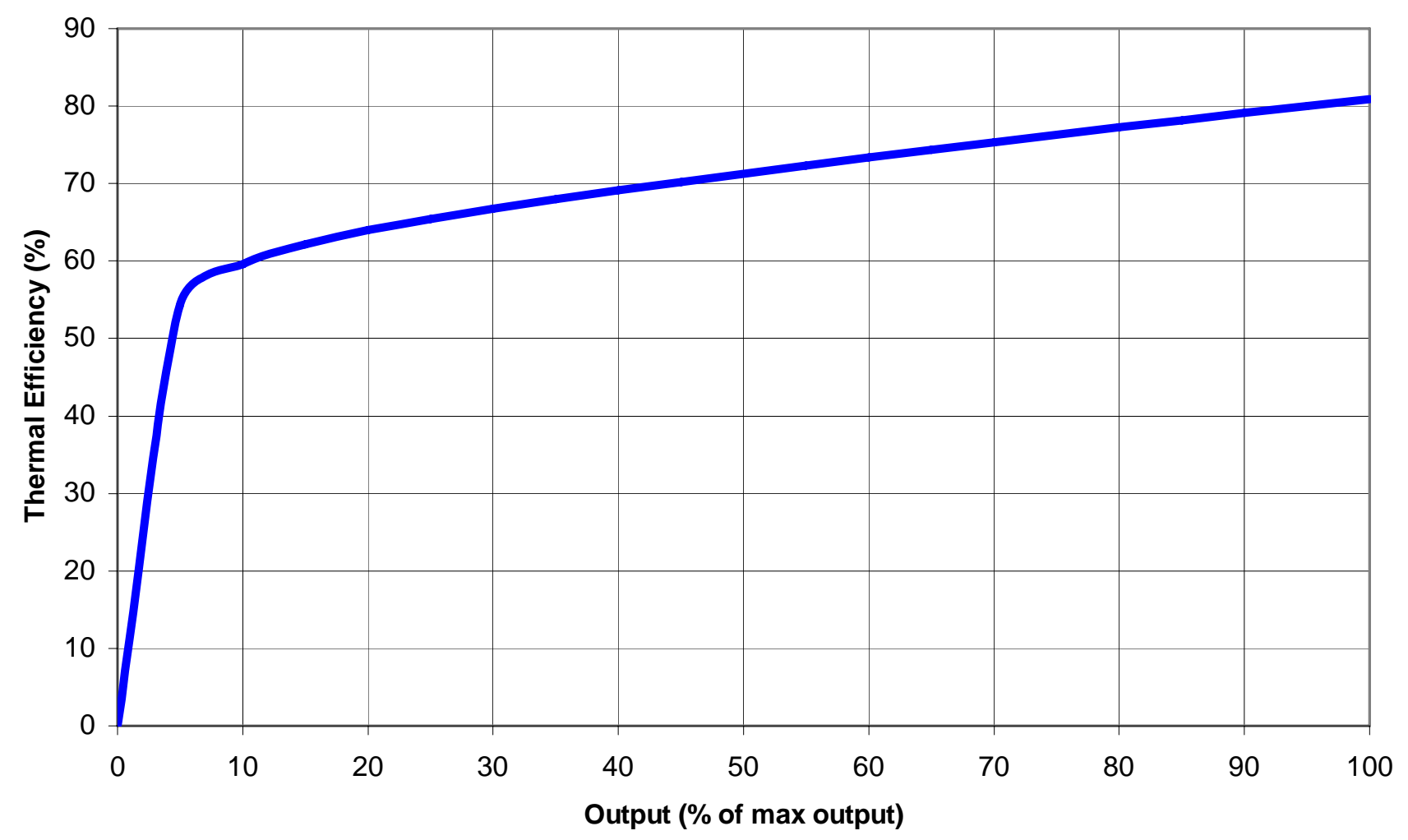

Figure A9-2. Thermal Efficiency vs. output expressed as a percentage of maximum output. Using regression from Figure A9-1.

From this curve, and the unit data, the steady state thermal efficiency of this unit is $80.9 \%$ and the idle loss is $1.15 \%$. The efficiency of this system for an average domestic hot water only load of $1720 \mathrm{Btu} / \mathrm{hr}$ would be $57.5 \%$.

\section{Combustion Efficiency}

Flue gas oxygen was typically $4.2 \%$, corresponding to $12.6 \% \mathrm{CO}_{2}$ and $25.2 \%$ excess air. Combustion efficiency was typically $85.5 \%$. 


\section{Appendix 10 \\ Results of Tests with Unit 10}

Unit Description: 22 year old, cast iron boiler removed from a home

Fuel:

oil

DOE Capacity: $\quad 206000$

Net IBR: $\quad 155000$

Aquastat...

Domestic Hot Water: "tankless coil” heat exchanger within boiler

Burner type: $\quad$ forced draft, retention head

Features:

Nominal AFUE: $\quad 84.0$ (based on prior listing data - unit no longer in production)

This unit was removed from a home as part of a heating system replacement by a local heating service company. The boiler was in fully operational condition without leaks and was included in this project as being representative of an old system in the field.

Table A10-1. Summary of Tests Done with Unit 10 and Results:

\begin{tabular}{|c|c|c|c|c|c|c|c|c|c|c|}
\hline Parameter: & $\begin{array}{l}\text { Test } \\
\text { ID } \\
\end{array}$ & $\begin{array}{l}\text { Condition } \\
\text { Code }\end{array}$ & \begin{tabular}{|l} 
Date \\
Ended
\end{tabular} & $\begin{array}{l}\text { Total } \\
\text { Duration }\end{array}$ & \begin{tabular}{|l} 
Draw \\
Pattern $^{1}$ \\
\end{tabular} & $\begin{array}{l}\text { Average } \\
\text { Input }\end{array}$ & $\begin{array}{l}\text { Average } \\
\text { Output }\end{array}$ & $\begin{array}{l}\text { Thermal } \\
\text { Efficiency }\end{array}$ & \begin{tabular}{|l|} 
Maximum \\
Boiler Temp
\end{tabular} & $\begin{array}{l}\text { Maximum } \\
\text { Draft } \\
\end{array}$ \\
\hline Units: & - & - & - & hrs & on/off & Btu/hr & Btu/hr & $(\%)$ & $\mathrm{F}$ & in $\mathrm{H} 2 \mathrm{O}$ \\
\hline & $10-1$ & $\mathrm{BI}$ & $2 / 22 / 2007$ & 14 & Idle & 2766 & 0 & 0 & 170 & $.005^{2}$ \\
\hline & $10-2$ & SS & $2 / 22 / 2007$ & 2 & Steady On & 153666 & 112284 & 73.1 & 143 & 0.05 \\
\hline & $10-3$ & $\mathrm{BI}$ & $2 / 23 / 2007$ & 14 & Idle & 3212 & 0 & 0 & 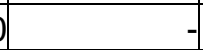 & $.056^{3}$ \\
\hline & $10-4$ & SS & $2 / 23 / 2007$ & 2 & Steady On & 152856 & 112770 & 73.8 & 148 & \\
\hline & $10-5$ & $\mathrm{HO}$ & $3 / 2 / 2007$ & 6 & $10 / 20$ & 49848 & 34745 & 69.7 & 163 & 0.0002 \\
\hline & $10-6$ & $\mathrm{HO}$ & $3 / 3 / 2007$ & 6 & $15 / 15$ & 75307 & 53686 & 71.3 & 160 & 0.0002 \\
\hline & $10-7$ & $\mathrm{HO}$ & $3 / 3 / 2007$ & 6 & $6 / 54$ & 16833 & 10112 & 60.1 & 143 & 0.0002 \\
\hline
\end{tabular}

Notes relevant to the Results Summary Table Above:

Condition Codes:

$\mathrm{BI}=$ idle test, boiler only

SI = idle test, system (DHW indirect tank included)

$\mathrm{HO}=$ heating load only, part load test

$\mathrm{DO}=$ domestic hot water load only, part load test

$\mathrm{HD}=$ combined heating and hot water, part load test

SS = steady state test, heating only

1. refers to on/off pattern of the draw, not the burner operation. The burner operated under control of the aquastat as normal.

2. For this test the boiler was vented through a conventional chimney. The average draft over the test period was on the order of 0.005 in $\mathrm{H}_{2} \mathrm{O}$.

3. For this test the boiler was vented through a conventional chimney but a draft inducer arrangement was used to impose an elevated draft throughout the test period. The average draft was 0.056 in $\mathrm{H}_{2} \mathrm{O}$. 


\section{Analysis of Input/Output Relationship}

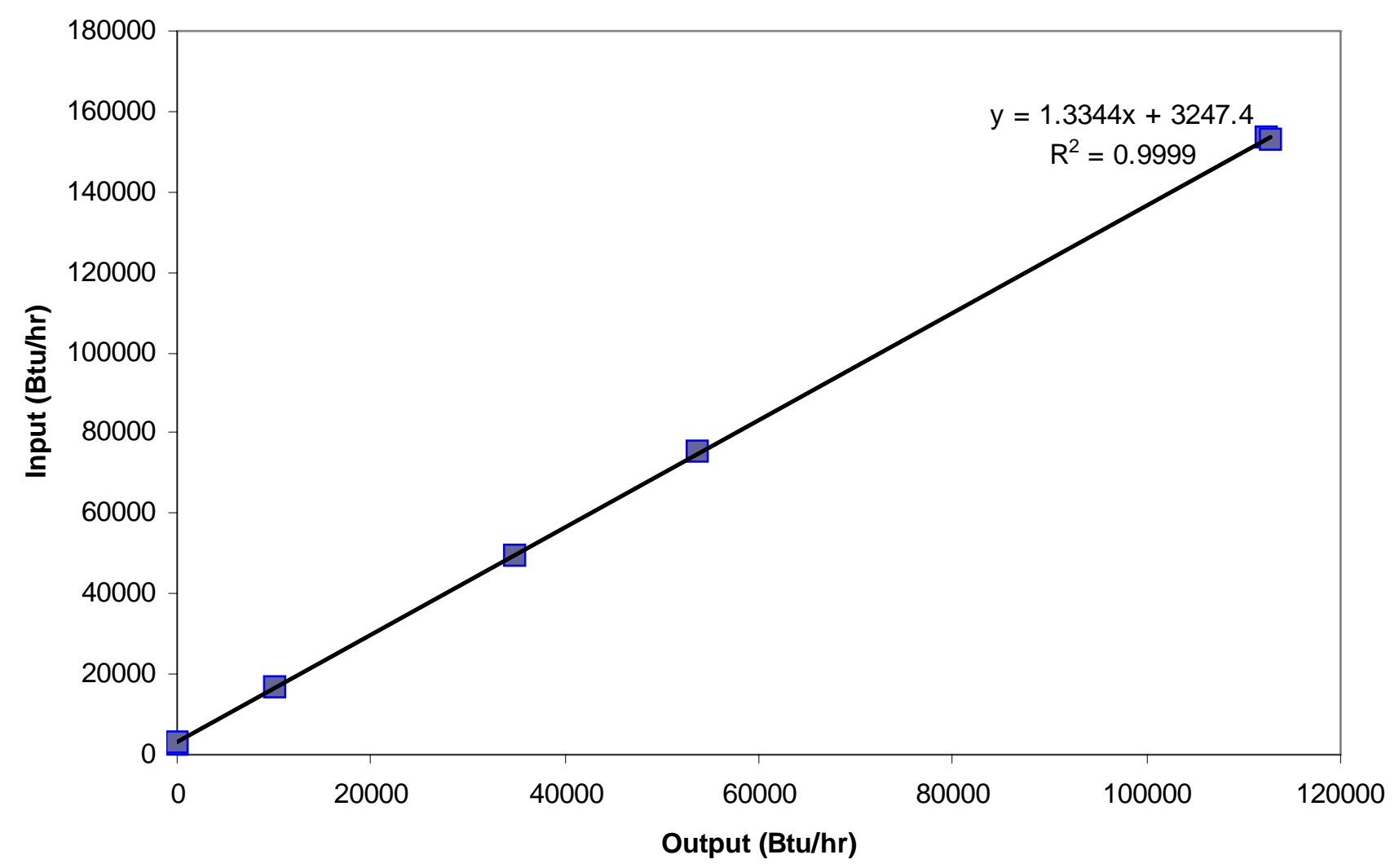

Figure A10-1. Input/output relation for all measured points 


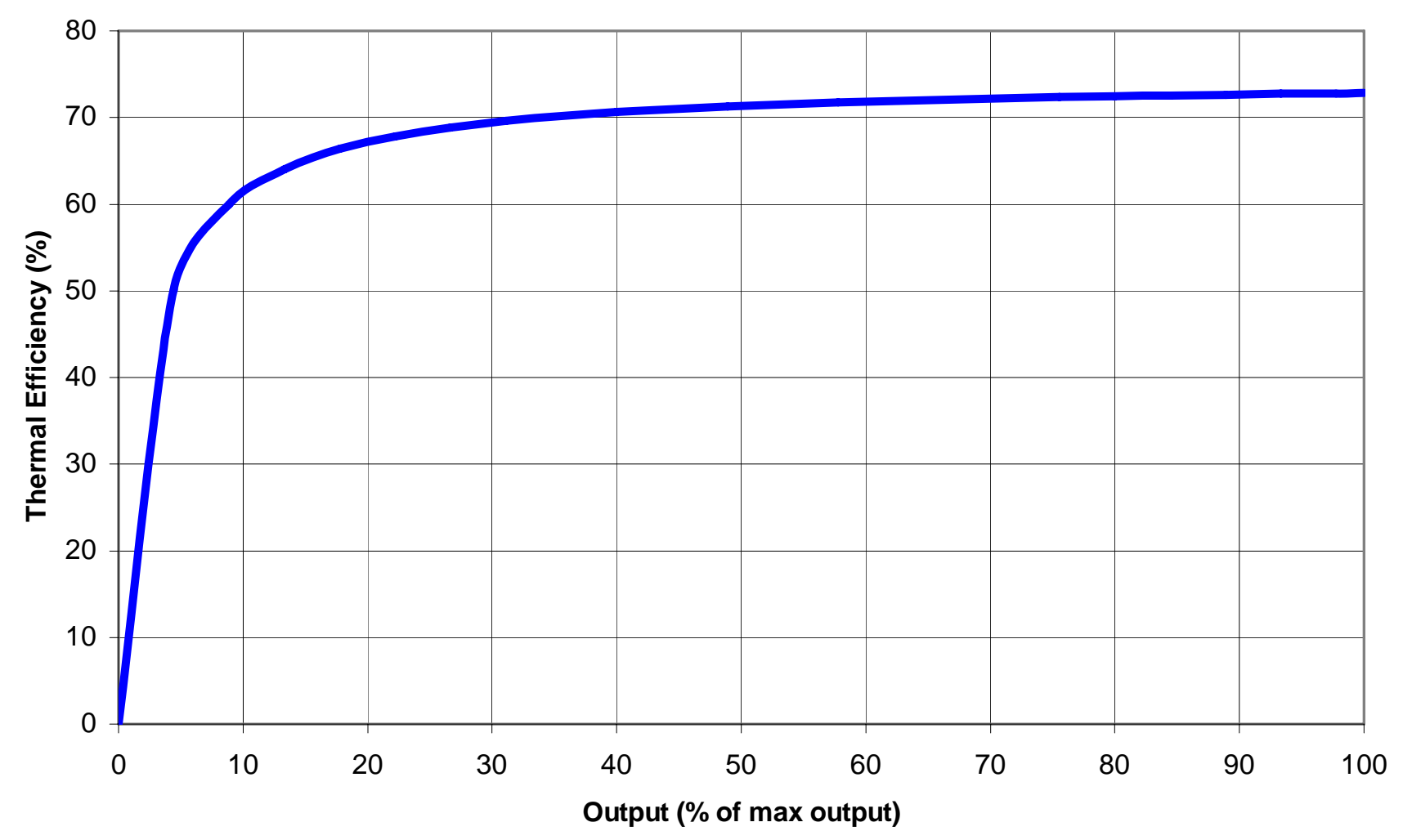

Figure A10-2. Thermal efficiency vs. output expressed as a percentage of maximum output. Using regression from Figure A10-1.

From this curve, and the unit data, the steady state thermal efficiency of this unit is $72.8 \%$ and the idle loss is $2.1 \%$. The efficiency of this system for an average domestic hot water only load of $1720 \mathrm{Btu} / \mathrm{hr}$ would be $31.0 \%$.

\section{Combustion Efficiency}

Combustion efficiency was measured during the two steady state tests and was found to be the same. Flue gas oxygen content was $7.9 \%$, corresponding to $9.6 \% \mathrm{CO} 2$ and $57 \%$ excess air. Flue gas temperature, averaged over the test period was $514 \mathrm{~F}$. Based on these measurements the combustion efficiency is $79.7 \%$. 


\section{Appendix 11 \\ Results of Tests with Unit 11}

Unit Description: condensing, cast aluminum

Fuel:

Natural Gas

Nominal heat output

Aquastat:

custom control - packaged by manufacturer.

Domestic Hot Water: 40 gallon indirect

Burner type: $\quad$ Premix, matrix burner

Features: $\quad$ Fully modulating control

Nominal AFUE: $\quad 95.0$

Table A11-1. Summary of Tests Done with Unit 11 and Results:

\begin{tabular}{|c|c|c|c|c|c|c|c|c|c|}
\hline Parameter & Test & Condition & Date & Total & Draw & Average & Average & Thermal & Maximum \\
\hline & ID & Code & Ended & Duration & Pattern & Input & Output & Efficiency & Boiler Temp \\
\hline Units: & - & - & - & hrs & on/off & Btu/hr & Btu/hr & $(\%)$ & $\mathrm{F}$ \\
\hline & $11-1$ & SS & $4 / 4 / 2007$ & 2 & Steady On & 160920 & 142361 & 88.50 & 149 \\
\hline & $11-2$ & SS & $4 / 5 / 2007$ & 2 & Steady On & 161220 & 138689 & 86.0 & 172 \\
\hline & $11-3$ & SS & $4 / 12 / 2007$ & 2 & Steady On & 65127 & 56290 & 86.4 & 151 \\
\hline & $11-4$ & SS & $4 / 12 / 2007$ & 2 & Steady On & 66417 & 60461 & 91.0 & 121 \\
\hline & $11-5$ & SS & $4 / 13 / 2007$ & 2 & Steady On & 67480 & 60747 & 90.0 & 126 \\
\hline & $11-6$ & SS & $4 / 17 / 2007$ & 2 & Steady On & 107400 & 93907 & 87.4 & 141 \\
\hline & 11-7 & $\mathrm{BI}$ & $4 / 19 / 2007$ & 12 & Idle & 1552 & 0 & 0 & 153 \\
\hline & $11-8$ & $\mathrm{BI}$ & $4 / 20 / 2007$ & 12 & Idle & 7761 & 0 & 0 & 195 \\
\hline & $11-9$ & SI & $4 / 27 / 2007$ & 15 & Idle & 929 & 0 & 0 & 180 \\
\hline
\end{tabular}

Notes relevant to the Results Summary Table Above:

Condition Codes:

$\mathrm{BI}=$ idle test, boiler only

SI = idle test, system (DHW indirect tank included)

$\mathrm{HO}=$ heating load only, part load test

$\mathrm{DO}=$ domestic hot water load only, part load test

$\mathrm{HD}=$ combined heating and hot water, part load test

SS = steady state test, heating only

The plastic vent system for this boiler is under positive pressure (from the burner fan). Vent pressure was not measured and so is not reported in Table A11-1 as it is for other systems tested.

This unit has a fully modulating control that adjusts burner firing rate based on the boiler temperature and setpoint temperature. This control also implements an outdoor reset function. For the purposes of these tests the control was operated in a manual mode - i.e. the firing rate was fixed for each specific test. For this unit a limited number of tests were done and this included only steady state and idle tests. To date no partial load tests have been done although these are planned for the future. 


\section{Analysis of Results}

Figure A11-1 shows the results of all steady state thermal efficiency tests with efficiency presented as a function of the supply water temperature. For this boiler the steady state performance is clearly very sensitive to the supply and return water temperatures. Table A11-2 provides further information on the measured parameters during these steady state tests.

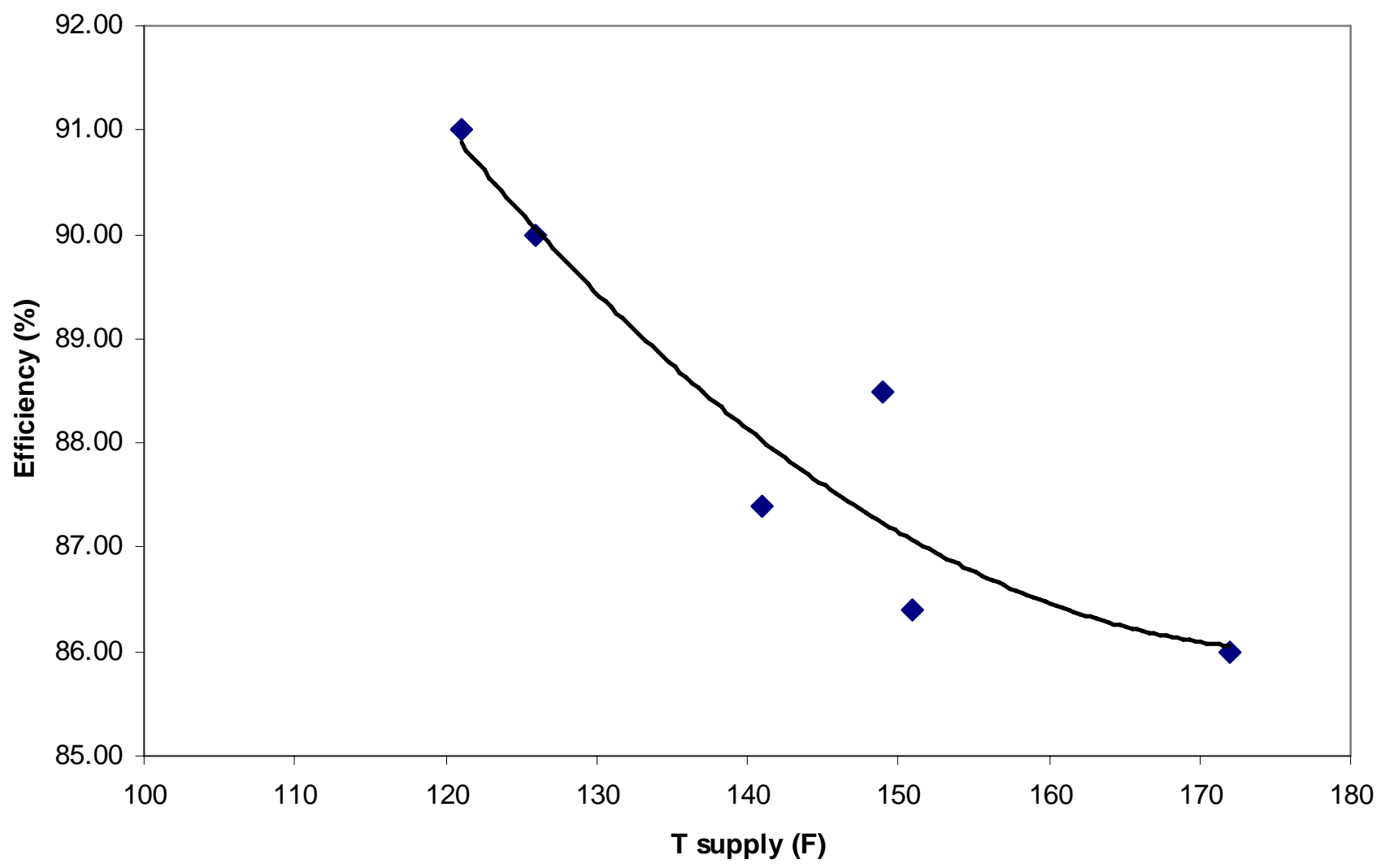

Figure A11-1. Measured steady state efficiency as a function of the boiler supply temperature.

Table A11-2 Steady State Tests - Additional Test Details

\begin{tabular}{|l|l|l|l|l|}
\hline Test No. & T Supply $(\mathrm{F})$ & T Return $(\mathrm{F})$ & T exhaust $(\mathrm{F})$ & Firing Rate $^{1}$ \\
\hline $11-1$ & 149 & 114 & 136 & $\mathrm{H}$ \\
\hline $11-2$ & 172 & 137 & 150 & $\mathrm{H}$ \\
\hline $11-3$ & 151 & 138 & 136 & $\mathrm{~L}$ \\
\hline $11-4$ & 121 & 106 & 112 & $\mathrm{~L}$ \\
\hline $11-6$ & 126 & 111 & 117 & $\mathrm{~L}$ \\
\hline
\end{tabular}

$1 \mathrm{H}=$ high, $\mathrm{M}=$ medium, $\mathrm{L}=$ low 
Figure A11-2 shows all input output points with the exception of the boiler-only idle point. At the highest load point there are a cluster of data points because these steady state tests were run at different water temperature conditions as shown in Table A4-1. This plot is repeated in Figure A11-3 with only one steady state data point shown, Test 11-2, during which the boiler average temperature was similar to that used during the part load tests. A comparison of Figures A11-2 and A11-3 shows that this step does not significantly affect the regression which is subsequently used to develop the efficiency/load curve.

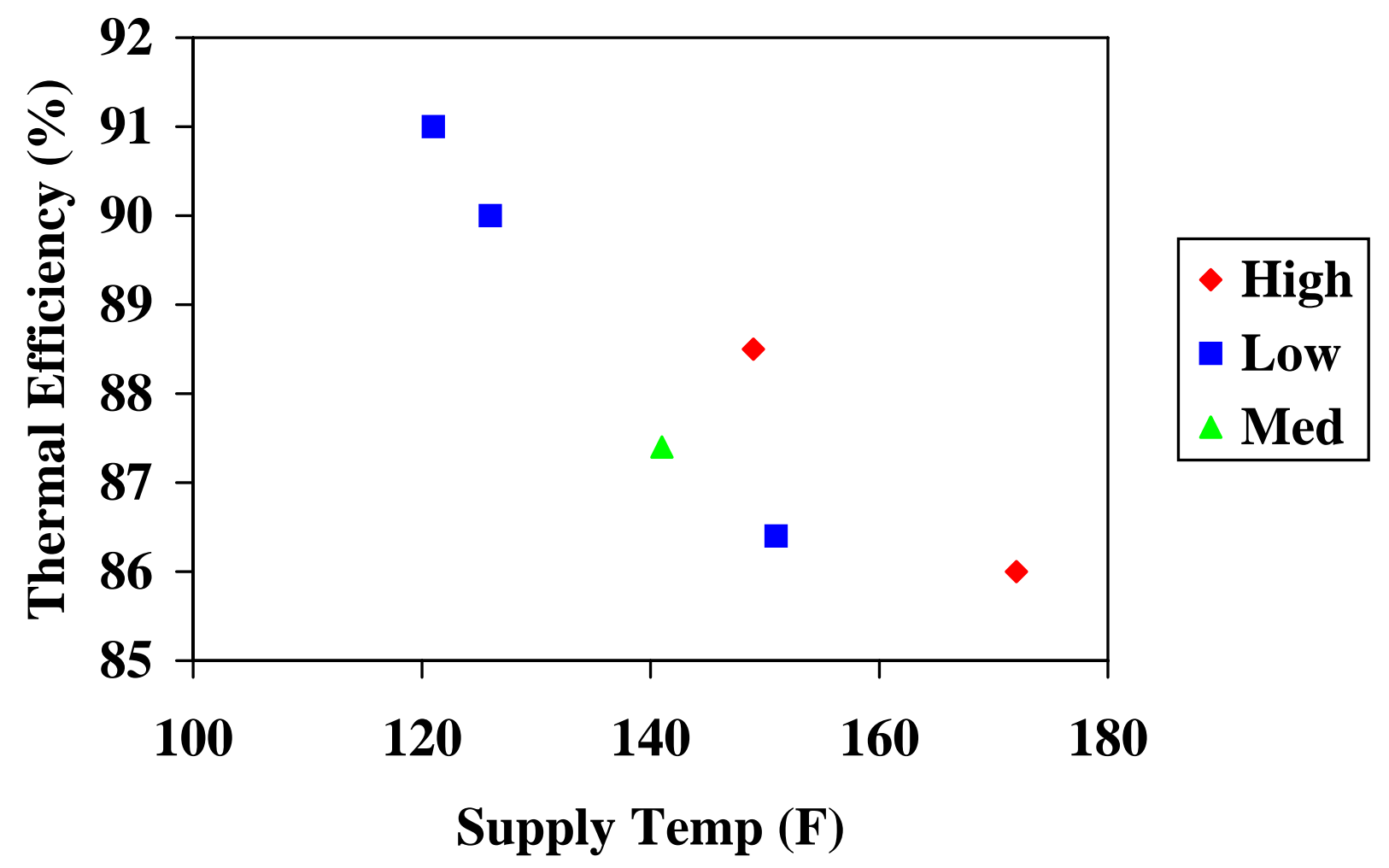

Figure A11-2. Steady state tests - identification of the low, medium, and high firing points

The boiler only idle tests, A11-7 and A11-8 were all done with the unit control set to operate in high fire only. For the low temperature test (A11-7), the idle loss is $0.96 \%$ of the steady state, high fire input. For the high temperature idle test (A11-8) the idle loss is $4.76 \%$ of the steady state, high fire input.

The system idle test A11-9 is more representative of how this system works. The domestic hot water tank is maintained at roughly a $135 \mathrm{~F}$ mean temperature. When the tank calls for heat the burner fires against an upper limit temperature of $180 \mathrm{~F}$. When the tank call is completed the circulator runs for a brief period to purge some of the heat from the boiler into the water tank. The nominal duration of this time is 30 seconds although it was observed to be almost twice that. At the end of this short purge the boiler temperature was reduced to about 150 F. The boiler will drift to a very low temperature ("cold start") until the next tank call is received. With this system the time period between tank calls is about 15 hours. The burner average input over a complete cycle is $.58 \%$ of the maximum input. 
Part load tests under heating and domestic hot water loads have not been done with this system to date. It is planned to do additional testing of this type, including variable temperature in the future. For the purpose of comparison with other systems the results at hand can be used to generate an approximate performance curve. For this it is assumed that: the idle input is $1000 \mathrm{Btu} / \mathrm{hr}$; the steady state, high fire input/output thermal efficiency is 88.5\%; and there is a linear input output relation between these two points. Using this, the linear relation becomes: Input $(\mathrm{Btu} / \mathrm{hr})=$ Output $(\mathrm{Btu} / \mathrm{hr}) * 1.1233+1000$. As with other units this can be used to calculate the efficiency at a domestic hot water average load of $1720 \mathrm{Btu} / \mathrm{hr}$ the efficiency would be $58.7 \%$.

\section{Combustion Efficiency}

Combustion efficiency measurements, including direct condensation rate measurements were done during two tests. In Test 11-5, the excess air was measured at 140\%, Flue gas exhaust temperature was $117 \mathrm{~F}$, sensible heat loss was $2.1 \%$, latent heat loss was $4.33 \%$, leading to a combustion efficiency of $93.6 \%$. The latent heat recovery was $5.23 \%$.

In Test 11-6 the excess air was 140\%, flue gas exit temperature was $128 \mathrm{~F}$, sensible heat loss was $2.6 \%$, latent heat loss was $8.46 \%$, leading to a combustion efficiency of $91.5 \%$. The latent heat recovery was $1.1 \%$.

For all tests, condensate formed in the flue pipe was drained separately and did not flow back into the boiler. 


\section{Appendix 12}

\section{Results of Tests with Unit 12}

Unit Description: $\quad$ cast iron, two section, non-condensing

Fuel:

oil

Nominal heat output $90,000 \mathrm{Btu} / \mathrm{hr}$

Aquastat:

Domestic Hot Water: 40 gallon indirect and tankless internal coil

Burner type:

Conventional retention head

Features:

Nominal AFUE: $\quad 83.5$

Table A12-1. Summary of Tests Done with Unit 12 and Results:

\begin{tabular}{|c|c|c|c|c|c|c|c|c|c|}
\hline Parameter & :Tes & Condition & Date & Total & Draw & Average & Average & Thermal & Maximum \\
\hline & ID & Code & Ended & Duration & Pattern & Input & Output & Efficiency & Boiler Temp \\
\hline Units: & - & - & - & hrs & on/off & Btu/hr & Btu/hr & $(\%)$ & $\mathrm{F}$ \\
\hline & $12-$ & SI - tankless & $4 / 25 / 2007$ & 14 & Idle & 4915 & & 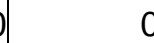 & 178 \\
\hline & $12-2$ & SI - indirect & $4 / 26 / 2007$ & 14 & Idle & 1168 & & 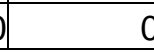 & 177 \\
\hline
\end{tabular}

Notes relevant to the Results Summary Table Above:

Condition Codes:

$\mathrm{BI}=$ idle test, boiler only

$\mathrm{SI}=$ idle test, system (DHW indirect tank included)

$\mathrm{HO}=$ heating load only, part load test

$\mathrm{DO}=$ domestic hot water load only, part load test

$\mathrm{HD}=$ combined heating and hot water, part load test

SS = steady state test, heating only

This system was installed to address a specific question: the relative performance of a system that produces hot water using an internal "tankless" coil heat exchanger and one that uses an indirect water heater. In other tests in this project both of these configurations were tested but not using the same boiler. The purpose of these tests was to implement a direct comparison between these two.

The boiler used for these tests is a conventional cast iron, 2 section boiler fired with a conventional retention head oil burner at the nominal rating for the boiler. With either approach for production of domestic hot water the performance will depend strongly upon the aquastat boiler control settings. A conventional triple-function aquastat was used which allows for adjustment of the high limit (maximum temperature during a heat call), low limit (temperature that the boiler maintains when a heat call is not present), and low limit differential. After some discussion with industry professionals the following control settings were selected as representative of typical field conditions.

1. Tankless Coil Case: High Limit - 180 F; Low Limit - 160 F; differential 15 F.

2. Indirect Tank Case: High Limit - 180 F; Low Limit - 130 F; differential 15 F. 
In the indirect tank case, when the tank calls for heat the boiler treats this as any other heat demand and the burner fires to maintain the high limit. Between tank calls the boiler is maintained at the low limit to reduce corrosion caused by condensation on the heat transfer surfaces. It should be noted that there is considerable difference in opinion about what is proper and typical. In the case where a tankless coil has internal scale after years of operation the low limit temperatures could be set higher to ensure adequate hot water supply. Further, some boiler manufacturers do not have a low limit (cold start) in which case the boiler will go to a much lower temperature between tank calls.

\section{Analysis of Results}

Following directly from the results presented in Table A12-1, the idle loss in the case of tankless operation Test $12-1$ is $4.87 \%$, while in indirect tank mode, Test $12-2$ it is $1.16 \%$. The difference between these two is clearly very large. For this unit part load test have not been done to date in either a domestic hot water mode or a space heating mode. However, based on the results with all of the other units tests it can be assumed that the linear relationship between input and output holds over the entire load range. Using this, and results of a steady state thermal efficiency test (78\%), the following linear input / output relations can be approximated:

Tankless mode: Input $=1.2196 *$ Output +4915

Indirect mode: $\quad$ Input $=1.2672 *$ Output +1168

As with other units these can be used to calculate the efficiency at a domestic hot water average load of 1720 Btu/hr the efficiency would be $24.5 \%$ for the tankless mode and $51.4 \%$ for the indirect mode respectively.

\section{Combustion Efficiency}

Flue gas oxygen was typically $5.8 \%$, corresponding to $11.0 \% \mathrm{CO} 2$, and $37 \%$ excess air. With a flue gas temperature of $496 \mathrm{~F}$, the combustion efficiency is $82.5 \%$. 